University of Rhode Island

DigitalCommons@URI

Open Access Master's Theses

2018

\title{
Annual Cycle Phenology and Winter Habitat Selection of White- Winged Scoters in Eastern North America
}

Dustin E. Meattey

University of Rhode Island, dustin_meattey@uri.edu

Follow this and additional works at: https://digitalcommons.uri.edu/theses

\section{Recommended Citation}

Meattey, Dustin E., "Annual Cycle Phenology and Winter Habitat Selection of White-Winged Scoters in Eastern North America" (2018). Open Access Master's Theses. Paper 1228.

https://digitalcommons.uri.edu/theses/1228

This Thesis is brought to you for free and open access by DigitalCommons@URI. It has been accepted for inclusion in Open Access Master's Theses by an authorized administrator of DigitalCommons@URI. For more information, please contact digitalcommons-group@uri.edu. 


\author{
ANNUAL CYCLE PHENOLOGY AND WINTER \\ HABITAT SELECTION OF WHITE-WINGED SCOTERS \\ IN EASTERN NORTH AMERICA \\ BY \\ DUSTIN E. MEATTEY
}

A THESIS SUBMITTED IN PARTIAL FULFILLMENT OF THE REQUIREMENTS FOR THE DEGREE OF

MASTER OF SCIENCE

IN

BIOLOGICAL AND ENVIRONMENTAL SCIENCES

UNIVERSITY OF RHODE ISLAND

2018 


\section{MASTER OF SCIENCE THESIS}

OF

DUSTIN E. MEATTEY

\section{APPROVED:}

Thesis Committee:

Major Professor $\quad$ Scott R. McWilliams
Peter W.C. Paton
Jason Osenkowski
Gavino Puggioni
Nasser H. Zawia
DEAN OF THE GRADUATE SCHOOL

UNIVERSITY OF RHODE ISLAND

2018 


\begin{abstract}
Concern over declining populations of several North American sea duck species has led to research addressing how environmental and anthropogenic factors in various stages of the annual cycle affect survival, habitat use, site fidelity, and migratory strategies. Southern New England provides key wintering habitat for White-winged Scoters (Melanitta fusca). This area has also pioneered the development of offshore wind energy in North America. I deployed implanted satellite transmitters in 52 adult female White-winged Scoters captured during the wintering period in southern New England, and on a molting area in the St. Lawrence River estuary in Quebec between 2015 and 2016. I used winter movement data to determine winter arrival and departure dates, total length of stay, home ranges, and site fidelity for scoters wintering in southern New England. Scoters spent over half of the annual cycle on the wintering grounds and demonstrated a high degree of inter-annual site fidelity to composite core-use areas. Sizes of individual $50 \%$ core-use home ranges were variable $(\bar{x}=868$ $\mathrm{km}^{2}$; range $=32$ to $4,220 \mathrm{~km}^{2}$ ) and individual $95 \%$ utilization distributions ranged widely $\left(\bar{x}=4,388 \mathrm{~km}^{2}\right.$; range $=272$ to $\left.18,235 \mathrm{~km}^{2}\right)$. More than half of all tagged birds occupied two or more discrete core-use areas that were up to $400 \mathrm{~km}$ apart. I combined these home range estimates with biotic and abiotic habitat data to calculate resource selection functions to model predicted relative probability of use for Whitewinged Scoters throughout the southern New England study area. Scoters selected for areas with lower salinity, lower sea surface temperature, higher chlorophyll- $a$ concentrations, and higher hard-bottom substrate probability. Resource selection function models classified $18,649 \mathrm{~km}^{2}(23 \%)$ of the study area as high probability of
\end{abstract}


use, which included or immediately bordered $420 \mathrm{~km}^{2}$ of proposed Wind Energy Area lease blocks. Important habitats and key environmental characteristics identified by this study should be carefully considered when siting and developing future offshore wind energy areas.

Understanding full annual cycle movements of long-distance migrants is essential for delineating populations, assessing connectivity, evaluating crossover effects between life stages, and informing management strategies for vulnerable or declining species. In a complementary second study, I used the same 52 satellitetagged female White-winged Scoters to document annual cycle phenology, delineate migration routes, identify primary areas used during winter, stopover, breeding, and molt, and to assess the strength of migratory connectivity and spatial population structure. Most scoters wintered along the Atlantic coast from Nova Scotia to southern New England, with some on Lake Ontario. Scoters followed four migration routes to breeding areas from Quebec to the Northwest Territories. Principal post-breeding molting areas were in James Bay and the St. Lawrence River estuary. Migration phenology was synchronous regardless of winter or breeding origin. Cluster analyses delineated two primary breeding areas, one molting, and one wintering area. Scoters demonstrated overall weak to moderate connectivity among life stages, with molting to wintering connectivity the strongest. Thus, White-winged Scoters that winter in eastern North America appear to constitute a single continuous population. 


\section{ACKNOWLEDGMENTS}

There are several people I would like to acknowledge whom I am indebted to for their hard work and contributions to this research. Foremost, I would like to thank my coadvisors Dr. Scott McWilliams and Dr. Peter Paton for their invaluable support and guidance throughout this project and my entire graduate school tenure. The knowledge and experience they have imparted on me will continue with me throughout my career. I would like to thank Jay Osenkowski for continuous friendship, funding support, and encouragement throughout this project and for serving on my thesis committee. I thank Dr. Gavino Puggioni for serving on my committee and for guidance with statistical analyses. I would like to thank Dr. Howard Ginsberg for chairing my defense. I am forever indebted to my friends and colleagues in the McWilliams and Paton labs, both past and present: Steve Brenner, Bill Buffum, Wales Carter, Clara Cooper-Mullin, Kristen DeMoranville, Clay Graham, Erin Harrington, Juliet Lamb, Martina Muller, and Megan Skrip. The relationships that we developed made me not only a better scientist, but a better person. Several people put in long, early morning hours to assist with scoter captures including: Josh Beuth, Lizzi Bonczek, Carl Brown, Susannah Corona, Alex Dalton, Dylan Ferreira, Tom Foley, Al Hanson, Bill Hanson, Jennifer Kilburn, Robby Lambert, Jessy Lee, Joshua Seibel, Chris Spies, Josh Stiller, Jim Tappero, Lucas Savoy, Vincent Spagnuolo, Francis St-Pierre, John Veale, Tim Welch, and Jason Williams. This project would not have been as successful without the tireless surgical work of Dr. Glenn Olsen, Dr. Michelle Kneeland, Dr. Ginger Stout, Dr. Stéphane Lair, Dr. Rozen Le Net, Dr. Benjamin Lamglait, and Cara Papakyrikos. Thanks to Capt. Len Greiner for renting out his house and allowing us to 
keep ducks in the basement! I have a great deal of thanks for Christine Lepage and Scott Gilliland who not only contributed to both of my thesis chapters, but also contributed their archival data and shared their prime capture location in the beautiful and unique St. Lawrence River estuary. Special thanks are due to Lucas Savoy and Biodiversity Research Institute for providing capture crews, boats, and capture equipment that made this project operate smoothly. Thanks to Andrew Gilbert for filtering, archiving, and providing access to satellite telemetry data. Funding for this research was provided by the Sea Duck Joint Venture, Rhode Island Department of Environmental Management, USFWS funds through the Wildlife Restoration Program, and University of Rhode Island. Sea Duck Joint Venture and Rhode Island Department of Environmental Management provided funding for satellite transmitter purchases and field efforts. Rhode Island DEM also provided boats, crews, and capture equipment that were invaluable for fielding multiple simultaneous capture efforts. Thanks to the National Park Service and Cape Cod National Seashore for field housing. I am extremely thankful to Dr. Pam Loring and Dr. Brian Gerber for their statistical guidance, and to Dr. Peter August for assistance with GIS analysis and presentation. I can't possibly forget to thank Deb Bourassa, who keeps the Natural Resources Science department functioning like a well-oiled machine, and whose administrative support made my project and entire graduate school experience run as smoothly as possible. Thanks to my family for their unending support throughout this process. Lastly, I am eternally grateful to my beautiful and supportive wife, Alishia. Graduate school has all at once been one of the most stressful, humbling, and rewarding things I've ever done, and none of it would have been possible without her 
unending support and encouragement. Your turn! As someone who has spent most of the last ten years studying sea ducks in various capacities, it has been an enormous honor to have been given the opportunity to study them under two highly-respected and accomplished biologists and professors. This is an important period for sea duck conservation and management, and I am grateful to have had the opportunity to make my small mark. 


\section{PREFACE}

This thesis follows the University of Rhode Island Graduate School guidelines for manuscript formatting. Manuscript 1 is titled "Resource selection and wintering phenology of White-winged Scoters in southern New England: Implications for offshore wind energy development" and has been submitted to The Condor. Manuscript 2 is titled "Annual cycle of White-winged Scoters (Melanitta fusca) in eastern North America: migration phenology, population delineation, and connectivity" and is formatted for submission to the Canadian Journal of Zoology. 


\section{TABLE OF CONTENTS}

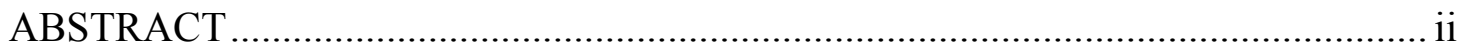

ACKNOWLEDGMENTS ...................................................................... iv

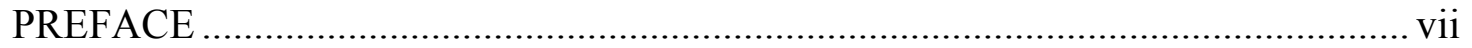

TABLE OF CONTENTS ............................................................................ viii

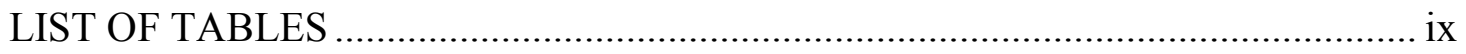

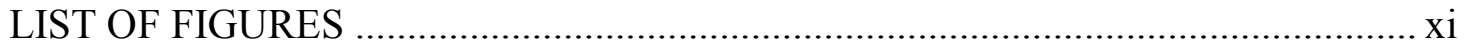

MANUSCRIPT - 1: RESOURCE SELECTION AND WINTERING PHENOLOGY

OF WHITE-WINGED SCOTERS IN SOUTHERN NEW ENGLAND:

IMPLICATIONS FOR OFFSHORE WIND ENERGY DEVELOPMENT ............ 1

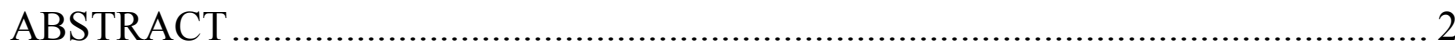

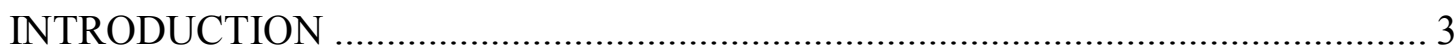

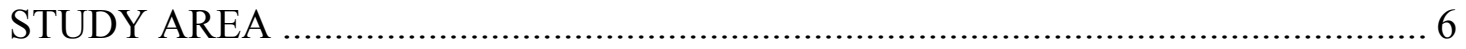

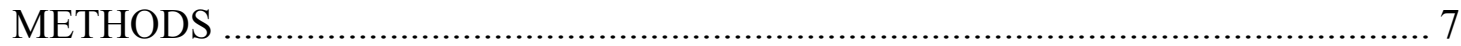

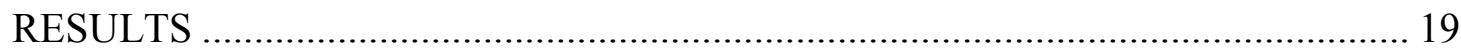

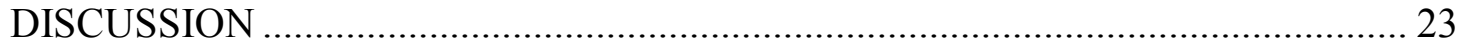

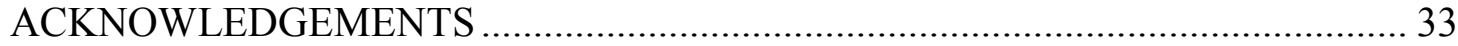

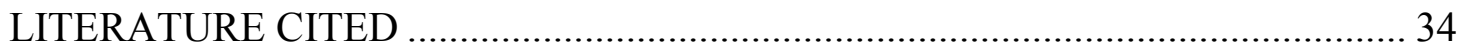

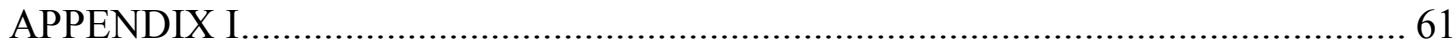

MANUSCRIPT - 2: ANNUAL CYCLE OF WHITE-WINGED SCOTERS

(MELANITTA FUSCA) IN EASTERN NORTH AMERICA: MIGRATION

PHENOLOGY, POPULATION DELINEATION, AND CONNECTIVITY ....... 71

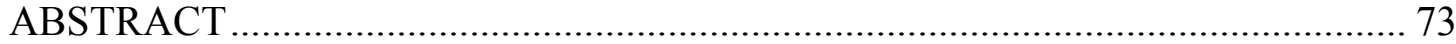

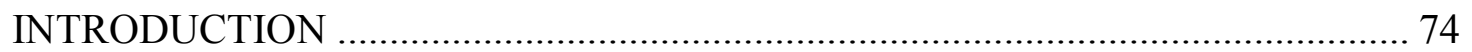

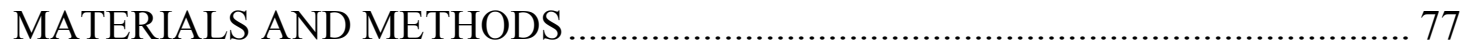

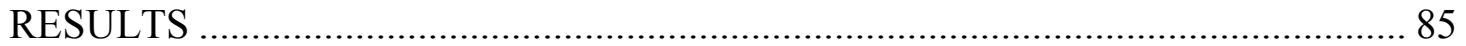

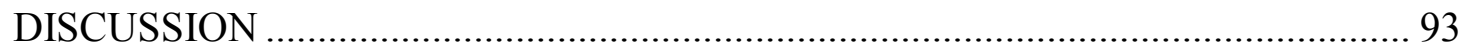

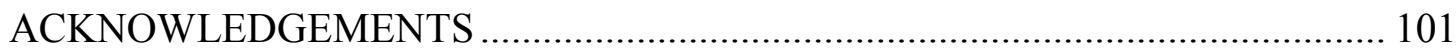

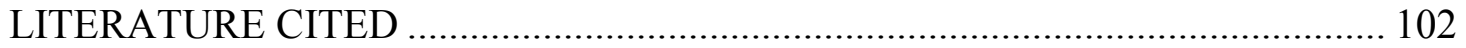

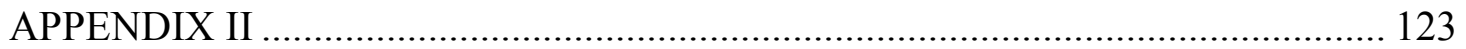




\section{LIST OF TABLES}

TABLE

PAGE

Table 1-1. Location class and frequency of randomly selected locations ( $n=40$ per bird) used to generate individual and composite $95 \%$ utilization distributions and $50 \%$ core-use areas for 40 white-winged scoters wintering in the southern New England study area.

Table 1-2. Fall arrival, spring departure, and total winter length of stay (LOS) within the southern New England study area for White-winged Scoters $(n=36)$ captured in 2015 and 2016

Table 1-3. Mean $(\bar{x})$, standard error (SE), and range of values for habitat variables sampled within composite $95 \%$ utilization distributions (available) and 50\% core-use areas (used) of White-winged Scoters $(n=40)$ wintering in the southern New England study area. 53

Table 1-4. Model parameters $(K)$, Akaike Information Criterion differences $\left(\Delta \mathrm{AIC}_{c}\right)$, maximized $\log$-likelihood $[\log (\mathrm{L})]$, and Akaike weights $\left(w_{\mathrm{i}}\right)$ for logistic regression models of winter habitat use versus availability used to estimate coefficients for exponential resource selection functions. Model parameters include distance from shore (DIST), water depth (WD), bottom slope (SL), hard bottom probability (HB), sediment grain size (SED), sea surface temperature (SST), sea surface salinity (SAL), and chlorophyll- $a$ concentrations (CHL). 54 
Table 1-5. Coefficients $(\beta)$ and upper and lower $95 \%$ confidence intervals of environmental parameters from the best-fit resource selection function model for White-winged Scoters $(n=40)$ wintering within the southern New England study area.

Table 2-1. Criteria used for assigning individual White-winged Scoter (Melanitta

fusca) locations to four stages of their annual cycle......................................... 115 


\section{LIST OF FIGURES}

FIGURE

PAGE

Figure 1-1. Study area (dashed line) and capture locations (solid symbols) of Whitewinged Scoters $(n=40)$ implanted with satellite transmitters in southern New England and Quebec during 2015 and 2016.

Figure 1-2. Composite kernel-based winter 95\% utilization distributions and 50\% core-use areas of White-winged Scoters ( $n=40 ; 31$ females, 9 males) implanted with satellite transmitters between 2010 and 2016 in relation to current and proposed offshore wind energy areas. 58

Figure 1-3. Quartile-based relative probability of use $(<25 \%$ to $>75 \%)$ predicted for White-winged Scoters across the southern New England study area by the top-ranked resource selection function model in relation to current and proposed offshore wind energy areas. 59

Figure 1-4. Second-winter (2016-2017) locations of five female White-winged Scoters in relation to composite ( $n=30$ individuals) kernel-based first-winter (2015-2016) $95 \%$ utilization distributions and $50 \%$ core-use areas. 60

Figure A-1-1. Water depth (m) raster used in logistic regression models for determining winter resource selection of White-winged Scoters in southern New England. Data were derived from the NOAA National Geophysical Data Center Coastal Relief Model (3 arc-second) for the United States. 63

Figure A-1-2. Distance from shore $(\mathrm{km})$ raster used in logistic regression models for determining winter resource selection of White-winged Scoters in southern New England. Data were derived by calculating the Euclidean distance from each pixel to 
the nearest segment of the NOAA Medium Resolution Digital Vector Shoreline $(1: 70,000)$

Figure A-1-3. Probability of hard bottom occurrence (0-1) data set used in logistic regression models for determining winter resource selection of White-winged Scoters in southern New England. Data were derived from a kernel-based probabilistic model using rock and boulder points extracted from NOAA Electronic Navigational Charts.

Figure A-1-4. Bottom sediment grain size (mm) data set used in logistic regression models for determining winter resource selection of White-winged Scoters in southern New England. Data were obtained from the Nature Conservancy's Northwest Atlantic Marine Ecoregional Assessment data portal. 66

Figure A-1-5. Bottom slope (degrees) data set used in logistic regression models for determining winter resource selection of White-winged Scoters in southern New England. Data were derived from the NOAA National Geophysical Data Center Coastal Relief Model (3 arc-second) for the United States.

Figure A-1-6. Sea surface temperature $\left({ }^{\circ} \mathrm{C}\right.$; six-year mean) raster data set used in logistic regression models for determining winter resource selection of White-winged Scoters in southern New England. Data were derived from interpolated data from high resolution satellite imagery and floating buoys. 68

Figure A-1-7. Sea surface salinity (practical salinity units [psu]; six-year mean) raster data set used in logistic regression models for determining winter resource selection of White-winged Scoters in southern New England. Data were derived from the Hybrid Coordinate Ocean Model (HYCOM) by the National Ocean Partnership Program... 69 
Figure A-1-8. Chlorophyll- $a\left(\mathrm{mg} / \mathrm{m}^{3}\right.$; six-year mean) raster data set used in logistic regression models for determining winter resource selection of White-winged Scoters in southern New England. Data were derived from monthly estimates produced by the NASA Goddard Space Flight Center's Ocean Data Processing System. .................. 70 Figure 2-1. Three locations where female White-winged Scoters (Melanitta fusca; $n=$ 52) were captured in 2015 and 2016 in eastern North America. 118 Figure 2-2. Migration chronology for female White-winged Scoters (Melanitta fusca; $n=52$ ) wintering in eastern North America. All 52 scoters captured are depicted, including those who did not provide data long enough to be included in summary or statistical analyses. Life stage blocks are based on median arrival and departure dates to and from each life stage. 119

Figure 2-2. Figure 2-3. Estimated spring migration routes $(n=27)$ between wintering and breeding areas for female White-winged Scoters (Melanitta fusca) captured in eastern North America. Lines represent connections of consecutive locations along migration, but do not necessarily represent actual migration paths. Colors symbolize identified migration routes: Blue $=$ direct overland, Orange $=$ coastal route, Green $=$ Great Lakes route, $\mathrm{Red}=$ James Bay route

Figure 2-4. Estimated molt migration routes $(n=21)$ between breeding and molting areas and fall migration routes $(n=17)$ between molting/staging and wintering areas of female White-winged Scoters (Melanitta fusca) captured in eastern North America. Lines represent connections of consecutive locations along migration, but do not necessarily represent actual migration paths.

Figure 2-5. Annual cycle migratory connectivity of female White-winged Scoters 
(Melanitta fusca; $n=27$ ) that migrated between breeding, molting, and wintering areas. Colored areas represent life stage area clusters identified by cluster analysis. Connectivity correlations account for migration between locations not assigned to clusters. Line width symbolizes comparative strength of connectivity. Lines indicate direction of migration, but do not represent actual migration routes........................ 122 Figure A-2-1. Figure A-2-1. Best per duty cycle locations for 52 adult female Whitewinged Scoters (Melanitta fusca) captured on wintering areas in southern New England and a molting area in the St. Lawrence River estuary, QC. Location dates range from 27 October 2015 to 6 December 2017. 


\section{MANUSCRIPT - 1}

Submitted to The Condor

White-winged Scoter winter resource selection

RESEARCH ARTICLE

Resource selection and wintering phenology of White-winged Scoters in southern New England: Implications for offshore wind energy development

Dustin E. Meattey, ${ }^{1,4 *}$ Scott R. McWilliams, ${ }^{1}$ Peter W.C. Paton, ${ }^{1}$ Christine Lepage, ${ }^{2}$ Scott G. Gilliland, ${ }^{3}$ Lucas Savoy, ${ }^{4}$ Glenn H. Olsen, ${ }^{5}$ and Jason E. Osenkowski ${ }^{6}$

${ }^{1}$ Department of Natural Resources Science, University of Rhode Island, Kingston, RI, USA

${ }^{2}$ Canadian Wildlife Service, Environment and Climate Change Canada, Quebec, QC, Canada

${ }^{3}$ Canadian Wildlife Service, Environment and Climate Change Canada, Sackville, NB, Canada

${ }^{4}$ Biodiversity Research Institute, Portland, ME, USA

${ }^{5}$ USGS Patuxent Wildlife Research Center, Laurel, MD, USA

${ }^{6}$ Rhode Island Department of Environmental Management, West Kingston, RI, USA

*Corresponding author: dustin_meattey@uri.edu 


\section{ABSTRACT}

Southern New England provides key wintering habitat for White-winged Scoters (Melanitta fusca). This area has also pioneered the development of offshore wind energy in North America and the U.S. Bureau of Ocean Energy Management (BOEM) has established nine Wind Energy Area (WEA) lease blocks along the Atlantic Outer Continental Shelf in areas that may provide important staging and wintering habitat for scoters and other species of sea ducks. Concern over the potential impact of offshore wind energy on sea duck populations has led to efforts to develop models to understand their distribution, habitat use and site fidelity. We used satellite telemetry to document winter phenology and site fidelity, as well as fine-scale resource selection and habitat use of 40 White-winged Scoters along the southern New England continental shelf. Scoters spent over half of the annual cycle on the wintering grounds and demonstrated a high degree of inter-annual site fidelity to composite core-use areas. Sizes of individual $50 \%$ core-use home ranges were variable $\left(\bar{x}=868 \mathrm{~km}^{2}\right.$; range $=32$ to $\left.4,220 \mathrm{~km}^{2}\right)$ and individual $95 \%$ utilization distributions ranged widely $(\bar{x}$ $=4,388 \mathrm{~km}^{2}$; range $=272$ to $18,235 \mathrm{~km}^{2}$ ). More than half of all tagged birds occupied two or more discrete core-use areas that were up to $400 \mathrm{~km}$ apart. Throughout the study area, scoters selected for areas with lower salinity, lower sea surface temperature, higher chlorophyll- $a$ concentrations, and higher hard-bottom substrate probability. Resource selection function models classified $18,649 \mathrm{~km}^{2}(23 \%)$ of the study area as high probability of use, which included or immediately bordered $\sim 420$ $\mathrm{km}^{2}$ of proposed WEA lease blocks. Future offshore wind energy developments in the region should avoid key habitats highlighted by this study and carefully consider the 
environmental characteristics selected by sea ducks when planning and siting future WEAs.

Keywords: habitat use, New England, offshore wind energy, phenology, resource selection function, satellite telemetry, White-winged Scoter

\section{INTRODUCTION}

Effective management and conservation of any migratory species relies on a thorough understanding of that species' seasonal distribution and resource use, as well as threats from anthropogenic and other sources. In North America, there is increasing concern over declines in populations of several sea duck species (Sea Duck Joint Venture Management Board 2014, Bowman et al. 2015). Reasons for these apparent declines are uncertain, although poor habitat conditions and foraging availability on wintering grounds have been linked to significant mortality events (Camphuysen et al. 2002), reduced annual survival (Petersen and Douglas 2004), and decreased productivity in subsequent breeding seasons (Oosterhuis and van Dijk 2002). Because sea ducks spend much of their annual cycle utilizing habitats in nonbreeding areas where direct anthropogenic threats are often greatest, understanding habitat use dynamics on their wintering grounds is important for conservation planning.

In North America, the first offshore wind energy development (OWED), a 5turbine, 30-megawatt facility off Block Island, Rhode Island, became operational in December 2016. Thus, the potential impact of OWEDs on sea duck populations is a recent conservation concern in the United States, particularly on their wintering grounds because numerous other multi-turbine wind energy leases have been issued 
for offshore areas in New England and mid-Atlantic states (Manwell et al. 2002, Breton and Moe 2009, Musial and Ram 2010). Potential negative interactions between sea ducks and OWED include collision risk, disturbance, and exclusion from key habitats and prey resources (Fox et al. 2006, Drewitt and Langston 2006, Furness et al. 2013, Dierschke et al. 2016). In Europe where biologists have been investigating the potential impacts of OWEDs on marine birds for over 20 years (Guillemette and Larsen 2002, Desholm and Kalhert 2005, Langston 2013, Bailey et al. 2014, Vallejo et al. 2017), collision risk is likely minimal for sea ducks (Desholm and Kahlert 2005, Bradbury et al. 2014), but avoidance behaviors including displacement from key foraging sites likely have more significant population-level impacts (Hüppop et al. 2006, Furness et al. 2013, Dierschke et al. 2016).

Sea ducks are particularly vulnerable because they usually forage in shallow, subtidal areas in substrates that are often favored for OWED (Fox 2003, Kaiser et al. 2006, Loring et al. 2014, Meattey et al. 2015). A review of post-construction studies at 20 offshore wind farms in Europe classified Common Scoters (Melanitta nigra) and Long-tailed Ducks (Clangula hyemalis) as weakly avoiding offshore wind farms (Dierschke et al. 2016). Peterson and Fox (2007) documented short-term displacement of Common Scoters from an OWED in Denmark for three years, though follow-up studies suggest that this displacement may be more long-lasting (Petersen et al. 2014). This loss of potential foraging habitat, as a result of avoidance and displacement, in areas with large concentrations of wintering sea ducks could have detrimental population-level effects. Habitat conditions and availability during the wintering period may have strong carry-over effects on reproductive success and productivity 
during the subsequent breeding season (Camphuysen et al. 2002, Oosterhuis and van Dijk 2002, Gurney et al. 2014). Also in Denmark, Common Eiders (Somateria mollissima) avoided flying close to or amongst wind turbines (Larsen and Guillemette 2007), suggesting that habitat use within and around wind farms may be greatly reduced. The cost of avoidance behaviors may be trivial relative to the energetic costs of long-distance migration, but the cumulative impact of avoiding multiple developments along a migration route could be significant (Masden et al. 2009). Thus, identification of important habitats used by sea ducks prior to offshore wind energy development informs the planning process and helps to avoid displacement of sea ducks from preferred habitats.

Satellite telemetry provides an increasingly effective tool for assessing population delineation, movement ecology, and habitat selection of marine birds including sea ducks (Oppel et al. 2008, Loring et al. 2014, Meattey et al. 2015, Berlin et al. 2017). In New England, recent telemetry studies of Black Scoter (Melanitta americana; Loring et al. 2014) and Common Eider (Beuth et al. 2017) provided essential information on their movement ecology and habitat use patterns. However, there remains a lack of information on the seasonal changes in abundance and distribution, as well as environmental drivers of habitat use, for other priority sea duck species in southern New England, such as White-winged Scoters (Melanitta fusca; Zipkin et al. 2010, Silverman et al. 2013, Sea Duck Joint Venture 2015).

White-winged Scoters are a long-lived species that winters along both the Atlantic and Pacific coasts of North America and breeds throughout the interior boreal forest from Alaska to central Canada (Brown and Fredrickson 1997). On their 
wintering grounds, White-winged Scoters generally feed on benthic mollusks and crustaceans in waters $\leq 20 \mathrm{~m}$ deep (Stott and Olson 1973, Lewis et al. 2007). The continental population of White-winged Scoters has experienced a long-term decline throughout the last half-century (Alisauskas et al. 2004, USFWS 2011), with steady rates of decreased annual harvest being recognized on the wintering areas, particularly on the Atlantic Coast (Rothe et al. 2015). White-winged Scoters remain one of the least-studied waterfowl species, thus management and conservation efforts, particularly on the wintering grounds, have been impeded by a lack of vital life history information.

The objectives of our study were to 1) use satellite telemetry to document finescale resource selection and habitat use patterns, and 2) summarize seasonal phenology of White-winged Scoters in southern New England during the nonbreeding period with a focus on identifying key time periods and locations at which Whitewinged Scoters may be vulnerable to ecological impacts of current and future offshore wind energy development.

\section{STUDY AREA}

Our $82,572 \mathrm{~km}^{2}$ study area included coastal and offshore habitat in the southwestern Gulf of Maine and the southern New England continental shelf ranging from Gloucester, Massachusetts to $\sim 80 \mathrm{~km}$ south of Long Island, NY and extending $\sim 90 \mathrm{~km}$ east of Cape Cod, MA $\left(39.93^{\circ} \mathrm{N}-42.52^{\circ} \mathrm{N}, 68.86^{\circ} \mathrm{W}-74.10^{\circ} \mathrm{W}\right.$; Figure 1). This region includes a geologically diverse array of coastline and offshore islands including Block Island, Martha's Vineyard, and Nantucket Island, as well as several moderately shallow bays and sounds including Cape Cod Bay, Nantucket Sound, Narragansett 
Bay, Buzzard's Bay, Block Island Sound, Rhode Island Sound, and Long Island Sound. This area also includes the Nantucket Shoals $\left(41.03^{\circ} \mathrm{N}, 69.94^{\circ} \mathrm{W}\right)$, a $2,000 \mathrm{~km}^{2}$ expanse of shallow (4-35 $\mathrm{m}$ deep), sandy-bottom habitat identified through extensive aerial surveys as having a high density of White-winged Scoters and other sea birds (Veit et al. 2016). The shoals support high concentrations of benthic amphipods (Avery et al. 1996) which are important in the winter diet of some sea duck species including Long-tailed Duck (White et al. 2009), and the breeding season diet of White-winged Scoters (Brown and Fredrickson 1986, Haszard and Clark 2007). Among White-winged Scoters wintering along the Atlantic coast, the highest densities occur between Cape Cod and Long Island Sound (Silverman et al. 2013), accounting for approximately $94 \%$ of the entire western Atlantic Coast wintering population (Silverman et al. 2012). Our study area included $\sim 4000 \mathrm{~km}^{2}$ of commercial offshore wind energy leases and planning areas off the coasts of Massachusetts, Rhode Island, and New York (Bureau of Ocean Energy Management 2012; Figure 1).

\section{METHODS}

\section{Capture and Marking}

We used floating mist net arrays (Brodeur et al. 2008) to capture White-winged Scoters in Cape Cod Bay, MA $\left(41.75^{\circ} \mathrm{N}, 70.31^{\circ} \mathrm{W}\right)$ and Long Island Sound, NY $\left(40.99^{\circ} \mathrm{N}, 72.83^{\circ} \mathrm{W}\right)$ during November 2015 and March $2016(n=104)$. We also captured White-winged Scoters using a submerged gill net technique (adapted from Breault and Cheng 1990) in August 2016 at a prominent molting location in the St. Lawrence River Estuary, Quebec, Canada $\left(48.69^{\circ} \mathrm{N}, 69.06^{\circ} \mathrm{W} ; n=262\right)$. We used 2-4 sets of mist nets (36 m long, $127 \mathrm{~mm}$ mesh) in nearshore $(<1 \mathrm{~km})$ areas previously 
identified as consistent feeding locations. We monitored nets with teams of 2-4 biologists in outboard boats from predawn to 3-6 hours after sunrise. Upon removal from the mist nets or gill nets, we determined the age and sex of all captured birds based on plumage characteristics (Carney 1992), cloacal examination, and bursal depth (Mather and Esler 1999). We also weighed each bird with a Pesola spring scale ( $\pm 5 \mathrm{~g}$ ), and uniquely banded each with a United States Geological Survey size 7 aluminum or incoloy butt-end leg band.

We selected 52 White-winged Scoters that were either second-year (SY) or after-second-year (ASY) to receive implanted satellite transmitters (Cape Cod Bay $n=$ 22; Long Island Sound $n=4$; Quebec $n=26$ ). Appropriate sample sizes for satellite telemetry studies vary depending on study objectives (Lindberg and Walker 2007). Hebblewhite and Haydon (2010) suggested that at least 30 individuals were needed to make population-level inferences on resource selection, while Thaxter et al. (2017) reported that area use in seabirds could be reliably characterized by tracking 13-41 individuals for at least 145 days. As this study was part of a larger multi-species project implemented by the Sea Duck Joint Venture to assess population-level linkages between wintering, breeding, and molting areas, we chose to implant only second-year (SY) or after-second-year (ASY) females with satellite transmitters. Females of many sea duck species including White-winged Scoters exhibit a high degree of natal and breeding philopatry (Eadie and Savard 2015, Mallory 2015), and would thus be more likely to provide consistent breeding location data to achieve those objectives. To increase sample size and improve robustness of resource selection function modeling, these particular analyses also included an additional 16 White- 
winged Scoters (11 males, 5 females) captured using gill nets during the molting period in the St. Lawrence River Estuary, Quebec, between 2010 and 2012. We only included location data from these Quebec birds in the resource selection and wintering area distribution analyses, thus no phenology results are reported here for these 20102012 Quebec-caught birds.

We implanted White-winged Scoters with a 35-38 g coelomic-implant Platform Terminal Transmitter (PTT) with an external antenna manufactured by either Microwave Telemetry Inc. (Microwave Telemetry, Inc., Columbia, Maryland, USA; $n$ =31) or by Telonics, Inc. (Model IMPTAV-2635; Telonics, Inc., Mesa, Arizona, USA; $n=21$ ). All PTTs were wrapped in nylon mesh and had a felt cuff at the antenna base to provide additional anchor points to stabilize the PTT within the body cavity and provide additional surface area for adhesion to the body wall (D. M. Mulcahy personal communication). After applying these external anchoring materials, transmitters were sterilized with ethylene oxide and allowed to de-gas before implanting. All transmitters were implanted by licensed veterinarians with prior sea duck surgery experience using sterile surgical procedures and techniques described by Korschgen et al. (1996). All birds were administered subcutaneous boluses of lactated Ringer's solution $(30 \mathrm{ml} / \mathrm{kg})$. Isoflurane given by mask, followed by intubation was used for the general anesthesia. All birds received a line-block of bupivacaine ( 2 $\mathrm{mg} / \mathrm{kg}$ ) or bupivacaine and lidocaine $(2 \mathrm{mg} / \mathrm{kg})$ at the site of the skin incision. During holding, transport, and recovery, we held birds separately in small pet carriers equipped with padded sides to avoid bill damage and a raised mesh floor above a bed of pine shavings to allow them to remain clean and dry. We allowed birds to recover 
in their crates for 1-2 hrs after surgery and then released them at or near their original capture location within $11 \mathrm{hrs}$ of initial capture $(\bar{x}=7.5$, range $=3.0-11.0)$. The project and methodology were approved by the University of Rhode Island Animal Care and Use Committee (IACUC \#AN1516-002).

\section{Location Data}

We used the Argos satellite-based location and collection system (Collecte Localisation Satellites 2017) to receive transmission signals and PTT diagnostic data from all deployed birds. We downloaded and archived transmission data nightly and subsequently filtered data through the Douglas Argos Filter (DAF; Douglas et al. 2012) to remove redundant data and unlikely point locations. Using the DAF, we employed a hybrid filter to retain the single location with the highest accuracy from each duty cycle to reduce redundant daily positional information in our analyses. Argos processing centers report calculated accuracy estimates for each of the four highest quality location classes (i.e., location classes $3,2,1$, and 0 had estimated accuracies of $<250 \mathrm{~m}, 250$ to $<500 \mathrm{~m}, 500$ to $<1,500 \mathrm{~m}$, and $>1,500 \mathrm{~m}$, respectively; accuracies were not estimated for location classes A, B, or Z (invalid location), however few locations of these classes were used in our analyses (Table 1). These accuracy estimates may be overestimated, however, as O'Connor (2008) calculated estimates of approximately $660 \mathrm{~m}, 1,000 \mathrm{~m}$, and 1,700 $\mathrm{m}$ for class 3,2 , and 1 locations, respectively.

Individual location data, internal body temperature, and PTT operational information were transmitted from each unit based on pre-programmed duty cycles. For the initial capture period in the fall of 2015 , we programmed PTTs with a duty 
cycle of $4 \mathrm{hrs}$ on and $72 \mathrm{hrs}$ off (hereafter intensive) for 57 cycles, which extended from capture date to mid-April 2016. This intensive duty cycle provided more frequent transmissions during winter to allow for a more robust analysis of winter habitat use. Thereafter, all PTTs switched to a $4 \mathrm{hrs}$ on and $96 \mathrm{hrs}$ off (hereafter conservative) cycle until the end of battery life. This conservative duty cycle reduced the frequency of transmissions during the nesting period when movements were greatly reduced, while also extending battery life to allow data collection from multiple winters. We programmed all transmitters deployed in March 2016 to begin on the conservative duty cycle for 54 cycles (until mid-October 2016). Thereafter, PTTs switched to the intensive duty cycle for 57 cycles until the end of their first full wintering period (until mid-April 2017). The transmitters then switched back to the conservative duty cycle until the end of battery life. Due to changes in capture timing, PTTs deployed in August 2016 were programmed to begin on the conservative duty cycle and later switch to the intensive cycle after the first winter period. While this was counter to our earlier fall deployments, we projected that the conservative duty cycle would provide an acceptable number of winter locations ( 40) sufficient for habitat analysis.

We programmed transmitters deployed in 2010-2012 with a duty cycle of $2 \mathrm{hrs}$ on and $72 \mathrm{hrs}$ off. The shorter on period was thought to increase battery life, although the fewer high-quality locations received from these transmitters resulted in the later use of the $4 \mathrm{hrs}$ on duty cycle. To minimize potential bias in habitat use and movement behavior associated with capture and surgery trauma, we excluded the first 14 days of data collected after release (Esler et al. 2000; Sexson et al. 2014). For the same reason, we only included birds that transmitted $>60$ days after release in our analyses. 
We used only one year's worth of data for each bird when calculating winter resource selection in order to standardize for mortality and PTT longevity and avoid biasing the analysis towards individuals that have over one year of data. As the potential exists for movement patterns and behavior of birds to be affected by transmitter implantation during the period following capture and deployment (Barron et al. 2010, White et al. 2013), we preferentially used data for an individual in the second winter they were tracked if such data existed. When calculating movement phenology and inter-annual site fidelity, multiple years of data were used when available. We managed and analyzed all telemetry data, as well as produced all maps, using ArcGIS 10.3.1 (Environmental Systems Research Institute, Inc., Redlands, CA). We performed all statistical analyses using the statistical software R 3.3.1 (R Core Team 2016).

\section{Winter Phenology and Length of Stay}

To determine when White-winged Scoters were present in the study area and potentially vulnerable to proposed and existing OWED, we calculated fall arrival dates, spring departure dates, and overall length of stay following criteria described by De La Cruz et al. (2009). We defined the fall arrival date into the study area as the median date between the last location outside the study area and the first location within the study area during fall migration. Similarly, we calculated the spring departure dates as the median date between the last location within the study area and the first location outside the study area during spring migration. We defined the first winter length of stay as the period between transmitter deployment and the spring departure date. We estimated the length of stay during the second winter period as the 
difference between the fall arrival date and the spring departure date plus one additional day, to account for the possibility that birds could have been present within the study area on either or both the arrival date and departure date. We report the overall winter length of stay as mean $\pm \mathrm{SE}$, whereas we report only the median (range) arrival and departure dates.

\section{Wintering Area Distribution}

Following Loring et al. (2014), we calculated utilization distributions for birds wintering within our study area by first randomly selecting 40 location points from within the study area for each individual. We then calculated individual kernel-based utilization distributions using the Gaussian kernel and likelihood cross-validation bandwidth estimator within Geospatial Modeling Environment 0.7.4.0 (Beyer 2015). The likelihood cross-validation bandwidth estimator provides a better fit and less variability than least squares cross-validation when estimating utilization distributions with samples sizes $<50$ (Horne and Garton 2006). The 40 locations for each bird were then pooled to estimate composite $95 \%$ kernel utilization distributions and $50 \%$ kernel core-use areas. In ArcGIS, we clipped each utilization distribution and core-use area to the National Oceanic and Atmospheric Administration's (NOAA) Medium Resolution Digital Vector Shoreline data (1:70,000; NOAA 2012), as White-winged Scoters are not typically found on inland freshwater areas during the wintering period, apart from relatively small numbers wintering in the Great Lakes (Prince et al. 1992). We then calculated the total area $\left(\mathrm{km}^{2}\right)$ of the individual and composite utilization distributions and core-use areas. We reported total area for individual and composite utilization distributions and core-use areas as $\bar{x} \pm \mathrm{SE}$. We used Wilcoxon rank-sum tests to 
compare total area of utilization distributions and core-use areas by sex and capture location. For birds with two or more distinct $50 \%$ core-use areas, we calculated the Euclidian distance $(\mathrm{km})$ between centroids of each area. For White-winged Scoters that spent two consecutive winters within the study area, we compared total area of utilization distributions and core-use areas between winters using paired t-tests.

\section{Site Fidelity}

We assessed winter site fidelity of White-winged Scoters between consecutive winter periods by determining the number of second winter (2016-2017) locations within the study area that fell within an individual's first winter (2015-2016) 50\% core-use area and $95 \%$ utilization distribution as well as those that occurred within the composite 2015-2016 core-use areas and utilization distributions. We measured mean $( \pm$ SE) geodesic distances between first and second winter core-use areas for each individual. We also calculated the percentage of second winter points for each individual that occurred within the first winter $50 \%$ core-use areas of all other individuals for which we had two winters of data to assess whether birds preferentially occurred within their own core-use area as compared to the core-use areas of other birds in the population.

\section{Resource Selection During Winter}

We used the composite $95 \%$ utilization distributions and 50\% core-use areas to assess White-winged Scoter habitat use and resource selection within the study area. We made no distinction between diurnal and nocturnal locations when calculating individual and composite home ranges, so resource selection estimates were based on a full 24-hr diel period. Following Loring et al. (2014) and Beuth et al. (2017), we investigated third-order resource selection (Johnson 1980) by quantifying and 
comparing habitat covariates within the composite $95 \%$ utilization distributions (available) and 50\% core-use areas (used; Manly et al. 2002; Sampling Protocol-A). We used Spatial Analyst in ArcGIS to generate the maximum number of random points within the $95 \%$ utilization distribution and $50 \%$ core-use area, with a minimum separation distance between points of $500 \mathrm{~m}$ to reduce spatial autocorrelation. We did not assess overlap between used and available samples as resource selection functions (RSF) are robust to such contamination (Johnson et al. 2006).

Several studies have shown that distribution patterns of wintering sea ducks are driven in large part by available food resources (Žydelis et al. 2006, Kirk et al. 2008) and ocean bottom geography (Loring et al. 2014, Beuth et al. 2017, Heinänen et al. 2017). We therefore chose a set of eight geophysical and oceanographic habitat variables that we hypothesized could serve as proxies for benthic invertebrate distributions and thus provide significant predictive ability in determining scoter use throughout the study area. To quantify distance from shore, we calculated the Euclidian distance $(\mathrm{km})$ from each resource unit to the nearest segment of the NOAA Medium Resolution Digital Vector Shoreline (1:70,000; NOAA 2017a). We measured water depth (m) and slope (degrees) within each resource unit using the NOAA National Geophysical Data Center Coastal Relief Model (3 arc-second) for the United States (NOAA 2017b). To estimate likely areas of hard bottom occurrence, we used a kernel-based probabilistic model developed by Loring (2012). We obtained sediment grain size data from the Nature Conservancy's Northwest Atlantic Marine Ecoregional Assessment data portal (Greene et al. 2010). These data were interpolated from pointbased sampling and classified based on grain size following the scale developed by 
Wentworth (1922). To convert this to a continuous dataset, we assigned the median grain size value from each ordinal class to pixels within each category. Following Meattey et al. (2015), we used Marine Geospatial Ecology Tools in ArcGIS to create long-term mean raster sets for oceanographic habitat variables including sea surface temperature, sea surface salinity, and chlorophyll- $a$ concentrations.

We obtained smoothed daily sea surface temperature (SST; degrees Celsius) estimates derived from interpolated data from high resolution satellite imagery and floating buoys (Stark et al. 2007). These data are collected at a spatial resolution of 0.05 degrees latitude and longitude. To estimate sea surface salinity (practical salinity units [psu]), we used the Hybrid Coordinate Ocean Model (HYCOM), which produces daily estimates at a spatial scale of 1.5 degrees latitude and longitude by the National Ocean Partnership Program (Chassignet et al. 2009). As an estimated proxy for biological productivity, we used monthly estimates of chlorophyll- $a$ concentrations $\left(\mathrm{mg} / \mathrm{m}^{3}\right)$ produced by the NASA Goddard Space Flight Center's Ocean Data Processing System. These data were derived from the Aqua sensor aboard the MODIS satellite system which produces radiometric measurements of chlorophyll fluorescence at a $4 \mathrm{~km}$ scale (Mueller et al. 2003). To account for the approximately six years of sampling data included in this study, we calculated six-year mean datasets for each of the oceanographic variables by averaging winter-month (1 October - 1 May) raster values. We randomly sampled habitat variables at $25 \%$ of resource units from both the $95 \%$ utilization distributions and 50\% core-use areas to reduce spatial autocorrelation between variables. All habitat data were in raster format and resampled to a 
standardized $250 \mathrm{~m} \mathrm{X} 250 \mathrm{~m}$ cell size (hereafter: resource units) prior to extraction and analysis.

We calculated Pearson product-moment correlations to assess correlations between all possible pairs of habitat covariates and checked for multicollinearity of variables using variance inflation factors (VIF). Within samples throughout the study period, pair-wise correlation among variables did not exceed 0.6 and VIF values were $\leq 2.0$. Therefore, we retained all variables through the modeling step. We used logistic regression to model habitat covariate effects and estimate the parameters for exponential resource selection models (Manly et al. 2002). All environmental variables, including quadratic terms for each to account for possible nonlinear relationships, were included in an initial global model. Non-linear terms for some variables (e.g., water depth, distance to shore) suggested significance in the global model, but after inspection parameter estimates were exceedingly low and not ecologically meaningful, thus only linear terms for each variable were included in further modeling. We performed backwards step-wise model selection, excluding uninformative parameters in order of least significance. We compared each model iteration, as well as an intercept-only and individual-parameter models using Akaike's Information Criterion adjusted for small sample size $\left(\mathrm{AIC}_{c}\right)$. We ranked models using $\mathrm{AIC}_{c}$ differences $\left(\triangle \mathrm{AIC}_{c}\right)$ and $\mathrm{AIC}_{c}$ weights $\left(\mathrm{w}_{\mathrm{i}}\right)$ to estimate the relative likelihood of each candidate model (Burnham and Anderson 2002). Competitive models were considered at $\leq 2.0 \Delta \mathrm{AIC}_{c}$ from the best performing model if they contained no uninformative parameters, and we selected the parameter coefficients from the most 
parsimonious model to calculate the RSF. Model residuals were checked for spatial autocorrelation by using a Moran's I test in the R package spdep (Bivand 2009).

We predicted relative probability of use for $77,390 \mathrm{~km}^{2}$ of our study area using the RSF derived from our highest ranked logistic regression model. We were unable to predict probability of use for $5,182 \mathrm{~km}^{2}$ of our study area due to incomplete spatial coverage of the sea surface temperature, salinity, and chlorophyll- $a$ datasets. We calculated the RSF model using equation 5.11 in Manly et al. (2002):

$$
\mathrm{W}(\mathrm{x})=\exp \left(\beta_{1} \mathrm{x}_{1}+\ldots+\beta_{\mathrm{n}} \mathrm{x}_{\mathrm{n}}\right)
$$

where $\mathrm{W}$ is relative probability of use, $\beta_{\mathrm{n}}$ are the model coefficients estimated from the logistic regression for each habitat parameter, and $\mathrm{x}_{\mathrm{n}}$ are the predictor variables. We used Raster Calculator in ArcGIS to complete the above equation and then reclassified the distribution into 4 quantile bins to characterize relative probability of use from low to high.

We evaluated the predictive ability of the top-ranked RSF using k-fold crossvalidation methods described by Johnson et al. (2006). We used Huberty's (1994) rule of thumb to partition resource units into $3 \mathrm{k}$-folds with approximately $37 \%$ of used resource units being used for model testing against $63 \%$ of remaining model training data. We partitioned resource selection functions predicted from the model training data into four quantile bins following Morris et al. (2016), who suggested that RSFs should be validated using the same classification scheme as presented visually. We determined strong predictive ability of the RSF model by a high $R^{2}$ value and a nonsignificant $\chi^{2}$ goodness-of-fit value between observed and expected proportions of use across quantile bins (Johnson et al. 2006). We assumed that areas classified with a 
high probability of selection in the RSF model were high quality habitat that should warrant conservation from developers when planning and siting future wind energy areas.

\section{RESULTS}

\section{Survival and Transmitter Performance}

Of the original 22 female White-winged Scoters implanted in Cape Cod Bay during fall 2015, two died within two weeks of transmitter deployment, eight transmitters went offline in presumed live birds either during the first winter or outside the study area during migration or breeding. Thus, sixteen female White-winged Scoters transmitted data throughout the entire 2015-2016 winter period, of which 14 spent the majority of at least one winter within the study area; six of these birds also transmitted throughout the winter of 2016-2017. Of the four female White-winged Scoters implanted in Long Island Sound in March 2016, two died before returning to the study area the following winter and two transmitters went offline in presumed live birds, thus none of these birds provided a full winter of data for resource selection analyses. Thirteen of the female White-winged Scoters deployed in the St. Lawrence River Estuary in August 2016 spent most of the 2016-2017 winter period within the study area. Two birds died within two weeks of transmitter deployment, one bird died ca. three months after deployment while still on the molting grounds, and two transmitters went offline in presumed live birds.

Locational accuracy classes of the best-per-duty-cycle locations used to calculate winter movement phenology and generate winter home ranges ranged from location class (LC) 3 to LC B, with most locations classified as $\geq \mathrm{LC} 2$ (estimated 
accuracy of $\leq 500 \mathrm{~m}$; Table 1). Among the randomly-selected locations used to generate composite winter home ranges, $74 \%$ of locations were classified as either LC 2 or LC 3.

\section{Winter Phenology}

We calculated spring departure dates for White-winged Scoter females deployed across all capture locations. Fall arrival dates were calculated for scoters captured during the molting period in the St. Lawrence River estuary in 2016, as well as those captured in Cape Cod Bay that returned during the second winter period (Table 2). Fall arrival date was not calculated for scoters captured in Cape Cod Bay or Long Island Sound, as captures took place after birds had already arrived at the study area. Total winter length of stay was calculated for scoters from Cape Cod Bay and the St. Lawrence River estuary. We were unable to calculate length of stay for scoters captured in Long Island Sound due to captures taking place in late winter. We found no significant difference in spring departure date based on initial capture location $\left(F_{[3,29]}=2.36, P=0.09\right)$. Tagged White-winged Scoter females spent an average of $\sim 53 \%$ (193 days) of their annual cycle within the southern New England study area.

\section{Wintering Area Distribution}

White-winged Scoters wintering in the study area had 50\% core-use areas ranging widely from 32 to $4,220 \mathrm{~km}^{2}\left(\bar{x}=868 \pm 174 \mathrm{~km}^{2}\right)$. Individual $95 \%$ utilization distributions ranged from 272 to $18,235 \mathrm{~km}^{2}\left(\bar{x}=4,387 \pm 761 \mathrm{~km}^{2}\right)$. For the 40 Whitewinged Scoters (31 females, 9 males) that spent an entire winter within the study area (including the additional 2010-2012 Quebec-caught birds), the composite core-use area was $2,054 \mathrm{~km}^{2}$ and the composite utilization distribution was $9,790 \mathrm{~km}^{2}$ (Figure 
2). Core-use areas were located in Cape Cod Bay, the outer edge of Nantucket Sound between Monomoy Island and Nantucket Island, Buzzards Bay, Long Island Sound and Montauk Point, as well as the Nantucket Shoals south of Nantucket Island. We found no significant difference in individual core-use areas or utilization distribution size based on initial capture location (Wilcoxon rank-sum test, $P=0.6$ and $P=0.7$, respectively). For White-winged Scoters that spent consecutive winters in the study area, total area of utilization distributions and core use areas decreased by $\sim 30 \%$ and $\sim 20 \%$, respectively, though this was not significant ( $P=0.2$ in both cases). One bird spent the majority of the 2015-2016 winter outside the study area, migrating to Lake Ontario shortly after deployment. Eleven tagged White-winged Scoters spent all or most of the winter outside the study area during the 2016-2017 winter. Alternate wintering areas included Lake Ontario, mid-coast Maine, and coastal Nova Scotia.

During the winter period, individual White-winged Scoters occupied 1-5 distinct $50 \%$ core-use areas, with 29 of 40 birds occupying two or more. The mean distance between the multiple core-use areas was $101 \mathrm{~km} \mathrm{(} \pm 16)$ and ranged from 37 to $404 \mathrm{~km}$. Composite scoter 95\% utilization distributions and 50\% core-use areas overlapped with or immediately bordered $484 \mathrm{~km}^{2}$ and $69 \mathrm{~km}^{2}$ of current wind energy area lease blocks, respectively.

\section{Site Fidelity}

Six female White-winged Scoters tagged in Cape Cod Bay in 2015 survived and continued to provide data into the winter of 2016-2017. All six birds returned to the study area, however, only five provided enough winter locations in their second winter to calculate home ranges. White-winged Scoter females that returned exhibited 
moderate to high degrees of winter site fidelity. Most locations during the 2016-2017 winter period were within the 2015-2016 composite core-use area $(\bar{x}=66 \% \pm 14$, range $=33-100 \%)$ and utilization distribution $(\bar{x}=97 \% \pm 2$, range $=91-100 \%$; Figure 4). However, individuals that returned to the study area during the 2016-2017 winter period exhibited varying degrees of site fidelity to their individual core-use areas $(\bar{x}=44 \% \pm 19$, range $=0-90 \%)$ and utilization distributions $(\bar{x}=59 \% \pm 21$, range $=0-100 \%)$ from the first winter. In comparison, scoters returning to the study area during the second winter were equally philopatric to first winter utilization distributions $(\bar{x}=57 \% \pm 8$, range $=0-100 \%)$, but had notably fewer locations within the first winter core-use areas $(\bar{x}=27 \% \pm 6$, range $=0-79 \%)$ of other birds in the population. The mean distance between first and second year core-use areas across individuals was $106 \pm 15 \mathrm{~km}$, with a maximum distance of $188 \mathrm{~km}$.

\section{Resource Selection During Winter}

Scoter core-use areas within our study area were generally shallower and closer to shore relative to utilization distributions, while bottom slope and sediment grain size were similar throughout (Table 3). The best performing logistic regression model estimating relative probability of use by White-winged Scoters $(n=40 ; 31$ females, 9 males) included four significant parameters (i.e., sea surface temperature, hard bottom probability, sea surface salinity, and chlorophyll- $a$ concentration) and accounted for $49 \%$ of Akaike weight (Table 4). The second-ranked model was within $2 \Delta \mathrm{AIC}_{c}$ but contained an uninformative parameter and thus was not considered competitive. Based on this best model, scoter core-use areas were negatively associated with sea surface temperature and sea surface salinity and positively associated with probability of hard 
bottom substrate and mean chlorophyll- $a$ concentrations, relative to utilization distributions (Table 5). Results from the k-fold cross-validation showed strong positive correlation $\left(R^{2}=0.83\right)$ between area-adjusted proportions of observed and expected habitat use and $\chi^{2}$ goodness-of-fit tests were non-significant across all three iterations of model validation $\left(K_{1}: \chi^{2}=1.53, P=0.67 ; K_{2}: \chi^{2}=1.34, P=0.72 ; K_{3}: \chi^{2}=\right.$ $1.65, P=0.65)$, indicating that the top-ranked RSF model was capable of reliably predicting cross-validated use locations. The model slightly under-predicted use in the highest quantile bin. We determined that a small degree of positive spatial autocorrelation was present in the residuals of our best performing model (Moran's $I=$ $0.2, P=0.001)$

The top-ranked RSF model was able to predict relative probability of use by White-winged Scoters for $77,390 \mathrm{~km}^{2}$ of the $82,572 \mathrm{~km}^{2}$ study area. Throughout the study area, $18,654 \mathrm{~km}^{2}(24.1 \%)$ were classified as low probability of use, $19,122 \mathrm{~km}^{2}$ (24.7\%) were classified as medium-low, $20,965 \mathrm{~km}^{2}(27.1 \%)$ were classified as medium-high, and 18,649 $\mathrm{km}^{2}$ (24.1\%) were classified as high probability of use (Figure 3). Approximately $420 \mathrm{~km}^{2}$ of current wind energy area lease blocks fell within or immediately bordered areas classified as high probability of use.

\section{DISCUSSION}

This study is the first to document spatially-explicit resource selection and habitat use of White-winged Scoters wintering on the Atlantic Coast of North America. The resulting estimates of probability of use across the study area provide important insights into specific areas and habitat characteristics that should be considered when planning for and siting offshore wind energy development. Additionally, our study 
provides important seasonal movement and phenology data on a female-only cohort of White-winged Scoters that can be used to better manage and conserve this species and their habitat during a crucial portion of their annual cycle.

\section{Winter Phenology}

The results from this study confirm past survey data (Silverman et al. 2013, Baldassarre 2014, Veit et al. 2016) and other telemetry studies (Sea Duck Joint Venture 2015, C. Lepage personal communication) highlighting the importance of this region for White-winged Scoters during winter. Satellite-tagged White-winged Scoters in this study spent $\sim 53 \%$ (193 days) of their annual cycle within the southern New England study area. This is longer than estimates for Black Scoters (Loring et al. 2014) and Common Eiders (Beuth et al. 2017), which spent an average of 147 days and 135 days, respectively, within the same New England wintering area. Surf Scoters (Melanitta perspicillata) wintering along the mid-Atlantic coast of the U.S. spent an average of 133 days on the wintering grounds (Meattey et al. 2015), while King Eiders (Somateria spectabilis) in the Bering Sea spent an average of 160 days on their wintering grounds (Oppel et al. 2008).

White-winged Scoters typically departed the study area by the third week of May. This is consistent with Black Scoters in the same area (range: 4 March - 24 May; Loring et al. 2014) but later than Common Eiders (range: 18 March - 20 April; Beuth et al. 2017). Also, aerial surveys from 2011-2015 documented White-winged Scoters were most abundant along the western edge of the Nantucket Shoals during the spring period (Veit et al. 2016), which was at the eastern edge of the Massachusetts offshore WEA lease blocks. While our home range analyses did not 
consider date of locations within the study area, many White-winged Scoters staged on the shoals during mid-May for 1-2 weeks prior to spring departure. This further suggests that Nantucket Shoals are a seasonally-important area for sea ducks, likely due to high densities of high-quality prey (e.g., a pelagic amphipod (Gammarus annulatus)) that sea ducks may rely on for reserve-building prior to long-distance migration (White et al. 2009). Most studies of winter diet composition of Whitewinged Scoters report very small percentages of non-bivalve prey (e.g. Polychaeta; Anderson et al. 2008), although the importance of soft-bodied prey such as amphipods has been well documented during the breeding period (Brown and Fredrickson 1986, Haszard and Clark 2007), suggesting the possibility that White-winged Scoters may take advantage of similar food sources during the winter months in pelagic habitats if available. Any disturbance to this area could have detrimental effects on Whitewinged Scoters during a crucial part of the annual cycle.

\section{Wintering Area Distribution}

Individual White-winged Scoters wintering in the study area varied widely in the size of their core-use and utilization distributions $\left(32-4,220 \mathrm{~km}^{2}\right.$ and $272-18,235 \mathrm{~km}^{2}$, respectively), but were generally larger than winter home ranges documented for other species of sea duck. As kernel home range estimates can vary depending on kernel method, sample size, and bandwidth estimators, direct comparisons among studies with non-identical methodologies should be interpreted with caution. Schamber et al. (2010) studying Black Scoter and King Eider in Bristol Bay, Alaska documented 95\% utilization distributions of $\sim 3670 \mathrm{~km}^{2}$ for eiders and $\sim 1298 \mathrm{~km}^{2}$ for scoter. The same study estimated composite $50 \%$ core-use areas of $448 \mathrm{~km}^{2}$ and $160 \mathrm{~km}^{2}$ for eider and 
scoter, respectively; however, probability contours were derived from full annual cycle locations so direct seasonal comparisons warrant caution. Winter home range sizes of White-winged Scoters in this study were higher than those reported for Harlequin Ducks in Prince William Sound, Alaska (11.5 km²; Iverson and Esler 2006). Communal foraging behavior in sea ducks and resulting depletion of local food sources is well documented (Guillemette et al. 1996; Kirk et al. 2007; Kirk et al. 2008; Loring et al. 2013). Large and variable winter home range sizes in our study may have been a result of changing prey densities throughout the winter, requiring birds to expand beyond core use areas to locate food. More than half the birds in our study occupied two or more disjoint core-use areas throughout a single winter. Several of these individuals occupied core-use areas in both the eastern (Cape Cod) and western (Long Island) portions of the study area, with the distance between core-use areas ranging as high as $404 \mathrm{~km}$. Several cases of White-winged Scoters using secondary wintering sites have also been documented with the 2010-2012 Quebec-caught birds, with several birds moving from Long Island to the Nantucket area in late winter, prior to spring migration (Lepage et al. in prep).

These instances of long-distance within-winter movements highlight the potential vulnerability of White-winged Scoters to offshore development in the area. Additionally, a recent study on Black Scoters throughout the migratory and wintering period in southern New England highlighted a tendency to venture outside near-shore core-use areas to locations further offshore, increasing the likelihood of encountering offshore wind energy facilities (Loring et al. 2014). While the locations of current wind energy lease blocks in the study area have minimal overlap with scoter core-use 
areas, the development of offshore structures such as wind turbines could act as an impediment to White-winged Scoters moving between important areas in Cape Cod Bay and Long Island Sound during the winter period.

\section{Site Fidelity}

White-winged Scoters in our study were highly philopatric to the broad southern New England wintering area and to the location of composite home ranges but exhibited varying degrees of inter-annual site fidelity to their individual home ranges. While the sample size of birds with location data spanning consecutive winters was small $(n=5$ females), our results are generally consistent with other studies of winter philopatry in sea ducks. In comparison, $82 \%$ of White-winged Scoters studied in Quebec from 2010-2012 returned to the same wintering area $(n=17$; C. Lepage personal communication). A study of Common Eiders wintering in southern New England found that about half of second winter locations fell within an individual's first-year core-use areas $(\sim 51 \%)$ and nearly all locations were within the composite core-use area (96\%; Beuth et al. 2017). In the same study area, wintering Black Scoters exhibited only $24 \%$ and $32 \%$ spatial overlap between first and second year core-use areas and utilization distributions, respectively (Loring et al. 2014). The site fidelity we observed was also generally lower than that reported for Surf Scoters in the midAtlantic (Meattey et al. 2015; 91\%), Common Eiders on the Pacific coast (Petersen et al. 2012; 95\%) as well as Harlequin Ducks (Histrionicus; Robertson et al. 2000; 62\%).

Knowledge of local prey distributions is one of several advantages that could result from a high rate of site fidelity among sea ducks (Robertson and Cooke 1999). The high rate of population-level site fidelity we observed supports this hypothesis, as 
many core-use areas we identified were located near high-productivity areas known to be of seasonal importance to sea ducks (i.e., Nantucket Shoals; White et al. 2009, Veit et al. 2016). The variability in individual-level site fidelity reported in our study suggests that White-winged Scoters are also able to adjust to changes in local environmental conditions between years to respond to shifting prey distributions and habitat quality.

\section{Resource Selection During Winter}

Scoter core-use areas within our study area were associated with areas of lower sea surface temperatures, lower salinity, higher probability of hard bottom substrate, and higher mean chlorophyll- $a$ concentrations relative to utilization distributions. Loring et al. (2014) and Beuth et al. (2017) found similar significant positive effects of hard bottom probability on Black Scoters and Common Eider in Rhode Island Sound, presumably foraging on sessile prey, such as blue mussels (Mytilus edulis) frequently abundant in harder substrates (Goudie and Ankney 1986). We found the importance of hard bottom probability in our models surprising, as White-winged Scoters are well documented to prefer prey in predominantly soft-sediment habitats (Stott and Olson 1973, Anderson et al. 2008). However, the significance of this habitat characteristic may be tied to interactions with other parameters not explored in our analyses and not directly related to foraging preference as would be expected with other species (i.e., Black Scoter and Common Eider).

While studies directly associating seasonally-dynamic climate variables to sea duck habitat use and distribution are limited, our study does corroborate findings by Zipkin et al. (2010) who found sea surface temperature to have a significant negative 
effect on long term White-winged Scoter count data in the Atlantic. More frequently, oceanographic climate variables affect benthic invertebrate physiology and distribution (Lesser et al. 2010, Waldeck and Larsson 2013, Sorte et al. 2016), which in turn can directly influence sea duck abundance and distribution (Perry et al. 2007, Kirk et al. 2008, Loring et al. 2013). Increases in sea surface temperature by only a few degrees, corresponding to a mild vs. cold winter period, were associated with 1519\% body mass loss in blue mussels in the Baltic Sea (Waldeck and Larsson 2013). Similarly, Lesser et al. (2010) documented blue mussels in the Gulf of Maine exhibiting increased expression of heat shock proteins and antioxidant enzyme activity when exposed to higher seawater temperatures. Such environmental stress has been associated with slower growth and impaired reproductive capacity (Petes et al. 2007). During the winter period when White-winged Scoters must build energy reserves for migration and breeding, selection for areas of lower sea surface temperature may be indicative of higher quality prey.

Chlorophyll- $a$, as a proxy for overall levels of primary productivity, and salinity can be important parameters for predicting both seabird and benthic invertebrate distributions (Chester et al. 1983, Balance et al. 1997, Suryan et al. 2012). We assumed that higher chlorophyll concentrations corresponded to increased primary productivity, and thus higher benthic biomass or food availability to foraging birds (Grebmeier 1993, Phillips et al. 2006). King Eiders in the Bering Sea during the molting period and winter were associated with areas of lower salinity (Phillips et al. 2006) and preference for foraging in low-temperature and high-chlorophyll areas has also been documented in other upper trophic-level sea birds, such as the Cape Gannet 
(Morus capensis) in the Benguela upwelling zone off South Africa (Grémillet et al. 2008). It is worth considering the narrow range of sea surface salinity values in both the used and available areas of this study. While our RSF model identified salinity as a significant, informative parameter, this may be a result of the large sample size and not indicative of ecological significance. Future studies should prioritize identifying the correlations between these oceanographic habitat variables and shellfish beds in southern New England, as these are likely a primary driver of sea duck distributions in the area.

We found that White-winged Scoters inhabited relatively shallow $(<25 \mathrm{~m})$, sandy areas that averaged $\sim 17 \mathrm{~km}$ from shore. This corroborates aerial surveys conducted south of Nantucket Island in Massachusetts between 2011 and 2015 which found that White-winged Scoters were the most pelagic of the sea duck species recorded (Silverman et al. 2013; Veit et al. 2016). Much of this bias towards areas farther from shore comes from the high abundance of White-winged Scoters, as was documented in our study, which utilize the Nantucket Shoals during winter. This area has been well-documented for its importance to wintering sea ducks (e.g. Sea Duck Joint Venture 2015) and holds high densities of pelagic amphipods and bivalves (White et al. 2009). This area also sits adjacent to a large expanse of wind energy lease blocks that skirt the shoals along their western edge. Future development in this area could pose a high risk of displacement, or act as a barrier to White-winged Scoters moving into or within this important habitat. Core-use areas for Black Scoters in Rhode Island averaged $\sim 15 \mathrm{~m}$ in water depth but were much closer to shore ( $\sim \mathrm{km}$; Loring et al. 2014). Similarly, Common Eiders in the same study area were found 
primarily in $<20 \mathrm{~m}$ of water within $2 \mathrm{~km}$ from shore (Beuth et al. 2017). King Eiders in the Bering Sea during winter were in slightly deeper water $(\sim 38 \mathrm{~m})$ but were within $12 \mathrm{~km}$ from shore (Phillips et al. 2006). In Europe, Common Scoters primarily forage in waters shallower than $20 \mathrm{~m}$ (Fox 2003). Foraging scoters are well documented to tend to congregate in areas with high prey density (Kirk et al. 2008; Loring et al. 2013), which occurs along the southern New England shelf at depths shallower than $26 \mathrm{~m}$ (Theroux and Wigley 1998). It is assumed that offshore development within this depth range would have the highest potential for displacement of wintering sea ducks in the study area. While core-use areas were found in areas close to shore, the results of our RSF model likely underestimate or incompletely predict probability of use in nearshore areas due to a lack of spatial coverage of habitat variables used in the model. Finally, we acknowledge that the presence of positive spatial autocorrelation in the model residuals from our top-ranked logistic regression model is a potential limitation of our study that we do not directly address in our analyses. However, we remain confident that our model results are not strongly impacted by these limitations, as the degree of autocorrelation was relatively low and our cross-validation results show very good predictive ability of our top model.

\section{Management and Conservation Implications}

In the United States, several sites along the mid-Atlantic Outer Continental Shelf have been proposed for offshore wind energy facilities, and commercial wind energy leases have been issued for offshore areas in Massachusetts, Rhode Island, Delaware, Maryland, and Virginia (Manwell et al. 2002, Breton and Moe 2009, Musial and Ram 2010). Large-scale surveys suggest these areas provide important staging and 
wintering habitat for several sea duck species (Silverman et al. 2013; Veit et al. 2016), and detailed studies of fine-scale habitat selection have confirmed this importance for multiple species that utilize these offshore waters (Loring et al. 2014, Meattey et al. 2015, Beuth et al. 2017, Berlin et al. 2017). Throughout southern New England from Long Island to Cape Cod, several state agencies have invested millions of dollars towards site-planning of wind energy facilities. For example, Rhode Island recently committed funding towards baseline monitoring of natural resources, including sea ducks (Winiarski et al. 2014), for the Rhode Island Ocean Special Area Management Plan (SAMP; RI Ocean SAMP 2010). Using the most current modeling frameworks, animal movement information gathered through these monitoring efforts can help integrate ecological data into marine spatial planning and policy (Masden et al. 2012; Lascelles et al. 2016).

The results from our study demonstrate that current lease areas for offshore wind energy development show minimal overlap with White-winged Scoter winter home ranges and areas predicted by our RSF model as having a high probability of use. However, the large proportion of birds utilizing multiple disjoint core-use areas, often on opposite sides of the study area, suggests caution when planning for and siting any future offshore wind energy developments. While direct collision risk is of minimal concern for sea ducks, the effects of displacement and obstruction could have compounding effects on birds' ability to utilize the entirety of the wintering area and respond to seasonally-dynamic prey distributions and habitat quality. Numerous White-winged Scoters spent more than half of the annual cycle on wintering grounds in southern New England, exhibited a high degree of inter-annual site fidelity to 
composite core-use areas, and demonstrated a tendency to range widely within the study area, often traveling across areas where current wind energy lease areas exist. Thus, important habitats and key environmental characteristics identified by this study should be carefully considered when siting and developing future offshore wind energy areas.

\section{ACKNOWLEDGEMENTS}

We would like to thank the dedicated field crews from Biodiversity Research Institute (BRI), University of Rhode Island (URI), Rhode Island Department of Environmental Management (RIDEM), U.S. Fish and Wildlife Service (USFWS), and Canadian Wildlife Service for long hours in the field conducting this study. Drs. Gavino Puggioni (URI), Juliet Lamb (URI), and Pamela Loring (USFWS) provided helpful insight on statistical analyses. We thank Carlyn Caldwell (USGS Patuxent) for preparing the transmitters for implanting and obtaining and organizing surgical supplies. We thank Dr. Alicia Berlin (USGS Patuxent) for reviewing this manuscript. Sea Duck Joint Venture and RIDEM provided satellite transmitter funding and field support. Dr. Jean-Pierre Savard (Science \&Technology, Environment and Climate Change Canada) shared supplemental telemetry data. We thank Andrew Gilbert (BRI) for compiling and archiving telemetry data. Finally, a very special thanks to Drs. Michelle Kneeland and Ginger Stout (BRI), Drs. Stéphane Lair, Rozenn Le Net, and Benjamin Lamglait (University of Montreal, Quebec), and Cara Papakyrikos (Tufts University) for their tireless work performing surgical implants.

Funding statement: Funding for this research was provided by the Rhode Island Department of Environmental Management, Division of Fish and Wildlife (WSFR 
Wildlife Restoration Grant W-38-R), the University of Rhode Island, and the Canadian Wildlife Service of Environment and Climate Change Canada. Sea Duck Joint Venture (U.S. Fish \& Wildlife Service) provided the satellite transmitters used in this study, as well as partial funding for the 2010-2012 Quebec scoter captures. None of the funders required approval of the manuscript before submission or publication, although some co-authors are associated with state and federal agencies that provided some of the funding and they reviewed the manuscript prior to publication.

Ethics statement: All required permits were secured prior to field work, and the project and methodology were approved by the University of Rhode Island Animal Care and Use Committee (IACUC \#AN1516-002).

Author contributions: DEM, SRM, PWCP, LS, and JEO conceived the ideas and designed methodology; GHO oversaw surgical team and advised on protocols; all authors contributed to field work and data collection; CL and SGG provided supplemental telemetry data; DEM analyzed the data; DEM led the writing of the manuscript. All authors provided critical input and edits to the drafts and gave final approval for publication.

\section{LITERATURE CITED}

Alisauskas, R. T., J. J. Traylor, C. J. Swoboda, and F. P. Kehoe (2004). Components of population growth rate for White-winged Scoters in Saskatchewan, Canada. Animal Diversity and Conservation 27:451-460. 
Anderson, E. M., J. R. Lovvorn, and M. T. Wilson (2008). Reevaluating marine diets of Surf and White-winged Scoters: Interspecific differences and the importance of soft-bodied prey. The Condor 110:285-295.

Avery, D. E., J. Green, and E. G. Durbin (1996). The distribution and abundance of pelagic gammarid amphipods on Georges Bank and Nantucket Shoals. Deep Sea Research Part II: Topical Studies in Oceanography 43:1521-1532.

Bailey, H., K. L. Brookes, and P. M. Thompson (2014). Assessing environmental impacts of offshore wind farms: lessons learned and recommendations for the future. Aquatic Biosystems 10:8.

Baldassarre, G. (2014). Ducks, geese, and swans of North America. Johns Hopkins University Press, Baltimore, MD, USA.

Ballance, L. T., R. L. Pitman, and S. B. Reilly (1997). Seabird community structure along a productivity gradient: importance of competition and energetic constraint. Ecology 78:1502-1518.

Barron, D. G., J. D. Brawn, and P. J. Weatherhead (2010). Meta-analysis of transmitter effects on avian behavior and ecology. Methods in Ecology and Evolution 1:180-187.

Berlin, A. M., L. Savoy, C. E. Gray, A. T. Gilbert, G. H. Olsen, S. Ford, W. A. Montevecchi, and I. J. Stenhouse (2017). Occurrence and migration of Surf Scoters wintering in offshore waters of the mid-Atlantic United States. Chapter 4 in Determining fine-scale use and movement patterns of diving bird species in federal waters of the mid-Atlantic United States using satellite telemetry (C. S. Spiegel et al., Editors). OCS Study BOEM 2017-069. U.S. Department of 
the Interior, Bureau of Ocean Energy Management, Division of Environmental Sciences, Sterling, VA.

Beuth, J. M., S. R. McWilliams, P. W. C. Paton, and J. E. Osenkowski (2017). Habitat use and movements of Common Eiders in New England. Journal of Wildlife Management 81:1276-1286.

Beyer, H. L. (2015). Geospatial modeling environment, version 0.7.4.0 (software). http://www.spatialecology.com/gme.

Bivand, R. (2009). Spatial dependencies: Weighting schemes, statistics and models. R package version 0.4-34. https://cran.rproject.org/web/packages/spdep/index.html.

Bowman, T. D., E. D. Silverman, S. G. Gilliland, and J. B. Leirness (2015). Status and trends of North American sea ducks: reinforcing the need for better monitoring. In Ecology and Conservation of North American Sea Ducks (Savard J.-P. L., D. V. Derksen, D. Esler, and J. M. Eadie, Editors). Studies in Avian Biology, CRC Press, New York, NY.

Bradbury, G., M. Trinder, B. Furness, A. N. Banks, R. W. G. Caldow, and D. Hume (2014). Mapping seabird sensitivity to offshore wind farms. PloS one 9:e106366.

Breault, A. M., and K. M. Cheng (1990). Use of submerged mist nets to capture diving birds. Journal of Field Ornithology 61:328-330.

Breton, S.-P., and G. Moe (2009). Status, plans and technologies for offshore wind turbines in Europe and North America. Renewable Energy 34:646-654. 
Brodeur, S., G. H. Mittelhauser, J.-P. L. Savard, P. W. Thomas, R. D. Titman, and D. Comeau (2008). Capture methods for migrating, wintering and molting sea ducks. Waterbirds 31:133-137.

Brown, P. W., and L. H. Fredrickson (1986). Food habits of breeding White-winged Scoters. Canadian Journal of Zoology 64:1652-1654.

Brown, P. W., and L. H. Fredrickson (1997). White-winged Scoter (Melanitta fusca). In The Birds of North America (P. G. Rodewald, Editor) Cornell Lab of Ornithology, Ithaca, NY, USA. https://birdsna.org/SpeciesAccount/bna/species/whwsco.

Bureau of Ocean Energy Management (2012). Commercial wind lease issuance and site assessment activities on the Atlantic outer continental shelf offshore Rhode Island and Massachusetts. Office of Renewable Energy Programs, U.S. Department of the Interior, Washington, D.C., USA.

Burnham, K. P., and D. R. Anderson (2002). Model selection and multimodel inference: a practical information-theoretic approach. Second edition. Springer, New York, NY, USA.

Camphuysen, C. J., C. M. Berrevoets, H. J. W. M. Cremers, A. Dekinga, R. Dekker, B. J. Ens, T. M. van der Have, R. K. H. Kats, T. Kuiken, M. F. Leopold, J. van der Meer, and T. Piersma (2002). Mass mortality of Common Eiders (Somateria mollissima) in the Dutch Wadden Sea, winter 1999/2000: starvation in a commercially exploited wetland of international importance. Biological Conservation 106:303-317. 
Carney, S. M. (1992). Species, age and sex identification of ducks using wing plumage. U.S. Department of the Interior, U.S. Fish and Wildlife Service, Washington, DC, USA.

Chassignet, E. P., H. E. Hurlburt, E. J. Metzger, O. M. Smedstad, J. A. Cummings, G. R. Halliwell, R. Bleck, R. Baraille, A. J. Wallcraft, C. Lozano, H. L. Tolman, et al. (2009). US GODAE: Global ocean prediction with the hybrid coordinate ocean model (HYCOM). Oceanography 22:64-75.

Chester, A. J., R. L. Ferguson, and G. W. Thayer (1983). Environmental gradients and benthic macroinvertebrate distributions in a shallow North Carolina estuary. Bulletin of Marine Science 33:282-295.

Collecte Localisation Satellites (2017). Argos User's Manual. http://www.argossystem.org/wp-content/uploads/2016/09/ArgosWeb_User_Manual.pdf.

De La Cruz, S. E. W., J. Y. Takekawa, M. T. Wilson, D. R. Nysewander, J. R. Evenson, D. Esler, W. S. Boyd, and D. H. Ward (2009). Spring migration routes and chronology of Surf Scoters (Melanitta perspicillata): a synthesis of Pacific Coast studies. Canadian Journal of Zoology 87:1069-1086.

Desholm, M., and J. Kahlert (2005). Avian collision risk at an offshore wind farm. Biology Letters 1:296-298.

Dierschke, V., R. W. Furness, and S. Garthe (2016). Seabirds and offshore wind farms in European waters: Avoidance and attraction. Biological Conservation 202:59-68. 
Douglas, D. C., R. Weinzierl, S. Davidson, R. Kays, M. Wikelski, and G. Bohrer (2012). Moderating Argos location errors in animal tracking data. Methods in Ecology and Evolution 3:999-1007.

Drewitt, A. L., and R. H. W. Langston (2006). Assessing the impacts of wind farms on birds. Ibis 148:29-42.

Eadie, J. M., and J.-P. L. Savard (2015). Breeding systems, spacing behavior, and reproductive behavior in sea ducks. In Ecology and Conservation of North American Sea Ducks (J. -P. L. Savard, D. V. Derksen, D. Esler, and J. M. Eadie, Editors). Studies in Avian Biology, CRC Press, New York, NY.

Esler, D., D. M. Mulcahy, and R. L. Jarvis (2000). Testing assumptions for unbiased estimation of survival of radiomarked Harlequin Ducks. Journal of Wildlife Management 64:591-598.

Fox, A. D. (2003). Diet and habitat use of scoters Melanitta in the Western Palearctic - a brief overview. Wildfowl 54:163-182.

Fox, A. D., M. Desholm, J. Kahlert, T. K. Christensen, and I. K. Peterson (2006). Information needs to support environmental impact assessment of the effects of European marine offshore wind farms on birds. Ibis 148:129-144.

Furness, R. W., H. Wade, and E. A. Masden (2013). Assessing vulnerability of marine bird populations to offshore wind farms. Journal of Environmental Management 119:56-66.

Goudie, R. I., and C. D. Ankney (1986). Body size, activity budgets, and diets of sea ducks wintering in Newfoundland. Ecology 67:1475-1482. 
Grebmeier, J. M. (1993). Studies of pelagic-benthic coupling extended onto the Soviet continental shelf in the northern Bering and Chukchi Seas. Continental Shelf Research 13:653-668.

Greene, J. K., M. G. Anderson, J. Odell, and N. Steinberg (Editors) (2010). The Northwest Atlantic Marine Ecoregional Assessment: Species, habitats and ecosystems. Phase One. The Nature Conservancy, Eastern U.S. Division, Boston, MA, USA.

Grémillet, D., S. Lewis, L. Drapeau, C. D. van Der Lingen, J. A. Huggett, J. C. Coetzee, H. M. Verheye, F. Daunt, S. Wanless, and P. G. Ryan (2008). Spatial mis-match in the Benguela upwelling zone: should we expect chlorophyll and sea-surface temperature to predict marine predator distributions? Journal of Applied Ecology 45:610-621.

Guillemette, M., A. Reed, and J. H. Himmelman (1996). Availability and consumption of food by Common Eiders wintering in the Gulf of St. Lawrence: evidence of prey depletion. Canadian Journal of Zoology 74:28-32.

Guillemette, M., and J. K. Larsen (2002). Postdevelopment experiments to detect anthropogenic disturbances: the case of sea ducks and wind parks. Ecological Applications 12:868-877.

Gurney, K. E. B., C. J. Wood, R. T. Alisauskas, M. Wayland, J.-M. A. DeVink, and S. M. Slattery (2014). Identifying carry-over effects of wintering area on reproductive parameters in White-winged Scoters: an isotopic approach. The Condor 116:254-264. 
Haszard, S., and R. G. Clark (2007). Wetland use by White-winged Scoters (Melanitta fusca) in the Mackenzie Delta Region. Wetlands 27:855-863.

Hebblewhite, M., and D. T. Haydon (2010). Distinguishing technology from biology: a critical review of the use of GPS telemetry data in ecology. Philosophical Transactions of the Royal Society B 365:2303-2312.

Heinänen, S., R. Žydelis, M. Dorsch, G. Nehls, and H. Skov (2017). High-resolution sea duck distribution modeling: Relating aerial and ship survey data to food resources, anthropogenic pressures, and topographic variables. Condor 119:175-190.

Horne, J. S., and E. O. Garton (2006). Likelihood cross-validation versus least squares cross-validation for choosing the smoothing parameter in kernel home-range analysis. Journal of Wildlife Management 70:641-648.

Huberty, C. J. (1994). Applied Discriminant Analysis. Wiley-Interscience, New York, NY, USA.

Hüppop, O., J. Dierschke, K.-M. Exo, E. Fredrich, and R. Hill (2006). Bird migration studies and potential collision risk with offshore wind turbines. Ibis 148:90109.

Iverson, S. A., and D. Esler (2006). Site fidelity and the demographic implications of winter movements by a migratory bird, the Harlequin Duck Histrionicus. Journal of Avian Biology 37:219-228.

Johnson, D. H. (1980). The comparison of usage and availability measurements for evaluating resource preference. Ecology 61:65-71. 
Johnson, C. J., S. E. Nielsen, E. H. Merrill, T. L. McDonald, and M. S. Boyce (2006). Resource selection functions based on use-availability data: theoretical motivation and evaluation methods. Journal of Wildlife Management 70:347357.

Kaiser, M. S., M. A. Rahman, M. M. Rahman, and S. A. Sharna (2006). Wind energy assessment for the coastal part of Bangladesh. Journal of Engineering and Applied Sciences 1:87-92.

Kirk, M., D. Esler, and W. S. Boyd (2007). Morphology and density of mussels on natural and aquaculture structure habitats: implications for sea duck predators. Marine Ecology Press Series 346:179-187.

Kirk, M., D. Esler, S. A. Iverson, and W. S. Boyd (2008). Movements of wintering Surf Scoters: predator responses to different prey landscapes. Oecologia 155:859-867.

Korschgen, C., K. Kenow, A. Gendron-Fitzpatrick, W. Green, and F. Dein (1996). Implanting intra-abdominal radiotransmitters with external whip antennas in ducks. Journal of Wildlife Management 60:132-137.

Langston, R. H. W. (2013). Birds and wind projects across the pond: a UK perspective. Wildlife Society Bulletin 37:5-18.

Larsen, J. K., and M. Guillemette (2007). Effects of wind turbines on flight behaviour of wintering Common Eiders: implications for habitat use and collision risk. Journal of Applied Ecology 44:516-522.

Lascelles, B. G., P. R. Taylor, M. G. R. Miller, M. P. Dias, S. Oppel, L. Torres, A. Hedd, M. Le Corre, R. A. Phillips, S. A. Shaffer, H. Weimerskirch, and C. 
Small (2016). Applying global criteria to tracking data to define important areas for marine conservation. Diversity and Distributions 22:422-431.

Lesser, M. P., M. A. Bailey, D. G. Merselis, and J. R. Morrison (2010). Physiological response of the blue mussel Mytilus edulis to differences in food and temperature in the Gulf of Maine. Comparative Biochemistry and Physiology Part A: Molecular \& Integrative Physiology 156:541-551.

Lewis, T. L., D. Esler, and W. S. Boyd (2007). Effects of predation by sea ducks on clam abundance in soft-bottom intertidal habitats. Marine Ecology Press Series 329:131-144.

Lindberg, M. S., and J. Walker (2007). Satellite telemetry in avian research and management: sample size considerations. Journal of Wildlife Management 71:1002-1009.

Loring, P. H. (2012). Phenology and habitat use of scoters along the southern New England continental shelf. MSc. Thesis, University of Rhode Island, Kingston, RI, USA.

Loring, P. H., P. W. C. Paton, S. R. McWilliams, R. A. McKinney, and C. A. Oviatt (2013). Densities of wintering scoters in relation to benthic prey assemblages in a North Atlantic estuary. Waterbirds 36:144-155.

Loring, P. H., P. W. C. Paton, J. E. Osenkowski, S. G. Gilliland, J.-P. L. Savard, and S. R. McWilliams (2014). Habitat use and selection of Black Scoters in southern New England and siting of offshore wind energy facilities. Journal of Wildlife Management 78:645-656. 
Mallory, M. L. (2015). Site fidelity, breeding habitats, and the reproductive strategies of sea ducks. In Ecology and Conservation of North American Sea Ducks (Savard J.-P. L., D. V. Derksen, D. Esler, and J. M. Eadie, Editors). Studies in Avian Biology, CRC Press, New York, NY, USA.

Manly, B. F. J., L. L. McDonald, D. L. Thomas, T. L. McDonald, and W. P. Erickson (2002). Resource selection by animals: statistical design and analysis for field studies. Kluwer Academic Publishers, Dordrecht, Netherlands.

Manwell, J. F., A. L. Rogers, J. G. McGowan, and B. H. Bailey (2002). An offshore wind resource assessment study for New England. Renewable Energy 27:175187.

Masden, E. A., D. T. Haydon, A. D. Fox, R. W. Furness, R. Bullman, and M. Desholm (2009). Barriers to movement: impacts of wind farms on migrating birds. ICES Journal of Marine Science 66:746-753.

Masden, E. A., R. Reeve, M. Desholm, A. D. Fox, R. W. Furness, and D. T. Haydon (2012). Assessing the impact of marine wind farms on birds through movement modelling. Journal of the Royal Society Interface 9:2120-2130.

Mather, D. D., and D. Esler (1999). Evaluation of bursal depth as an indicator of age class of Harlequin Ducks. Journal of Field Ornithology 70:200-205.

Meattey, D., L. Savoy, A. Gilbert, J. Tash, C. Gray, A. Berlin, C. Lepage, S. Gilliland, T. Bowman, J. Osenkowski, and C. Spiegel (2015). Wintering movements and habitat use of Surf Scoter (Melanitta perspicillata) in the mid-Atlantic U.S. In Wildlife densities and habitat use across temporal and spatial scales on the mid-Atlantic outer continental shelf: Final report to the Department of Energy 
EERE Wind \& Water Power Technologies Office. (Williams, K. A., E. E. Connelly, S.M. Johnson, and I. J. Stenhouse, Editors) Award Number: DEEE0005362. Report BRI 2015-11, Biodiversity Research Institute, Portland, ME, USA.

Morris, L. R., K. M. Proffitt, and J. K. Blackburn (2016). Mapping resource selection functions in wildlife studies: concerns and recommendations. Applied Geography 76:173-183.

Mueller, J. L., G. S. Giulietta, C. R. McClain, R.R. Bidigare, C. Trees, W. M. Balch, J. Dore, D. T. Drapeau, D. Karl, L. Van Heukelem, and J. Perl (2003). Ocean optics protocols for satellite ocean color sensor validation, revision 5, volume V: Biogeochemical and bio-optical measurements and data analysis protocols. National Aeronautical and Space Administration, Goddard Space Flight Center, Greenbelt, MD, USA.

Musial, W., and B. Ram (2010). Large-scale offshore wind power in the United States: assessment of opportunities and barriers. U.S. Department of Energy, National Renewable Energy Laboratory Publication NREL/TP-500-40745. Golden, CO, USA.

NOAA National Geophysical Data Center, Medium Resolution Shoreline, Accessed January 2017a, http://shoreline.noaa.gov/data/datasheets/medres.html.

NOAA National Geophysical Data Center, U.S. Coastal Relief Model, Accessed January 2017b, http://ngdc.noaa.gov/mgg/coastal/crm.html. 
O’Connor, M. (2008). Surf Scoter (Melanitta perspicillata) ecology on spring staging grounds and during the flightless period. MSc. Thesis, McGill University, Montreal, Canada.

Oosterhuis, R., and K. van Dijk (2002). Effect of food shortage on the reproductive output of Common Eiders Somateria mollissima breeding at the Griend (Wadden Sea). Atlantic Seabirds 4:29-38.

Oppel, S., A. N. Powell, and D. L. Dickson (2008). Timing and distance of King Eider migration and winter movements. Condor 110:296-305.

Perry, M. C., A. M. Wells-Berlin, D. M. Kidwell, and P. C. Osenton (2007). Temporal changes of populations and trophic relationships of wintering diving ducks in Chesapeake Bay. Waterbirds 30:4-16.

Petersen, M. R., and D. C. Douglas (2004). Winter ecology of Spectacled Eiders: environmental characteristics and population change. Condor 106:79-94.

Petersen, M. R., D. C. Douglas, H. M. Wilson, and S. E. McCloskey (2012). Effects of sea ice on winter site fidelity of Pacific Common Eiders (Somateria mollissima v-nigrum). Auk 29:399-408.

Peterson, I. K., and A. D. Fox (2007). Changes in bird habitat utilization around the Horns Rev 1 offshore wind farm, with particular emphasis on common scoter. National Environmental Research Institute Report, Aarhus, Denmark.

Petersen, I. K., R. D. Nielsen, and M. L. Mackenzie (2014). Post-construction evaluation of bird abundances and distributions in the Horns Rev 2 offshore wind farm area, 2011 and 2012. DCE - Danish Centre for Environment and Energy, Aarhus University, Denmark. 
Petes, L. A., B. A. Menge, and G. D. Murphy (2007). Environmental stress decreases survival, growth and reproduction in New Zealand mussels. Journal of Experimental Marine Biology and Ecology 351:83-91.

Phillips, L. M., A. N. Powell, and E. A. Rexstad (2006). Large-scale movements and habitat characteristics of King Eiders throughout the nonbreeding period. Condor 108:887-900.

Prince, H. H., P. I. Padding, and R. W. Knapton (1992). Waterfowl use of the Laurentian Great Lakes. Journal of Great Lakes Research 18:673-699.

R Core Team (2016). R: A language and environment for statistical computing. $\mathrm{R}$ Foundation for Statistical Computing, Vienna, Austria. ISBN 3-900051-07-0, URL http://www.R-project.org/.

Rhode Island Ocean Special Area Management Plan (RI Ocean SAMP) (2010). Rhode Island Coastal Resources Management Council, Wakefield, RI, USA.

Robertson, G. J., F. Cooke, R. I. Goudie, and W. S. Boyd (2000). Spacing patterns, mating system, and winter philopatry in Harlequin Ducks. Auk 117:299-307.

Robertson, G. J., and F. Cooke (1999). Winter philopatry in migratory waterfowl. Auk 116:20-34.

Rothe, T. C., P. I. Padding, L. C. Naves, and G. J. Robertson (2015). Harvest of sea ducks in North America. In Ecology and Conservation of North American Sea Ducks (Savard J.-P. L., D. V. Derksen, D. Esler, and J. M. Eadie, Editors). Studies in Avian Biology, CRC Press, New York, NY, USA. 
Schamber, J. L., P. L. Flint, and A. N. Powell (2010). Patterns of use and distribution of King Eiders and Black Scoters during the annual cycle in northeastern Bristol Bay, Alaska. Marine Biology 157:2169-2176.

Sea Duck Joint Venture (2015). Atlantic and Great Lakes sea duck migration study: progress report June 2015 [Online]. < seaduckjv.org/wpcontent/uploads/2014/12/AGLSDMS-Progress-Report-June2015_web.pdf>.

Sea Duck Joint Venture Management Board (2014). Sea Duck Joint Venture Strategic Plan 2014-2018. U.S. Fish and Wildlife Service, Anchorage, AK, USA; Canadian Wildlife Service, Sackville, New Brunswick, Canada.

Sexson, M. G., D. M. Mulcahy, M. Spriggs, and G. E. Myers (2014). Factors influencing immediate post-release survival of Spectacled Eiders following surgical implantation of transmitters with percutaneous antennae. Journal of Wildlife Management 78:550-560.

Silverman, E. D., D. T. Saalfeld, J. B. Leirness, and M. D. Koneff (2013). Wintering sea duck distribution along the Atlantic coast of the United States. Journal of Fish and Wildlife Management 4:178-198.

Silverman, E. D., J. B. Leirness, D. T. Saalfeld, M. D. Koneff, and K. D. Richkus (2012). Atlantic coast wintering sea duck survey, 2008-2011. Division of Migratory Bird Management, U.S. Fish and Wildlife Service, Laurel, MD, USA.

Sorte, C. J. B., V. E. Davidson, M. C. Franklin, K. M. Benes, M. M. Doellman, R. J. Etter, R. E. Hannigan, J. Lubchenco, and B. A. Menge (2016). Long-term 
declines in an intertidal foundation species parallel shifts in community composition. Global Change Biology 23:341-352.

Stark, J. K., C. J. Donlon, M. J. Martin, and M. E. McCulloch (2007). OSTIA: An operational, high resolution, real time, global sea surface temperature analysis system., Oceans 07 IEEE Aberdeen, conference proceedings. Marine challenges: coastline to deep sea. Aberdeen, Scotland.

Stott, R. S., and D. P. Olson (1973). Food-habitat relationships of sea ducks on the New Hampshire coastline. Ecology 54:996-1007.

Suryan, R. M., J. A. Santora, and W. J. Sydeman (2012). New approach for using remotely sensed chlorophyll $a$ to identify seabird hotspots. Marine Ecology Press Series 451:213-225.

Thaxter, C. B., N. A. Clark, V. H. Ross-Smith, G. J. Conway, W. Bouten, and N. H. K. Burton (2017). Sample size required to characterize area use of tracked seabirds. Journal of Wildlife Management 81:1098-2017.

Theroux, R. B., and R. L. Wigley (1998). Quantitative composition and distribution of the macrobenthic invertebrate fauna of the Continental Shelf ecosystems of the Northeastern United States. NOAA Technical Report NFMS 140, Seattle, WA, USA.

USFWS (2011). Action plan for White-winged Scoter. U.S. Fish and Wildlife Service, Anchorage, Alaska. Unpublished Report. 43 pp. + appendices.

Vallejo, G. C., K. Grellier, E. J. Nelson, R. M. McGregor, S. J. Canning, F. M. Caryl, and N. McLean (2017). Responses of two marine top predators to an offshore wind farm. Ecology and Evolution 7:8698-8708. 
Veit, R., R., T. P. White, S.A. Perkins, and S. Curley (2016). Abundance and distribution of seabirds off southeastern Massachusetts, 2011-2015. U.S. Department of the Interior, OCS Study BOEM 2016-067, Sterling, VA, USA.

Waldeck, P., and K. Larsson (2013). Effects of winter water temperature on mass loss in Baltic blue mussels: implications for foraging sea ducks. Journal of Experimental Marine Biology and Ecology 444:24-30.

Wentworth, C. K. (1922). A scale of grade and class terms for clastic sediments. Journal of Geology 30:377-392.

White, T. P., R. R. Veit, and M. C. Perry (2009). Feeding ecology of Long-tailed Ducks Clangula hyemalis wintering on the Nantucket Shoals. Waterbirds 32:293-299.

White, C. R., P. Cassey, N. G. Schimpf, L. G. Halsey, J. A. Green, and S. J. Portugal (2013). Implantation reduces the negative effects of bio-logging devices on birds. Journal of Experimental Biology 216:537-542.

Winiarski, K. J., D. L. Miller, P. W. C. Paton, and S. R. McWilliams (2014). A spatial conservation prioritization approach for protecting marine birds given proposed offshore wind energy development. Biological Conservation 169:7988.

Zipkin, E. F., B. Gardner, A. T. Gilbert, A. F. O’Connell, J. A. Royle, and E. D. Silverman (2010). Distribution patterns of wintering sea ducks in relation to the North Atlantic Oscillation and local environmental characteristics. Oecologia 163:893-902. 
Table 1-1. Location class and frequency of randomly selected locations $(n=40$ per bird) used to generate individual and composite $95 \%$ utilization distributions and $50 \%$ core-use areas for 40 White-winged Scoters wintering in the southern New England study area.

\begin{tabular}{lcc}
\hline $\begin{array}{l}\text { Location } \\
\text { class }^{\text {a }}\end{array}$ & Frequency & Percent \\
\hline LC 3 & 738 & 45 \\
LC 2 & 482 & 30 \\
LC 1 & 201 & 12 \\
LC 0 & 64 & 4 \\
LC A & 95 & 6 \\
LC B & 55 & 3 \\
\hline
\end{tabular}

${ }^{a}$ Locations classified by accuracy intervals (m): LC $3(<250)$, LC 2 (250 to $\left.<500\right)$, LC 1 (500 to $<1,500)$, LC 0 ( $>1,500$; Douglas et al. 2012; Collecte Localisation Satellites 2017). Accuracy estimates are not assigned for location classes LC A or LC B. 
Table 1-2. Fall arrival, spring departure, and total winter length of stay (LOS) within the southern New England study area for Whitewinged Scoters $(n=36)$ captured in 2015 and 2016.

\begin{tabular}{cccccc}
\hline Winter & Capture location & $\boldsymbol{N}$ & Fall arrival & Spring departure & LOS (days) \\
\hline $2015-2016$ & Cape Cod Bay & 12 & --- & 20 May (22 April - 27 May) & $198( \pm 3)$ \\
$2016-2017$ & $\begin{array}{c}\text { Cape Cod Bay } \\
\text { Long Island Sound }\end{array}$ & 7 & 14 November (17 October - 12 January) & 19 May (8 May - 27 May) & $179( \pm 16)$ \\
& St. Lawrence River & 13 & 31 October (13 October - 12 November) & 17 May (12 May - 13 May) & --- \\
\end{tabular}


Table 1-3. Mean $(\vec{x})$, standard error (SE), and range of values for habitat variables sampled within composite $95 \%$ utilization distributions (available) and 50\% core-use areas (used) of White-winged Scoters $(n=40)$ wintering in the southern New England study area.

\begin{tabular}{lllll}
\hline \multicolumn{1}{c}{ Habitat covariate } & $\begin{array}{l}\text { Used } \\
\bar{x} \pm \text { SE }\end{array}$ & Range & $\begin{array}{l}\text { Available } \\
\bar{x} \pm \text { SE }\end{array}$ & Range \\
\hline Distance from shore $(\mathrm{km})$ & $17.3 \pm 1.1$ & $0.3-63.4$ & $19.5 \pm 0.5$ & $0.0-72.4$ \\
Water depth $(\mathrm{m})$ & $24.0 \pm 0.6$ & $3.0-47.0$ & $25.7 \pm 0.3$ & $0.0-87.0$ \\
Bottom slope (degrees) & $0.3 \pm 0.1$ & $0.0-3.3$ & $0.2 \pm 0.1$ & $0.0-2.5$ \\
Hard bottom probability $(0-1)$ & $0.04 \pm 0.01$ & $0.0-0.8$ & $0.02 \pm 0.01$ & $0.0-0.8$ \\
Sediment grain size $(\mathrm{mm})$ & $0.3 \pm 0.1$ & $0.02-0.5$ & $0.3 \pm 0.0$ & $0.02-0.5$ \\
Sea surface temperature $\left({ }^{\circ} \mathrm{C}\right)$ & $8.6 \pm 0.1$ & $7.8-11.4$ & $8.7 \pm 0.1$ & $7.6-13.3$ \\
Sea surface salinity $(\mathrm{psu})$ & $32.7 \pm 0.1$ & $31.9-32.9$ & $32.7 \pm 0.1$ & $31.5-32.9$ \\
Chlorophyll- $a\left(\mathrm{mg} / \mathrm{m}^{3}\right)$ & $5.3 \pm 0.1$ & $2.3-8.3$ & $5.1 \pm 0.04$ & $2.3-21.6$ \\
\hline
\end{tabular}


Table 1-4. Model parameters $(K)$, Akaike Information Criterion differences $\left(\Delta \mathrm{AIC}_{c}\right)$, maximized $\log$-likelihood $[\log (\mathrm{L})]$, and Akaike weights $\left(w_{\mathrm{i}}\right)$ for logistic regression models of winter habitat use versus availability used to estimate coefficients for exponential resource selection functions. Model parameters include distance from shore (DIST), water depth (WD), bottom slope (SL), hard bottom probability (HB), sediment grain size (SED), sea surface temperature (SST), sea surface salinity (SAL), and chlorophyll- $a$ concentrations (CHL).

\begin{tabular}{llrll}
\hline Model parameters & $\boldsymbol{K}$ & $\Delta \mathbf{A I C}_{\boldsymbol{c}}$ & $\boldsymbol{\operatorname { l o g } ( \mathbf { L } )}$ & $\boldsymbol{w}_{\mathbf{i}}$ \\
\hline CHL, HB, SAL, SST & 5 & $0.0^{\mathrm{a}}$ & -731.2 & 0.49 \\
CHL, HB, SAL, SL, SST & 6 & 1.0 & -730.7 & 0.29 \\
CHL, HB, SAL, SED, SL, SST & 7 & 2.5 & -730.5 & 0.14 \\
CHL, HB, SAL, SED, SL, SST, WD & 8 & 4.4 & -730.4 & 0.06 \\
CHL, DIST, HB, SAL, SED, SL, SST, WD & 9 & 6.4 & -730.4 & 0.02 \\
HB & 2 & 9.7 & -739.1 & 0.00 \\
SAL & 2 & 14.4 & -741.5 & 0.00 \\
WD & 2 & 17.9 & -743.2 & 0.00 \\
CHL & 2 & 18.3 & -743.4 & 0.00 \\
SST & 2 & 18.9 & -743.7 & 0.00 \\
DIST & 2 & 18.9 & -743.7 & 0.00 \\
SL & 2 & 19.0 & -743.8 & 0.00 \\
Intercept only & 1 & 20.2 & -745.4 & 0.00 \\
SED & 2 & 22.2 & -745.4 & 0.00 \\
\hline
\end{tabular}

${ }^{\mathrm{a}}$ Lowest $\mathrm{AIC}_{c}$ value: 1472.5 
Table 1-5. Coefficients ( $\beta$ ) and upper and lower $95 \%$ confidence intervals of environmental parameters from the best-fit resource selection function model for White-winged Scoters $(n=40)$ wintering within the southern New England study area.

\begin{tabular}{lrrr}
\hline Variable & \multicolumn{1}{c}{$\boldsymbol{\beta}$} & Lower 95\% CL & Upper 95\% CL \\
\hline Sea surface salinity $(\mathrm{psu})$ & -0.8384 & -1.573 & -0.079 \\
Hard bottom probability $(0-1)$ & 2.6098 & 1.210 & 4.004 \\
Sea surface temperature $\left({ }^{\circ} \mathrm{C}\right)$ & -0.2519 & -0.475 & -0.043 \\
Chlorophyll- $a\left(\mathrm{mg} / \mathrm{m}^{3}\right)$ & 0.0867 & 0.002 & 0.171 \\
\hline
\end{tabular}


Figure 1-1. Study area (dashed line) and capture locations (solid symbols) of Whitewinged Scoters $(n=40)$ implanted with satellite transmitters in southern New England and Quebec during 2015 and 2016.

Figure 1-2. Composite kernel-based winter 95\% utilization distributions and 50\% core-use areas of White-winged Scoters ( $n=40 ; 31$ females, 9 males) implanted with satellite transmitters between 2010 and 2016 in relation to current and proposed offshore wind energy areas.

Figure 1-3. Quartile-based relative probability of use $(<25 \%$ to $>75 \%)$ predicted for White-winged Scoters across the southern New England study area by the top-ranked resource selection function model in relation to current and proposed offshore wind energy areas.

Figure 1-4. Second-winter (2016-2017) locations of five female White-winged Scoters in relation to composite ( $n=30$ individuals) kernel-based first-winter (2015-2016) $95 \%$ utilization distributions and $50 \%$ core-use areas. 
Figure 1-1.

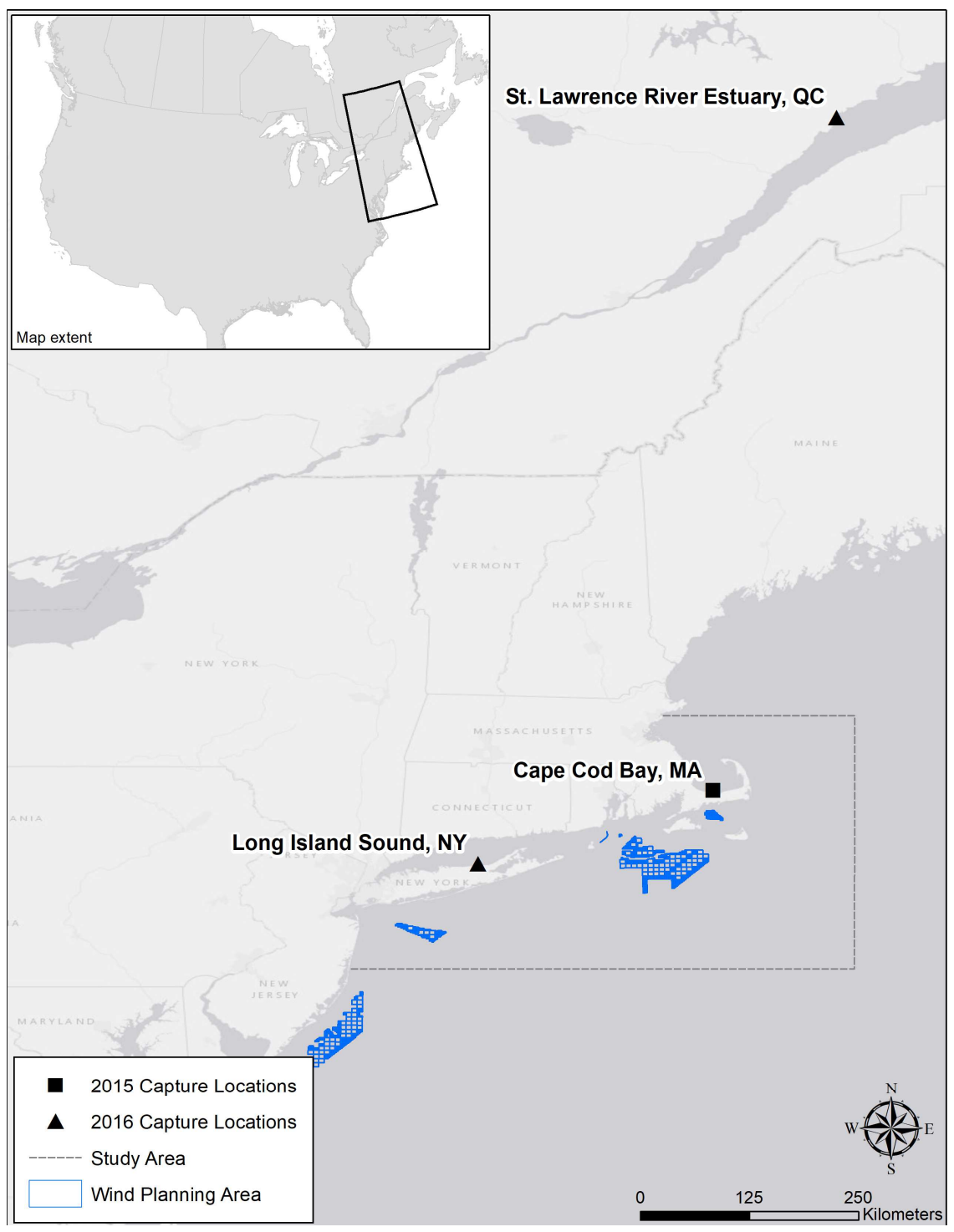




\section{Figure 1-2.}

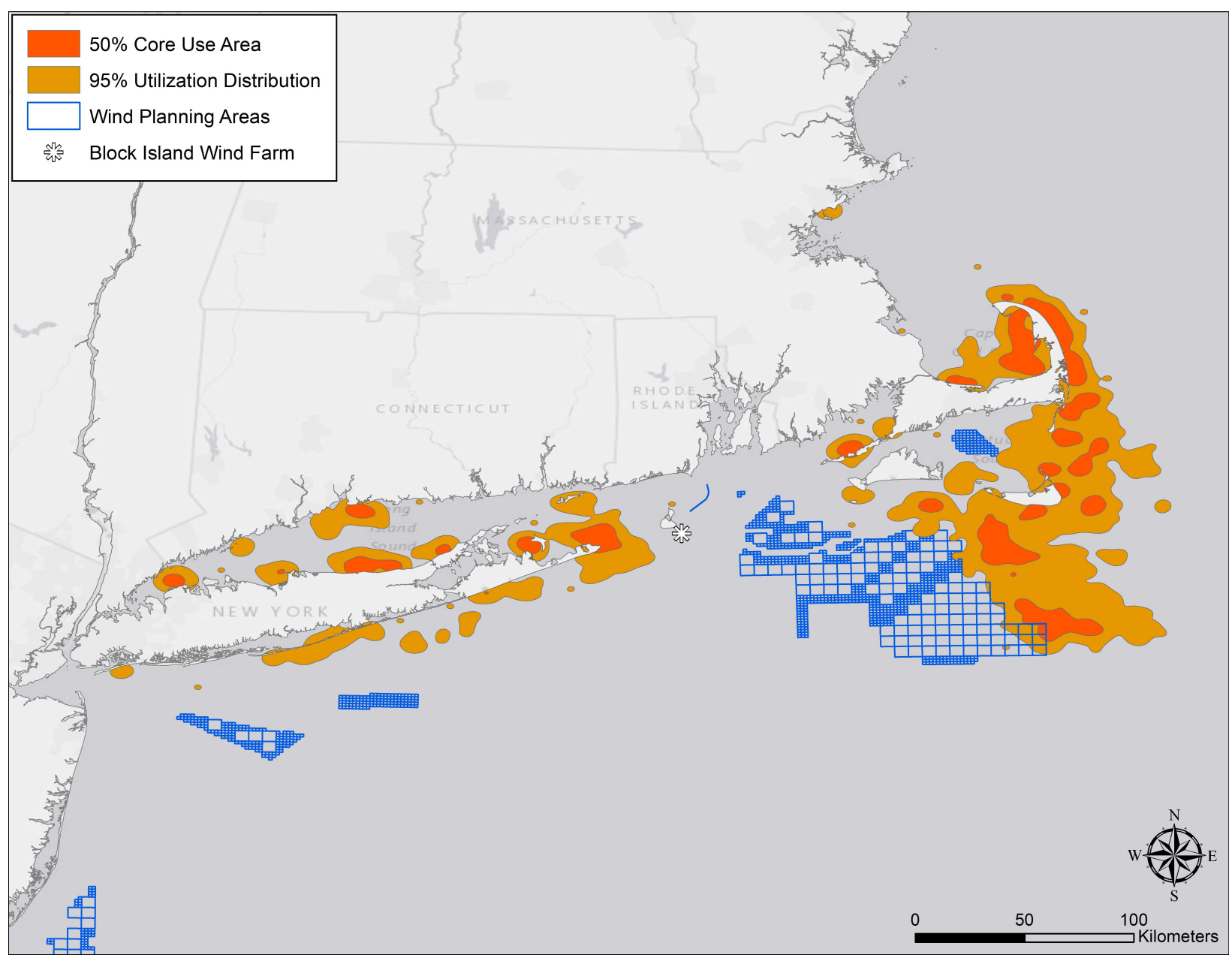




\section{Figure 1-3.}

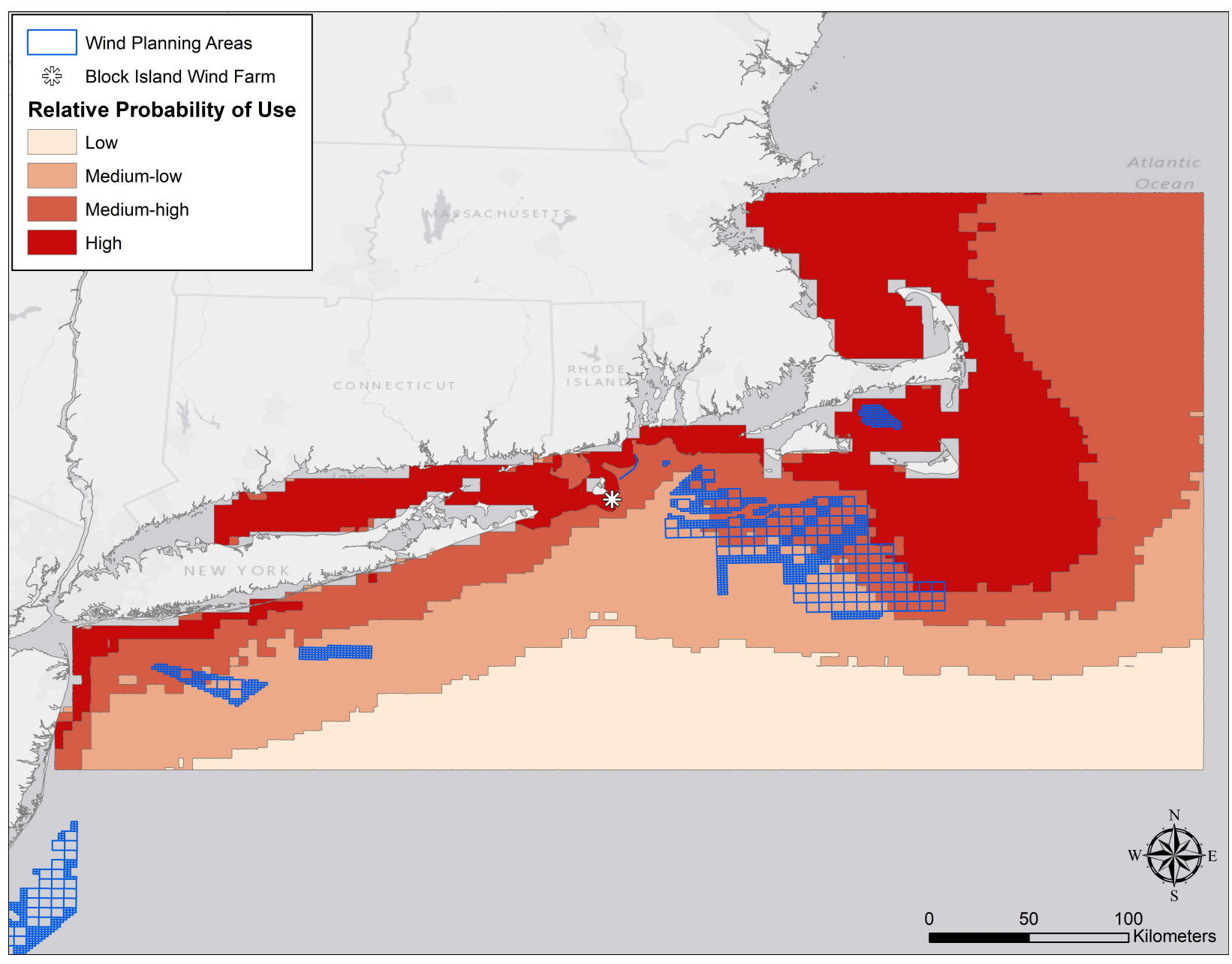




\section{Figure 1-4.}

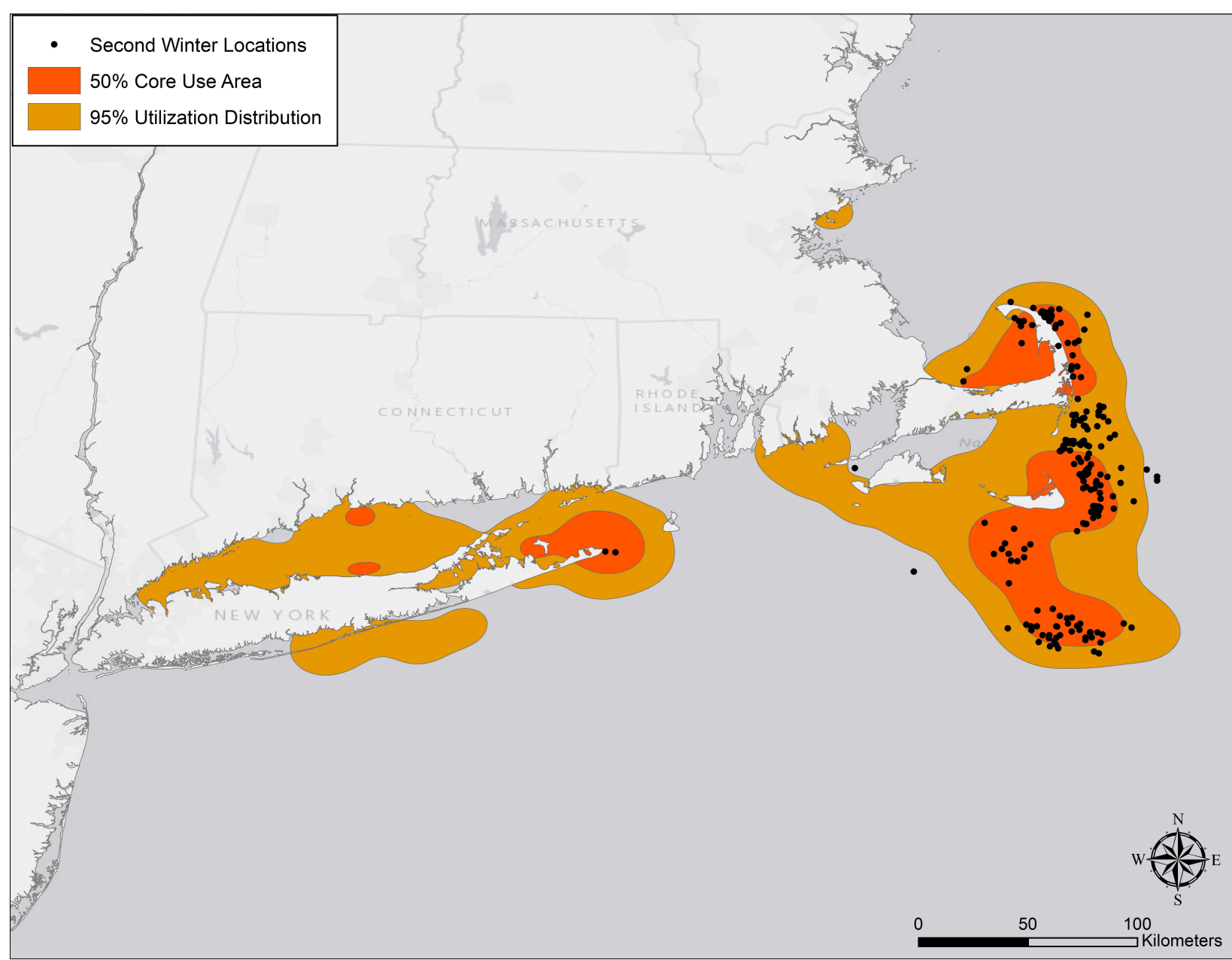




\section{APPENDIX I}

Figure A-1-1. Water depth (m) raster used in logistic regression models for determining winter resource selection of White-winged Scoters in southern New England. Data were derived from the NOAA National Geophysical Data Center Coastal Relief Model (3 arc-second) for the United States.

Figure A-1-2. Distance from shore $(\mathrm{km})$ raster used in logistic regression models for determining winter resource selection of White-winged Scoters in southern New England. Data were derived by calculating the Euclidean distance from each pixel to the nearest segment of the NOAA Medium Resolution Digital Vector Shoreline $(1: 70,000)$.

Figure A-1-3. Probability of hard bottom occurrence (0-1) data set used in logistic regression models for determining winter resource selection of White-winged Scoters in southern New England. Data were derived from a kernel-based probabilistic model using rock and boulder points extracted from NOAA Electronic Navigational Charts. Figure A-1-4. Bottom sediment grain size $(\mathrm{mm})$ data set used in logistic regression models for determining winter resource selection of White-winged Scoters in southern New England. Data were obtained from the Nature Conservancy's Northwest Atlantic Marine Ecoregional Assessment data portal.

Figure A-1-5. Bottom slope (degrees) data set used in logistic regression models for determining winter resource selection of White-winged Scoters in southern New England. Data were derived from the NOAA National Geophysical Data Center Coastal Relief Model (3 arc-second) for the United States. 
Figure A-1-6. Sea surface temperature $\left({ }^{\circ} \mathrm{C}\right.$; six-year mean) raster data set used in logistic regression models for determining winter resource selection of White-winged Scoters in southern New England. Data were derived from interpolated data from high resolution satellite imagery and floating buoys.

Figure A-1-7. Sea surface salinity (practical salinity units [psu]; six-year mean) raster data set used in logistic regression models for determining winter resource selection of White-winged Scoters in southern New England. Data were derived from the Hybrid Coordinate Ocean Model (HYCOM) by the National Ocean Partnership Program. Figure A-1-8. Chlorophyll- $a\left(\mathrm{mg} / \mathrm{m}^{3}\right.$; six-year mean) raster data set used in logistic regression models for determining winter resource selection of White-winged Scoters in southern New England. Data were derived from monthly estimates produced by the NASA Goddard Space Flight Center's Ocean Data Processing System. 
Figure A-1-1.

๙

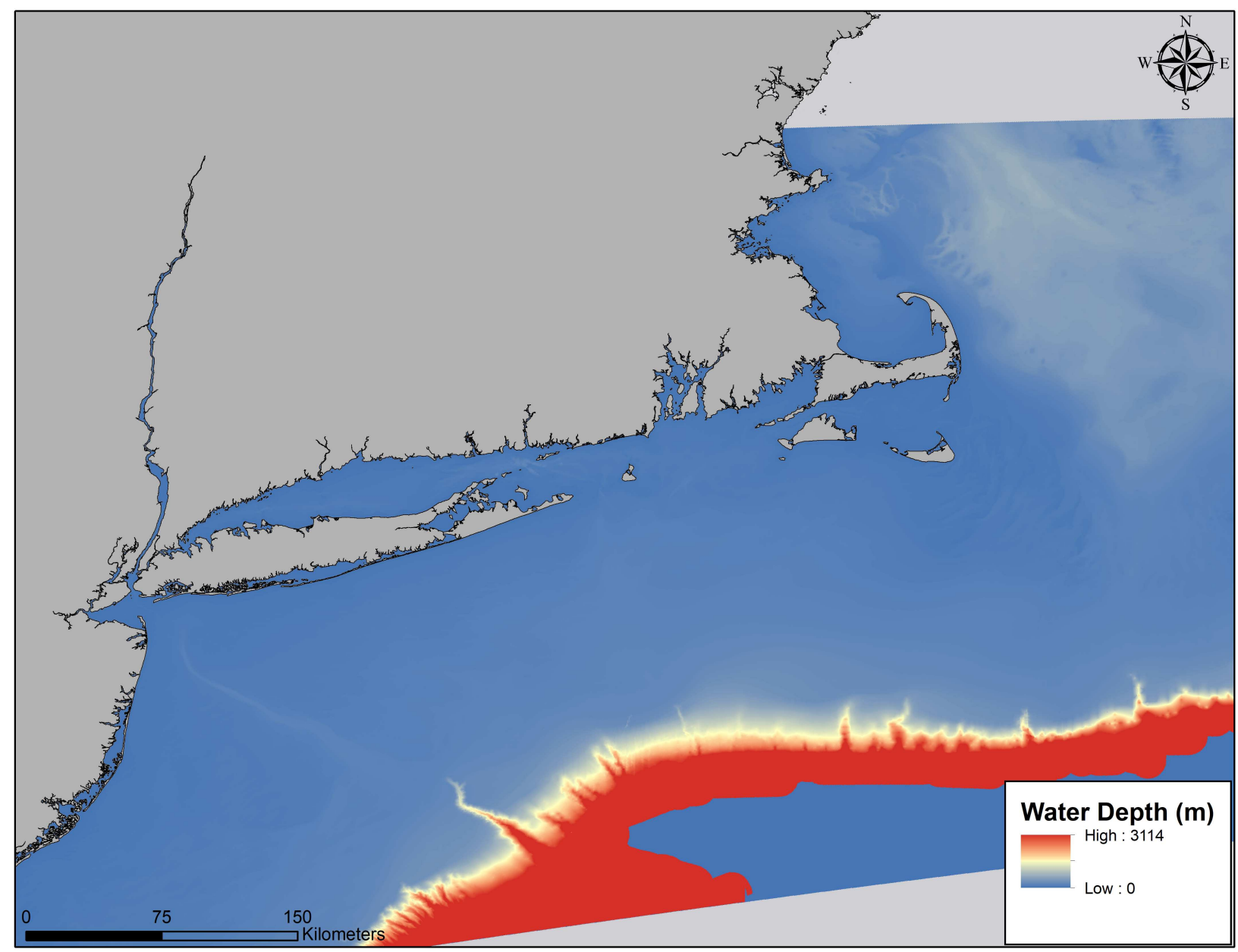


Figure A-1-2.

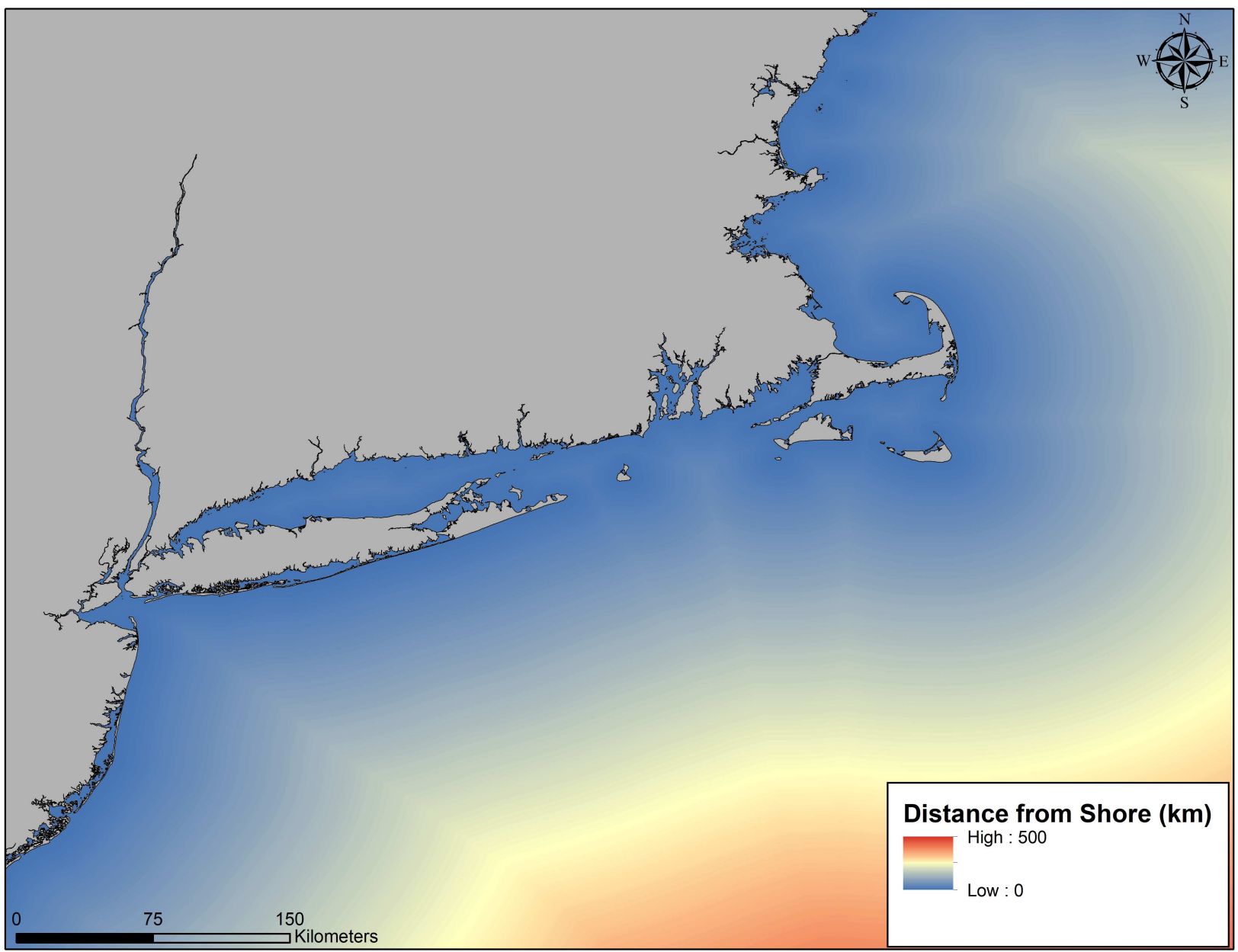


Figure A-1-3.

जे

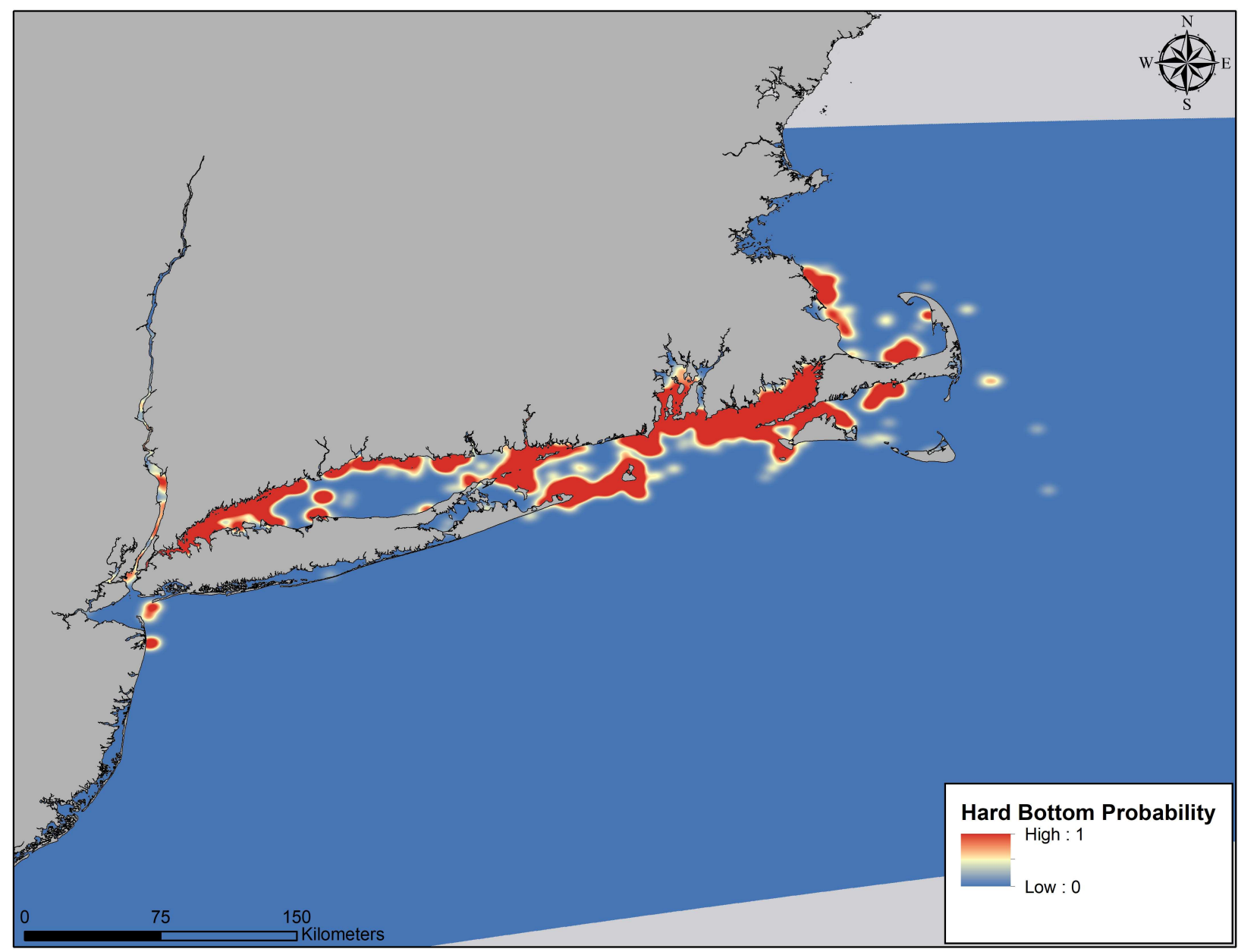


Figure A-1-4.

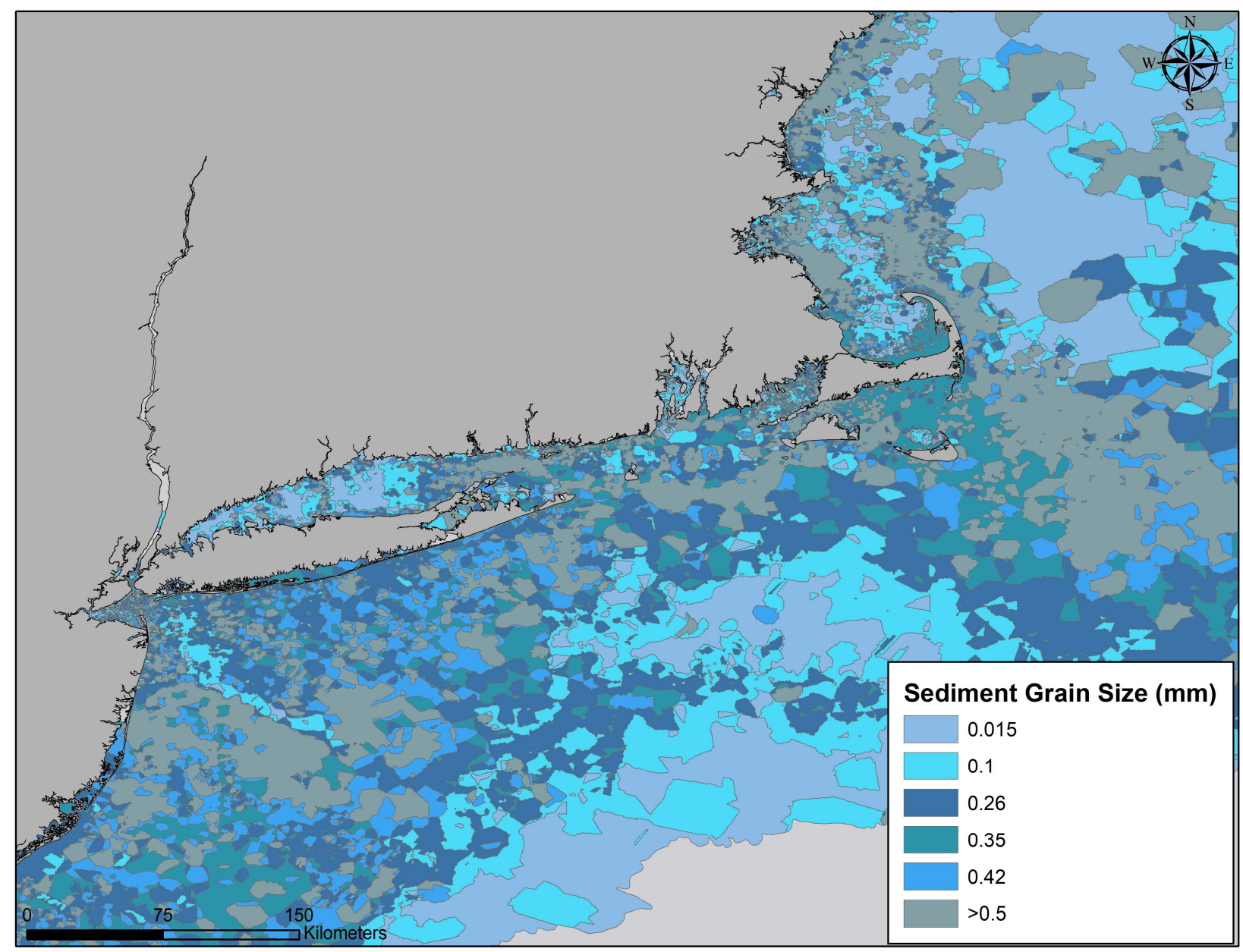


Figure A-1-5.

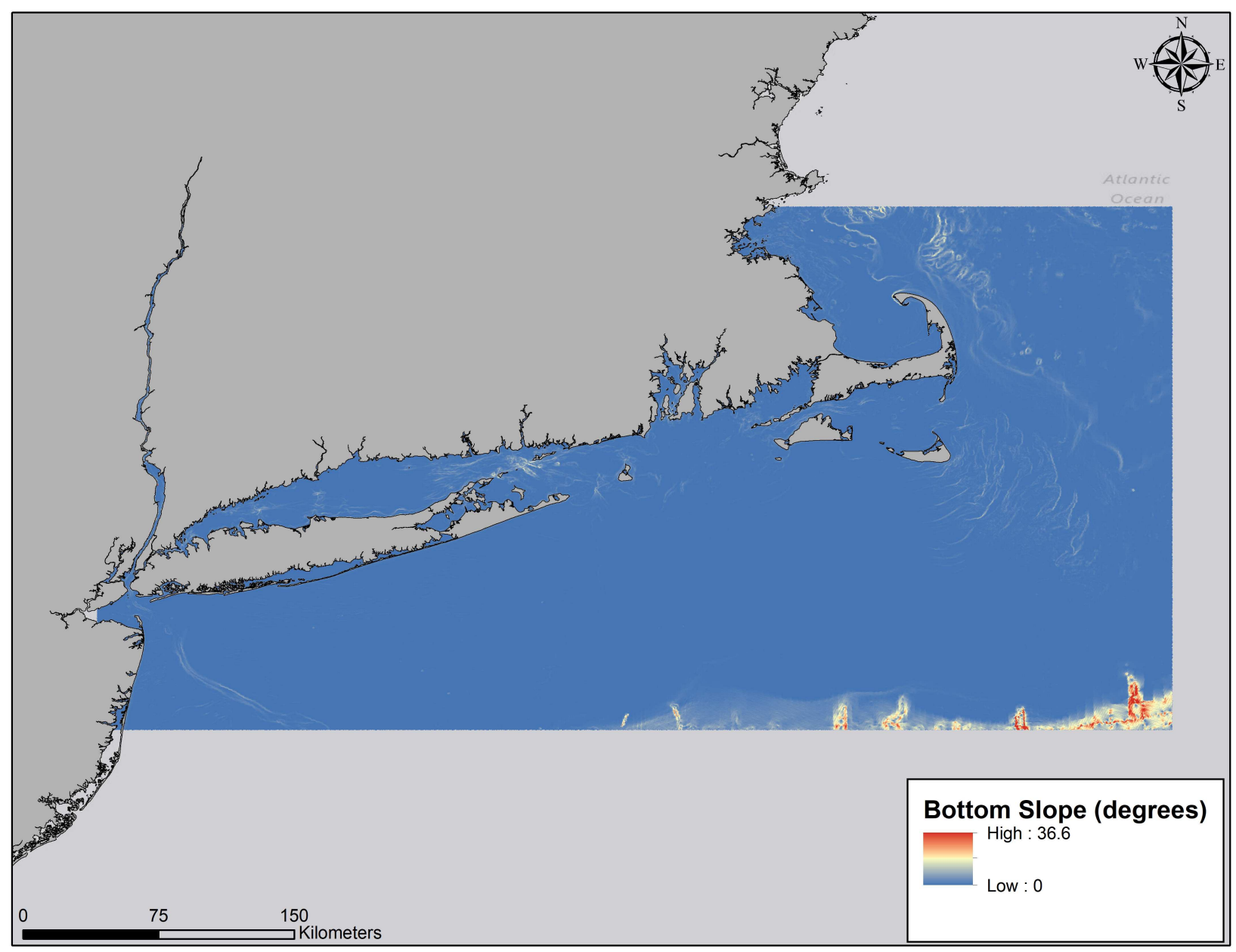


Figure A-1-6.

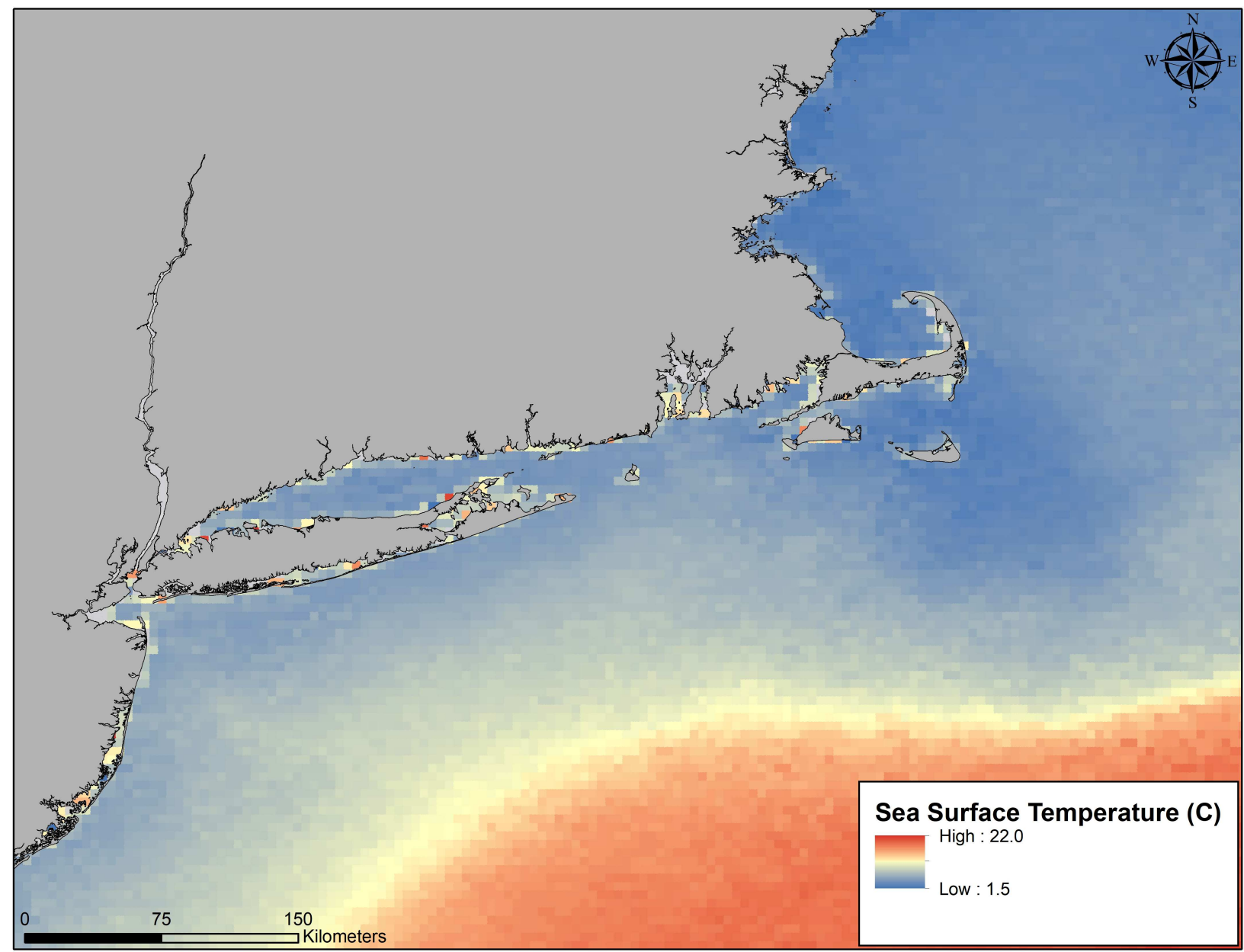


Figure A-1-7.

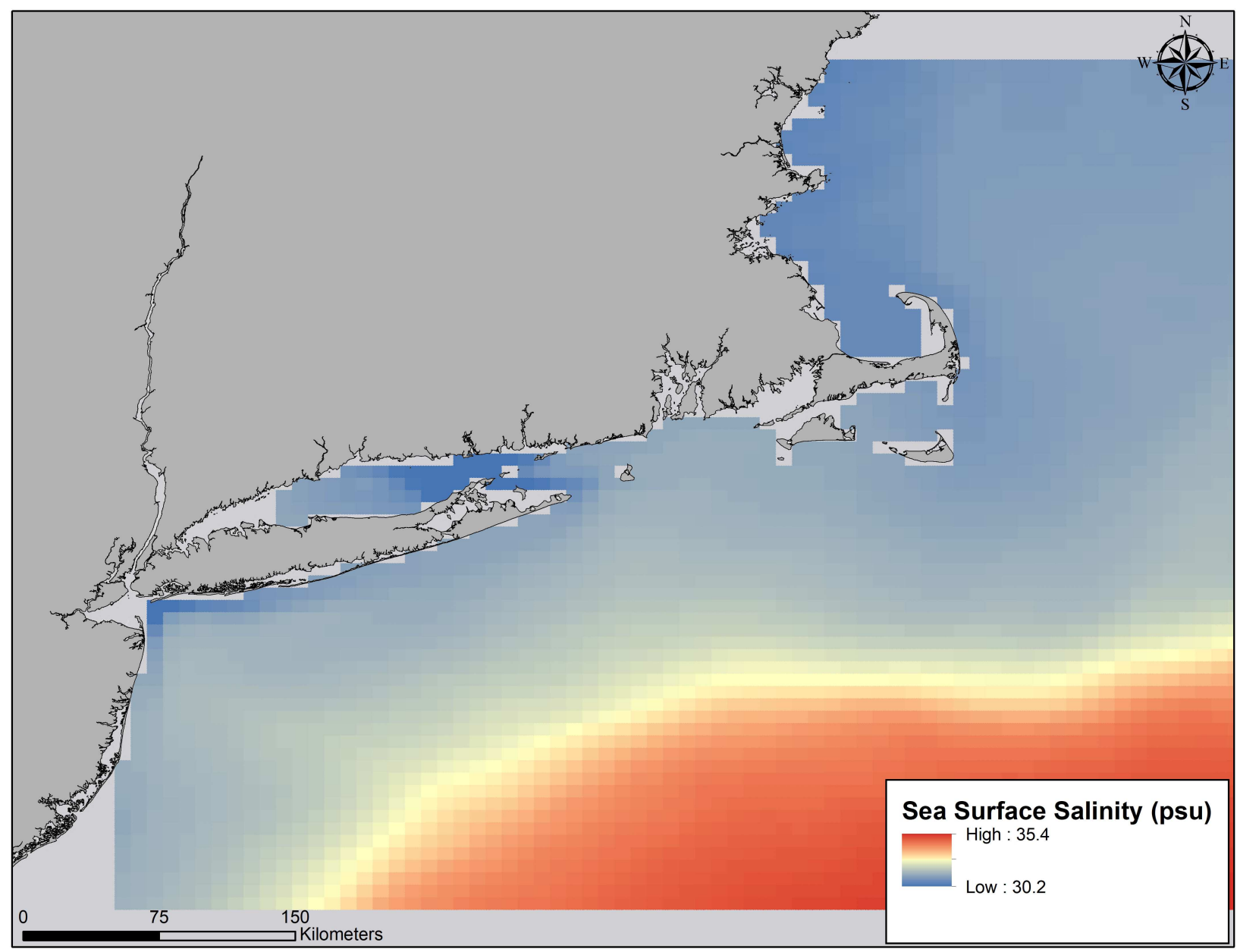


Figure A-1-8.

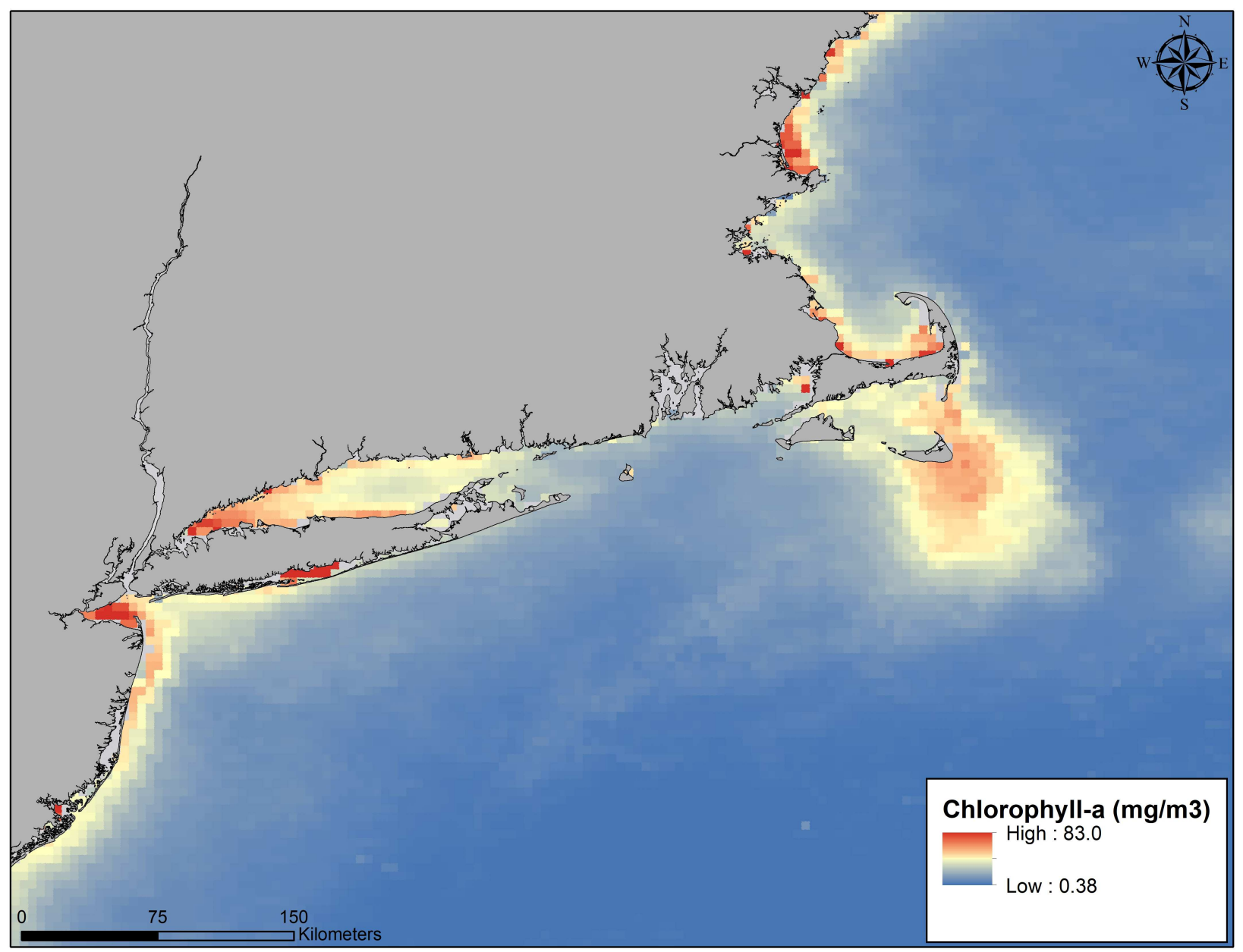




$$
\begin{gathered}
\text { MANUSCRIPT - } 2 \\
\text { Formatted for submission to the Canadian Journal of Zoology }
\end{gathered}
$$

\section{Annual cycle of White-winged Scoters (Melanitta fusca) in eastern North}

America: migration phenology, population delineation, and connectivity

D.E. Meattey, S.R. McWilliams, P.W.C. Paton, C. Lepage, S.G. Gilliland, L. Savoy, G.H. Olsen, and J.E. Osenkowski

D.E. Meattey. Department of Natural Resources Science, University of Rhode Island, 1 Greenhouse Road, Kingston, RI, USA. dustin_meattey@uri.edu

S.R. McWilliams. Department of Natural Resources Science, University of Rhode Island, 1 Greenhouse Road, Kingston, RI, USA. srmcwilliams@uri.edu

P.W.C. Paton. Department of Natural Resources Science, University of Rhode Island, 1 Greenhouse Road, Kingston, RI, USA.ppaton@uri.edu

C. Lepage. Canadian Wildlife Service, Environment and Climate Change Canada, Quebec, QC, Canada. christine.lepage@canada.ca

S.G. Gilliland. Canadian Wildlife Service, Environment and Climate Change Canada, Sackville, NB, Canada. scott.gilliland@canada.ca

L. Savoy. Biodiversity Research Institute, 276 Canco Road, Portland, ME, USA. lucas.savoy@,briloon.org

G.H. Olsen. USGS Patuxent Wildlife Research Center, Laurel, MD, USA. golsen@usgs.gov

J.E. Osenkowski. Rhode Island Department of Environmental Management, West Kingston, RI, USA. jay.osenkowski@dem.ri.gov 
Corresponding author: D.E. Meattey (dustin_meattey@uri.edu), University of

Rhode Island, 1 Greenhouse Road, Kingston, RI, USA, Phone: (207) 650-8903 


\section{ABSTRACT}

Understanding full annual cycle movements of long-distance migrants is essential for delineating populations, assessing connectivity, evaluating crossover effects between life stages, and informing management strategies for vulnerable or declining species. We used implanted satellite transmitters to track up to two years of annual cycle movements of 52 adult female White-winged Scoters (Melanitta fusca (L., 1758)) captured in the eastern United States and Canada. We used these data to document annual cycle phenology, delineate migration routes, identify primary areas used during winter, stopover, breeding, and molt, and to assess the strength of migratory connectivity and spatial population structure. Most scoters wintered along the Atlantic coast from Nova Scotia to southern New England, with some on Lake Ontario. Scoters followed four migration routes to breeding areas from Quebec to the Northwest Territories. Principal post-breeding molting areas were in James Bay and the St. Lawrence River estuary. Migration phenology was synchronous regardless of winter or breeding origin. Cluster analyses delineated two primary breeding areas, one molting, and one wintering area. Scoters demonstrated overall weak to moderate connectivity among life stages, with molting to wintering connectivity the strongest. Thus, White-winged Scoters that winter in eastern North America appear to constitute a single continuous population.

Key words: White-winged Scoter, Melanitta fusca, population delineation, migratory connectivity, annual cycle, satellite telemetry, phenology, migration 


\section{INTRODUCTION}

Monitoring movement patterns of long-distance migratory animals over space and time provides insights into key aspects of their ecology (Trierweiler et al. 2014; Hallworth et al. 2015; Stanley et al. 2015). For example, estimating the inter-annual movements of female waterbirds reveals the extent of immigration and emigration from designated breeding areas (Madsen et al. 2014). Coordinated movements of individuals as they migrate between the same breeding and non-breeding areas suggests strong migratory connectivity (Webster et al. 2002; Moore and Krementz 2017). Quantifying the spatial connectivity of a long-distance migrant throughout their annual cycle can identify key breeding, stopover, molting, and wintering areas (Mehl et al. 2005; Bustnes et al. 2010; Barbaree et al. 2016) as well as delineate population structure. Strong connectivity is often the product of geographically or demographically separate subpopulations (Heath et al. 2006; Fraser et al. 2013). The strength of connectivity (i.e., the extent to which individuals from discrete breeding or non-breeding areas remain in sympatry after migration) can also have critical implications for conservation strategies that consider the full annual cycle of a species.

Understanding migratory connectivity is especially vital for species of conservation concern, as environmental events and stressors during the non-breeding season are well documented to affect population dynamics and productivity during the breeding season (Oosterhuis and van Dijk 2002; Gurney et al. 2014; Sedinger and Alisauskas 2014). Effective conservation and management relies on the identification of distinct population units from which accurate population size estimates and vital rates can be determined (Menu et al. 2002; Swoboda 2007). Similarly, the 
identification of discrete migratory flyways allows for more effective designation of management regions which may warrant varied harvest regulations (Krapu et al. 2011). A classic example of the importance of population delineation in waterfowl is "migratory" and "resident" populations of Canada Geese (Branta canadensis (L., 1758)) in the Atlantic Flyway of the United States (Heusmann 1999; Sheaffer et al. 2007). Differential survival and harvest pressure led to steep declines in some migratory populations, while sedentary residents exploded to nuisance levels (Heusmann 1999), leading biologists and managers to develop targeted hunting seasons to reduce harvest of the migratory population.

Population structure in waterfowl species is typically female-mediated, as females from most species demonstrate strong natal and breeding site philopatry (Eadie and Savard 2015; Mallory 2015), whereas males are more likely to disperse depending on their paired status (Anderson et al. 1992). Most studies of waterfowl populations have focused on breeding areas when defining demographic or genetic structure within a population. However, Robertson and Cooke (1999) suggested that other annual cycle stages such as the wintering period are also important to consider. For example, pair formation in many species of waterfowl likely takes place on the wintering grounds (Robertson et al. 1998; Smith et al. 2000), so the proportion of males and females that exhibit site fidelity to certain wintering areas may be more important in determining population structure. Waterfowl are also unique among most migratory birds in that there is a post-breeding flightless remigial molt period in the annual cycle. Some individuals migrate thousands of kilometers to specific coastal or freshwater habitats to undergo a flightless molt for about 34-49 days (Savard et al. 2007; Dickson et al. 
2012). These molt migrations add another level of complexity to the standard concept of migratory connectivity that typically only considers breeding and wintering areas as key life stages where individuals from discrete areas or subpopulations may mix or remain isolated.

For several species of North American sea ducks, long-term population declines have increased conservation concern and highlighted the need for focused understanding of annual cycle dynamics (Alisauskas et al. 2004; Žydelis et al. 2006; De La Cruz et al. 2014; Bowman et al. 2015). The causes of these declines remain uncertain in part because sea ducks range across the arctic during summer and inhabit often remote, offshore marine environments during the nonbreeding period. As such, delineating the populations of North American sea ducks is a high priority of the Sea Duck Joint Venture (Sea Duck Joint Venture Management Board 2014), and understanding the migratory connectivity between breeding, molting, and wintering areas for these populations is crucial for species management and conservation (Mallory et al. 2006; Robert et al. 2008; De La Cruz et al. 2009). However, there remains a lack of detailed information about the population structure, migration strategies, and annual cycle movements of priority sea duck species including the White-winged Scoter (Melanitta fusca (L., 1758)).

White-winged Scoters are a long-lived sea duck species that has apparently experienced a long-term decline throughout the last half-century (Alisauskas et al. 2004). White-winged Scoters primarily winter along both the Atlantic and Pacific coasts of North America, with increasing populations overwintering on the Great Lakes, and breed throughout the interior boreal forest from Alaska to central Canada 
(Brown and Fredrickson 1997). White-winged Scoters are generally regarded as allopatric eastern and western populations, but studies have suggested some degree of sympatry during the breeding period (Swoboda 2007; Gurney et al. 2014). As in many sea duck species, breeding females show a high degree of natal and breeding area philopatry (Brown and Brown 1981; Traylor et al. 2004; Eadie and Savard 2015; Mallory 2015). Lepage et al. (unpublished data) documented individual male Whitewinged Scoters migrating to different breeding areas in consecutive years, which suggests that males may follow a different female each year. Several recent studies have focused on the western population of White-winged Scoters wintering along the Pacific Coast (Safine and Lindberg 2008; Dickson et al. 2012; Gurney et al. 2014; Uher-Koch et al. 2014), whereas much less is known about the movement ecology of the eastern population of White-winged Scoters that winter along the Atlantic coast.

We deployed satellite transmitters in adult female White-winged Scoters from capture locations along the Atlantic Coast including a molting site and two wintering sites. Our primary objective was to identify the linkages between important breeding and non-breeding areas to determine population delineation and assess migratory connectivity of White-winged Scoters wintering along the Atlantic coast of North America. This information will be useful for informing management and conservation efforts by highlighting important geographic areas and phenology, as well as providing a better understanding of the connectivity between key areas utilized throughout the annual cycle where birds may face varying degrees of environmental and anthropogenic stressors.

\section{MATERIALS AND METHODS}




\section{Capture and marking}

We used floating mist net arrays (Brodeur et al. 2008) to capture White-winged Scoters (hereafter, scoters) in Cape Cod Bay, MA $\left(41.7^{\circ} \mathrm{N}, 70.3^{\circ} \mathrm{W}\right)$ and Long Island Sound, NY (40.9 $\left.{ }^{\circ} \mathrm{N}, 72.8^{\circ} \mathrm{W}\right)$ from October to November 2015 and March 2016 (Fig. 1). We used 2-4 sets of mist nets (36 m long, 100 or $127 \mathrm{~mm}$ mesh) in nearshore $(<1$ $\mathrm{km}$ ) areas previously identified as consistent feeding locations. We monitored nets with teams of 2-4 biologists in outboard boats from predawn to 3-6 hours after sunrise. We also captured scoters using a submerged gill net, adapted from Breault and Cheng (1990) in August 2016 at a known molting location in the St. Lawrence River estuary, Quebec, Canada $\left(48.7^{\circ} \mathrm{N}, 69.1^{\circ} \mathrm{W}\right.$; Fig. 1). Upon removal from the mist nets or gill nets, we determined the age and sex of all captured scoters based on cloacal protuberance (hatch-year birds), plumage characteristics (Carney 1992) and bursal depth (Mather and Esler 1999). We also weighed each bird with a Pesola spring scale ( \pm 5 g; Pesola AG, Chaltenbodenstrasse 4A, 8834 Schindellegi, Switzerland), and uniquely banded each with a United States Geological Survey size 7 aluminum or incoloy butt-end leg band.

We selected 52 female scoters that were aged either second-year (SY) or aftersecond-year (ASY) to receive implanted satellite transmitters (Cape Cod Bay $n=22$; Long Island Sound $n=4$; Quebec $n=26$ ). Females of many sea duck species including White-winged Scoters exhibit a high degree of natal and breeding philopatry (Eadie and Savard 2015) and would thus be more likely to provide consistent breeding location data to achieve our objectives. We chose to implant only adult female scoters 
with satellite transmitters because survival and likelihood of breeding is higher in adults compared to hatch-year birds (Brown and Brown 1981).

Veterinarians implanted scoters with a 35-38-g coelomic-implant Platform Terminal Transmitter (PTT) with an external antenna manufactured by either Microwave Telemetry Inc. (Microwave Telemetry, Inc., Columbia, Maryland, USA; $n$ =31) or by Telonics, Inc. (Model IMPTAV-2635; Telonics, Inc., Mesa, Arizona, USA; $n=21$ ). Veterinarians with prior sea duck surgery experience used sterile surgical procedures and techniques described by Korschgen et al. (1996) and Iverson et al. (2006) for all implants. Prior to implantation, the veterinarians wrapped all PTTs in nylon mesh and added a felt cuff at the antenna base to provide additional anchor points to stabilize the PTT within the body cavity and provide additional surface area for adhesion to the body wall (Iverson et al. 2006), and skin (felt cuff) at antenna exit site. After applying these external anchoring materials, we sterilized transmitters with ethylene oxide and allowed them to de-gas before implanting.

Veterinarians administered subcutaneous boluses of lactated Ringer's solution (10$30 \mathrm{ml}$, Hospira, Inc., Lake Forest, Illinois, USA) to all scoters. Isoflurane (Isoflurane, USP, Piramel Enterprises Limited, Andhra Pradesh, India) given by mask, followed by intubation was used for the general anesthesia. All birds received a line-block of bupivacaine $(2 \mathrm{mg} / \mathrm{kg}, 5 \mathrm{mg} / \mathrm{ml}$, Hospira, Inc.) or bupivacaine and lidocaine $(2 \mathrm{mg} / \mathrm{kg}$, $20 \mathrm{mg} / \mathrm{ml}$, Lidocaine $\mathrm{HCl}$ Injection, USP, Hospira, Inc.) at the site of the skin incision. During holding, transport, and recovery, we held birds separately in small pet carriers equipped with padded sides to avoid bill damage and a raised mesh floor above a bed of pine shavings to allow them to remain clean and dry. We allowed birds to recover 
in their crates for 1-2 hrs after surgery and then released scoters at or near their original capture location within $11 \mathrm{hrs}$ of initial capture $(\bar{x}=7.5$, range $=3.0-11.0)$. The project and methodology were approved by the University of Rhode Island Animal Care and Use Committee (IACUC \#AN1516-002).

\section{Location data}

We used the Argos satellite-based location and collection system (Collecte Localisation Satellites 2017) to receive transmission signals and PTT diagnostic data from all deployed scoters. We downloaded and archived transmission data nightly and subsequently filtered data through the Douglas Argos Filter (DAF; Douglas et al. 2012) to remove redundant data and unlikely point locations. Using the DAF, we employed a hybrid filter to retain the single location with the highest accuracy from each duty cycle to reduce redundant daily positional information in our analyses. Argos processing centers report calculated accuracy estimates for each of the four highest quality location classes (i.e., location classes $3,2,1$, and 0 had estimated accuracies of $<250 \mathrm{~m}, 250$ to $<500 \mathrm{~m}, 500$ to $<1,500 \mathrm{~m}$, and $>1,500 \mathrm{~m}$, respectively). We did not estimate accuracies for location classes A, B, or Z (invalid location) because these location classes were not used in our analyses and rarely occurred.

Individual location data, internal body temperature, and PTT operational information were transmitted from each unit based on pre-programmed duty cycles. This project was also a part of a study examining resource selection and winter habitat use in White-winged Scoters (Chapter 1), therefore we programmed PTTs on more intensive duty cycles during the winter months to increase the frequency of transmissions during the non-breeding period. Duty cycles switched to more 
conservative transmission schedules during the migratory and breeding periods and typically remained on those schedules until the end of battery life. We programmed transmitters with two different seasons of on/off duty cycles (i.e., 'Season 1' $=4$ hours on, 72 hours off duty cycle; 'Season 2' $=4$ hours on, 96 hours off). We programmed PTTs for scoters captured in the fall of 2015 to transmit on the Season 1 duty cycle for 57 cycles, which extended from capture date to mid-April 2016. Thereafter, all PTTs switched to Season 2 until the end of battery life. This Season 2 duty cycle reduced the frequency of transmissions during the nesting period when movements were greatly reduced, while also extending battery life to allow data collection over multiple years. We programmed all transmitters deployed in March 2016 to begin on the Season 2 duty cycle for 54 cycles (until mid-October 2016). Thereafter, PTTs switched to Season 1 for 57 cycles until the end of their first full wintering period (until mid-April 2017). These transmitters deployed in March 2016 then switched back to Season 2 until the battery died. Due to changes in capture timing, we programmed PTTs deployed in August 2016 to begin on the Season 2 duty cycle and then switch to Season 1 after the first winter period.

We managed and analyzed all telemetry data, as well as produced all maps, using ArcGIS 10.4.1 (Environmental Systems Research Institute, Inc., Redlands, CA). We performed all statistical analyses using the statistical software R v3.3.1 (R Core Team 2016).

\section{Annual cycle phenology and migration strategies}

We used the highest quality location collected during each duty cycle to calculate the timing of movements and identify key geographic areas throughout each stage of 
the annual cycle. To account for location error associated with satellite-derived locations we assigned breeding, wintering, and molting areas to each bird by calculating a centroid from all of that individual's locations that were recorded during each time period. We used temporal life stage criteria adapted from the Sea Duck Joint Venture (2015) to assign locations to each life stage (Table 1). Due to the varying accuracy estimates of each location and the time gaps between consecutive locations during the "breeding" period, we did not attempt to quantify nesting success of birds that migrated to suspected breeding areas. During the wintering period, some birds ( $n$ $=2$ ) began the winter in one area before migrating large distances to a new wintering area. In these instances, we classified the individual's wintering area as the area in which it spent the majority of the wintering period. More detailed and robust descriptions of intra-winter movements and home range size are described in Chapter 1. To minimize potential bias in habitat use and movement behavior associated with capture and surgery trauma, we excluded the first 14 days of data collected after release (Esler 2000; Sexson et al. 2014). For the same reason, we only included birds that transmitted $>60$ days after release in our analyses. We summarize movement data collected from 27 October 2015 to 6 December 2017.

We used data collected over a one-year period for each individual to calculate their breeding, wintering, and molting centroids. This approach standardized for mortality and PTT longevity and avoided biasing the analysis towards individuals that had PTTs transmit for longer time periods. As the potential exists for movement patterns and behavior of birds to be affected by transmitter implantation during the period following capture and deployment (Barron et al. 2010; White et al. 2013), we 
preferentially used data for an individual in the second year they were tracked when possible. When calculating movement phenology and inter-annual site fidelity, we used multiple years of data when available.

We calculated the arrival dates to areas within each life stage as the median date between the last location outside that area and the first location within it. Likewise, we calculated departure dates as the median date between the last location within and first location outside of a particular area. We estimated total length of stay within an area during each life stage as the difference between the departure date and the arrival date at each location plus one additional day. We added an additional day to account for biases associated with the length of time transmitters were off during their duty cycles, thus the approach accounted for the possibility that a bird was present in an area on both the arrival and departure date (De La Cruz et al. 2009).

Following De La Cruz et al. (2009), we calculated total duration of spring migration as the difference between the winter departure date and the date of arrival at the breeding location plus one additional day. Similarly, we estimated duration of fall migration as the difference between the departure date from the molting grounds and the arrival date at the wintering area plus one day. We defined spring and fall migration routes based on the first recorded location at least $200 \mathrm{~km}$ from the wintering area or fall staging area, at which point we considered migration to have been initiated. To estimate migration routes and total distances travelled by migrating scoters, we measured straight-line geodesic distances between consecutive locations during migration periods. We report the overall length of stay at a location and total migration duration and distance as mean $\pm \mathrm{SE}$ (range), whereas we report only the 
median (range) arrival and departure dates. We used one-way ANOVA to test for statistical significance of migration phenology based on wintering location and migration route, as well as to assess differences in migratory duration and distance among different migration strategies. We used Tukey-HSD for multiple comparisons when ANOVA indicated significance. We considered results significant at $P<0.05$. Analyses were replicated using non-parametric Kruskal-Wallis tests and significance was not affected.

\section{Population delineation and migratory connectivity}

To assess for spatial population structuring on either the breeding, molting, or wintering grounds, we performed cluster analyses on all centroid locations within the breeding, molting, and wintering areas using the OPTICS function in R package dbscan (Hahsler 2016; but see Ankerst et al. 1999). This method uses an ordering algorithm similar to a density-based spatial clustering algorithm (i.e. DBSCAN function) to calculate the number of clusters that best represents the breeding, molting, or wintering area centroids for all individuals combined. The algorithm allowed for the possibility that some centroids would not be assigned to a cluster (Hahsler 2016). The algorithm inputs included an epsilon neighborhood which effectively set a distance threshold for identifying clusters. We determined an appropriate value for the epsilon neighborhood by identifying the "knee" in a plot of calculated k-nearest neighbor distances of our point matrices. We set the minimum number of points allowed for identifying a cluster to 5 , as tests with fewer points identified multiple small clusters that we did not consider ecologically meaningful. 
We conducted the Mantel test $\left(r_{M}\right)$ using the R package ade4 (Dray and Dufour 2007) to quantify migratory connectivity between different life stages. This model did not require an a priori designation of distinct population units and thus served as a null model that only considered distances among individuals during two different life stages. The null hypothesis of random mixing among individuals would thus produce an expected correlation coefficient ( $\left.r_{M}\right)$ of zero (Ambrosini et al. 2009). We constructed distance matrices of centroid locations for the breeding, molting, and wintering periods for birds who provided data between successive life stages (i.e., a bird would not be included if a molting area was known but it did not survive to the subsequent winter). We then computed Mantel test coefficients of connectivity between 1) wintering and breeding, 2) breeding and molting, and 3) molting and wintering periods. We determined statistical significance at $P<0.05$ after 9999 random permutations.

To further test whether scoters in the eastern United States behave as multiple distinct sub-units or as a single continuous population, we used linear regression to model the effect of breeding longitude on arrival date to the wintering grounds. We also tested the relationship between spring departure date from the wintering grounds and ultimate breeding longitude, given the hypothesis that birds breeding farthest west from their wintering area would arrive on their wintering area later and depart earlier in the spring than birds that did not migrate as far between breeding and wintering areas.

\section{RESULTS}


We initially deployed satellite transmitters in 52 female White-winged Scoters. Seven individuals were excluded from analysis due to mortality or radio failure within 60 days of deployment. An additional 10 birds died prior to their first breeding season post-deployment and were not included in any analyses after their first wintering period. We were able to document spring migration routes and breeding areas for 27 individuals. We documented molting areas for 23 individuals and fall migration routes for 17. Five individuals provided data long enough to document breeding locations and migration routes in their second year after deployment.

\section{Annual cycle phenology and migration strategies}

We collected movement data of female scoters across a two-year time-period, allowing for the identification of key geographic areas used throughout the annual cycle as well as the phenological patterns underlying each life stage. Annual cycle phenology and longitudinal location data for all birds deployed in this study are presented in Fig. 2. We describe below in more detail the spatial and temporal movements of female scoters within the wintering, breeding, and molting stages of the annual cycle.

\section{Wintering}

All female scoters captured near Cape Cod or Long Island generally remained in southern New England throughout the winter, except one bird that migrated west to Lake Ontario $\left(43.6^{\circ} \mathrm{N}, 77.8^{\circ} \mathrm{W}\right)$ approximately three weeks after deployment. In contrast, birds captured during the molting period in the St. Lawrence River estuary wintered throughout a broader geographic range. Fifteen of 24 (62\%) scoters captured in Quebec that survived through fall migration wintered throughout southern New 
England to south of Long Island, NY, with one bird later relocating to Lake Ontario for the remainder of the winter. Three (12\%) scoters wintered along the coast of Nova Scotia $\left(45.0^{\circ} \mathrm{N}, 63.8^{\circ} \mathrm{W}\right)$, four $(15 \%)$ individuals spent most of the winter on Lake Ontario, and one $(4 \%)$ wintered along the mid-coast of Maine $\left(44.1^{\circ} \mathrm{N}, 69.0^{\circ} \mathrm{W}\right.$; Fig. 3). We found no significant difference in spring departure date $\left(F_{[2,24]}=2.10, P=\right.$ $0.14)$, breeding ground arrival date $\left(F_{[2,24]}=0.29, P=0.75\right)$, migration duration $\left(F_{[2,24]}\right.$ $=0.57, P=0.57)$ of birds among different wintering locations. Total length of stay in the wintering areas was $189 \pm 6(110-225)$ days. Total spring migration distance was significantly shorter for birds wintering on Lake Ontario than those wintering in southern New England $(P=0.02)$. However, the low sample size of birds wintering in areas outside of southern New England likely precludes robust analysis.

\section{Spring migration}

We were able to determine the spring migration routes of 27 scoters (Fig. 3). Scoters from all capture locations generally initiated spring migration by either heading northeast along the Canadian Maritime coast (i.e. Nova Scotia and New Brunswick; $n=11)$ or northwest overland $(n=16)$. Within the group that undertook the northwest overland route, we identified three distinct spring migration routes to suspected breeding areas including an overland route stopping over at James Bay $(n=$ 5), a direct overland route from the wintering areas to inland breeding locations $(n=$ $8)$, and an overland route stopping over in the Great Lakes $(n=3)$. Those that migrated along the coastal route through the Canadian Maritime provinces crossed over the St. Lawrence River estuary before continuing on to eventual breeding areas. We recorded two individual scoters using different migration routes between years. 
Both birds migrated from southern New England using the overland route through James Bay $\left(52.8^{\circ} \mathrm{N}, 80.3^{\circ} \mathrm{W}\right)$ during their first spring migration; one switched to the coastal route through the St. Lawrence River estuary during its second year and the other took a direct inland route apparently bypassing James Bay during the second year. However, this bird had a large gap in transmissions ( $\sim 3$ weeks) between its last location in the wintering area and its first inland location, so a stopover in James Bay could have occurred without being detected.

Across birds from all wintering areas, the median date of spring migration initiation was 15 May (27 April - 27 May, $n=28$ ). We found no significant differences in spring departure date based on migration route. Across all birds, spring migration lasted $24 \pm 2(8-43)$ days. Migration along the coastal route $(29 \pm 3,14-$ 41 days) took significantly longer than the direct overland route (18 $\pm 3,8-28$ days; $P=0.03)$. Total spring migration distance averaged 3,034 $\pm 157(1,480-4,090) \mathrm{km}$ across birds from all wintering locations. There was no significant difference in total migration distance among migration routes $\left(F_{[3,23]}=1.33, P=0.29\right)$ and linear regression found no correlation between migration duration and total migration distance $\left(R^{2}=0.004, F_{[1,25]}=0.09, P=0.76\right)$. We also found no correlation between spring departure date and total migration distance $\left(R^{2}=0.00005, F_{[1,25]}=0.001, P=\right.$ 0.97). Median arrival date at suspected breeding locations was 8 June (25 May - 27 June). There was no significant difference in arrival date among migration routes $\left(F_{[3,23]}=1.37, P=0.28\right)$.

We identified spring staging areas for 22 scoters. Staging areas included James Bay $(n=8)$, St. Lawrence River estuary $(n=7)$, Prince Edward Island $\left(46.3^{\circ} \mathrm{N}\right.$, 
$\left.63.3^{\circ} \mathrm{W} ; n=2\right)$, Lake Ontario $(n=1)$, the Gulf of St. Lawrence $\left(48.2^{\circ} \mathrm{N}, 62.0^{\circ} \mathrm{W} ; n=\right.$ 1), as well as inland freshwater locations in eastern Ontario $(n=2)$ and central Manitoba $(n=1)$. Length of stay at spring staging locations was $18 \pm 1.5(8-33)$ days.

\section{Breeding}

Among birds from all capture locations, 24 individuals migrated to suspected breeding areas during the first breeding season post-deployment. For scoters that migrated to potential breeding areas, individuals spent $57 \pm 5$ (25 - 101) days at breeding areas before departing to molting areas (Fig. 2). The median departure date from the breeding area was 8 August (23 June -9 September). Five birds transmitted long enough to document migration to breeding locations in consecutive years. In all cases, birds returned to the same location in the second year, suggesting strong breeding site fidelity for female scoters.

Suspected breeding sites for individuals ranged in longitude from $68^{\circ} \mathrm{W}$ to $115^{\circ} \mathrm{W}$; northeastern Quebec to the southwest of Ungava Bay $\left(59.8^{\circ} \mathrm{N}, 67.8^{\circ} \mathrm{W}\right)$, the Hudson Bay lowlands of northern Manitoba, northwestern Manitoba, northeastern Saskatchewan, Nunavut, and areas of the Northwest Territories surrounding Great Slave Lake $\left(62.5^{\circ} \mathrm{N}, 111.3^{\circ} \mathrm{W}\right.$; Fig. 3). One bird migrated during early June as far west as the southeastern portion of the Yukon Territories, but only remained for $\sim 5$ days suggesting this individual did not initiate nesting.

\section{Breeders vs. non-breeders}

Eight of the 35 birds (23\%) alive during summer did not migrate to the breeding grounds during the first breeding season after deployment. Of these eight birds, only 
one provided data long enough to determine breeding status in the subsequent year. This bird migrated to the breeding grounds during their potential second breeding season. We found that non-breeding scoters departed the wintering area an average of six days later than suspected breeders, but this difference was non-significant $\left(F_{[1,29]}=\right.$ $1.29, P=0.27)$ and was likely influenced by a single outlier that did not depart her wintering area until late June. Non-breeding birds migrated directly from the wintering grounds to suspected molting or staging areas (e.g., James Bay, the St. Lawrence River estuary, and mid-coast Maine) until they returned to their wintering areas.

\section{Remigial molt}

Molting areas appeared to be directly related to breeding status. Most birds that migrated to suspected breeding areas, and transmitted long enough to record subsequent molting areas, spent the molt period in James Bay (57\%; $n=13$; Fig. 4). One bird appeared to molt in Nunavut along the western shore of Hudson Bay, two molted along the southwest shore of Hudson Bay, two molted among the Belcher Islands $\left(56.2^{\circ} \mathrm{N}, 79.4^{\circ} \mathrm{W}\right)$ in southeastern Hudson Bay, and three molted in the St. Lawrence River estuary. One bird that apparently nested near Great Slave Lake, Northwest Territories, appeared to migrate only $50 \mathrm{~km}$ west to molt on a small inland pond. Non-breeding females primarily molted in the St. Lawrence River estuary (75\%; $n=6$ ), apart from two birds that molted in James Bay and mid-coast Maine, respectively. Two breeding females transmitted long enough to document consecutive molting sites, and both returned to the same location within James Bay in both years. For birds migrating from suspected breeding areas $(n=21)$, median arrival date on the molting grounds was 12 August (18 July - 14 September; Fig. 2). All birds that 
molted away from the breeding grounds remained at or near their molting area until fall migration was initiated.

\section{Fall Migration}

We documented fall migration routes of 17 scoters, which were less variable than spring migration (Fig. 4). Most birds $(n=12)$ that molted in James Bay undertook a direct overland flight to southern New England, except one individual that flew along a coastal route through the St. Lawrence River estuary and Canadian Maritimes. Birds that molted in the St. Lawrence River estuary either took a direct overland route to southern New England, a coastal route to Nova Scotia, or an overland route to Lake Ontario. Total migration duration across all birds $(n=29)$ was $6 \pm 3(2-79)$ days. Most scoters migrated directly to their wintering areas without using stopover locations. One individual that migrated from James Bay stopped in Chaleur Bay $\left(47.9^{\circ} \mathrm{N}, 65.5^{\circ} \mathrm{W}\right)$ for two weeks before continuing to southern New England. One female scoter that molted near her breeding area in the Northwest Territories took 15 days to complete fall migration after a one-week stopover on a freshwater pond in northern Manitoba. One individual staged on Lake Champlain $\left(44.4^{\circ} \mathrm{N}, 73.3^{\circ} \mathrm{W}\right)$ on the border of Vermont and New York for roughly 2.5 months before ultimately wintering on Lake Ontario, which represented the longest duration migration we documented. Median arrival date to the wintering area was 1 November (27 September - 10 February; Fig. 2). There was no significant difference in fall departure date from different molting areas $\left(F_{[3,24]}=1.29, P=0.28\right)$. We also found no significant difference in arrival date to the wintering areas $\left(F_{[3,24]}=0.39, P=0.76\right)$ or total fall migration duration based on molting area $\left(F_{[3,24]}=0.35, P=0.79\right)$. 


\section{Population delineation and migratory connectivity}

We identified two disjoint clusters of eight and ten breeding centroids, respectively, with nine breeding centroids not assigned to any cluster. The two identified breeding clusters were located southwest of Hudson Bay and immediately surrounding Great Slave Lake in the Northwest Territories of Canada (Fig. 5). Analysis on molting area centroids revealed one single cluster encompassing all of James Bay. Five additional molting areas inland within the breeding grounds, as well as Hudson Bay and the St. Lawrence River estuary were unclassified. Cluster analysis on wintering areas identified a single cluster encompassing all locations within southern New England. Additional wintering areas in the Great Lakes $(n=2)$, Long Island Sound $(n=4)$ and Canadian Maritimes $(n=3)$ were not assigned to any cluster (Fig. 5).

We found weak, non-significant migratory connectivity between wintering and breeding areas $\left(r_{M}=0.13, P=0.15\right)$ among the 27 females where both locations were known within the same year. Connectivity between breeding and molting areas exhibited a weak, though slightly more positive correlation, although this relationship was not statistically significant $\left(n=21, r_{M}=0.24, P=0.08\right)$. Connectivity between molting areas and wintering areas exhibited the most positive correlation among life stages, exhibiting moderate but non-significant connectivity $\left(n=20, r_{M}=0.46, P=\right.$ $0.07)$.

We found no relationship between either breeding longitude and wintering arrival date $\left(R^{2}=0.06, F_{[1,19]}=1.24, P=0.28\right)$ or spring departure date and breeding longitude $\left(R^{2}=0.04, F_{[1,25]}=1.09, P=0.31\right)$, suggesting no difference in migration 
phenology for White-winged Scoters in the eastern United States irrespective of their breeding and wintering area.

\section{DISCUSSION}

This study provides comprehensive documentation of annual cycle phenology, migration patterns, and population delineation of female White-winged Scoters in eastern North America. This information provides a rationale for managing eastern White-winged Scoters as a single, continuous population and highlights key geographic areas throughout their range that warrant consideration for conservation efforts.

\section{Annual cycle phenology and migration strategies}

White-winged Scoters in this study were initially captured either during the wintering period or during remigial molt prior to fall migration, allowing us to assess seasonal distribution and migration chronology for birds starting in distinctly different life stages. We corroborated past survey data (Silverman et al. 2013; Baldassarre 2014; Veit et al. 2016), and telemetry studies (Chapter 1; C. Lepage unpublished data) that highlighted the importance of southern New England as a wintering area for White-winged Scoters, as most individuals captured on their molting grounds subsequently wintered in this region. Results from the USA Atlantic Coast Wintering Sea Duck Survey estimated that $94 \%$ of eastern White-winged Scoters winter between Cape Cod Bay and Long Island Sound (Silverman et al. 2012, 2013). Satellite-tagged female White-winged Scoters in our study spent approximately 52\% (189 days) of their annual cycle at their wintering areas. This is within the same range as Whitewinged Scoters of both sexes tagged during the molting period in the St. Lawrence 
River estuary (173 \pm 31 days; Lepage et al., unpublished), but longer than estimates for Black Scoters (Melanitta americana (Swainson, 1832); Loring et al. 2014) and Common Eiders (Somateria mollissima (L., 1758); Beuth et al. 2017) wintering in southern New England, which spent an average of 147 days and 135 days, respectively. Surf Scoters (Somateria perspicillata (L., 1758)) wintering along the mid-Atlantic coast of the U.S. spent an average of 133 days on the wintering grounds (Meattey et al. 2015), while King Eiders (Somateria spectabilis (L., 1758)) in Alaska spent an average of 160 days wintering on the Bering Sea (Oppel et al. 2008).

Spring migration chronology in eastern White-winged Scoters was consistent with past observations of sea duck migration, as most birds in our study departed their wintering area by the third week of May. Timing was similar to Black Scoter departure dates from southern New England (range: 4 March - 24 May; Loring et al. 2014) but later than Common Eiders (range: 18 March - 20 April; Beuth et al. 2017). Surf Scoters wintering in four different locations along the Pacific Coast also initiated spring migration between mid-April and late-May (De La Cruz et al. 2009). Timing of migration and arrival to breeding locations showed little variation based on wintering location or migration route, and exhibited no relationship with overall migration distance or duration, suggesting that scoters breeding throughout the entire documented range exhibit relatively synchronous migration. Petersen (2009) similarly found no correlation between dates of migration initiation and migration distance in Common Eiders migrating from coastal Russia and Alaska. In contrast, Surf Scoters on the Pacific Coast appeared to migrate earlier from southern wintering areas than from northern areas (De La Cruz et al. 2009) 
Recent satellite telemetry studies have highlighted individual variation in migration routes and timing. Surf Scoters on the Pacific Coast used three separate migration routes from coastal wintering areas to breeding locations in the Northwest Territories (De La Cruz et al. 2009). Similarly, Petersen (2009) documented Common Eiders wintering in the western Beaufort Sea using three distinct migration strategies to breeding areas. We documented four primary spring migration routes based on two criteria, the initial direction of travel from the wintering area, as well as differences in spring staging or stopover sites along each route. Most birds staged on larger coastal water bodies, with few birds stopping over on smaller inland freshwater areas. This stopover strategy of using coastal stopover sites is similar to Surf Scoters on the Pacific coast and Alaska (De La Cruz et al. 2009; Lok et al. 2011). However, we note that the reduced transmission frequency for most birds during migration could have missed short inland stopovers, particularly for individuals that undertook direct overland routes from wintering areas to breeding areas. The total duration of spring migration did not differ among individuals during this study based on wintering locations or migration routes. Similarly, Mosbech et al. (2006) found little difference in migration duration among breeding populations of Northern Common Eider (S. $m$. borealis (C.L. Brehm, 1824)) in Greenland and arctic Canada that utilized different migratory routes. In contrast, Common Eiders in Alaska using different migration strategies demonstrated some variation in migration duration, which Petersen (2009) attributed to differences in migration distance and length of stay at stopover locations.

Breeding areas identified in this study represent much of the known breeding range for White-winged Scoters in eastern North America (Brown and Fredrickson 
1997; Lepage et al., unpublished data), with probable breeding birds ranging as far west as Great Slave Lake in the Northwest Territories. Two scoters were found as far west as Great Bear Lake in the Northwest Territories and the southeastern portion of the Yukon Territories, although they did not remain long enough to be classified as nesting in this region. Four scoters migrated to suspected breeding areas in northern Quebec, much farther east than the known breeding range for the species. Lepage et al. (unpublished data) also documented two White-winged Scoters breeding in Quebec further west in the coastal lowlands of northeastern James Bay which support the largest known breeding concentration of White-winged Scoters in Quebec (Benoit et al. 1994, 1996).

Eastern scoters breeding in the Northwest Territories and as far east as northern Saskatchewan likely overlap with breeding scoters from Pacific and Alaskan wintering areas. For example, White-winged Scoters breeding at Redberry Lake in northern Saskatchewan represent wintering populations from both the Atlantic (25\%) and Pacific (75\%) coasts based on stable isotope analysis (Swoboda 2007). Despite this overlap, satellite telemetry studies have yet to document scoters wintering on opposite coasts in different years. This pattern of east-west segregation is likely the result of historic population isolation during the last glaciation (Talbot et al. 2015) and is likely maintained due to pair formation during the non-breeding period followed by subsequent repairing each year. Similar disjunct distributions have been documented in other bird species in North America such as Cooper's Hawk (Accipiter cooperii (Bonaparte, 1828); Sonsthagen et al. 2012) and Sharp-shinned Hawk (Accipiter striatus (Vieillot, 1807); Hull and Girman 2005), with eventual population overlap 
being attributed to westward expansion following glacial retreat (Hull and Girman 2005).

We identified two principal molting areas for eastern White-winged Scoters. Most birds that migrated to suspected breeding areas apparently molted within James Bay or Hudson Bay based on the timing and length of their stopovers. All scoters that molted away from the breeding area migrated to molting areas in a seasonally-appropriate direction (i.e. along fall migration routes) rather than undergoing a true molt migration in a different direction from the expected fall migration route as has been observed in some species of ducks and geese (Yarris et al. 1994). Timing of arrival on molting grounds typically varies by age, sex, and reproductive status (Savard and Petersen 2015), with males, sub-adults, and non-breeding females undertaking remigial molt before breeding females (Petersen 1980, 1981; Savard et al. 2007; Dickson et al. 2012). Lepage et al. (unpublished data) documented adult male White-winged Scoters arriving on molting areas in the St. Lawrence River estuary nearly a month earlier than breeding females. While our study consisted of only adult females, arrival dates to their molting areas were approximately three weeks later than arrival dates of males reported in that study. We did not investigate differences in migration chronology between non-breeding and breeding females in our study, as non-breeding scoters migrated directly to their eventual molting areas after the wintering period, thus we were unable to determine the approximate date that molt was initiated.

Molting areas for many sea ducks often also serve as fall staging locations (Petersen et al. 2006; Savard et al. 2011; Savard and Petersen 2015). Scoters in our study remained at or near their molting areas throughout the fall until migrating 
relatively quickly to their wintering area. Similar to most scoters in our study, Harlequin Ducks (Histrionicus (L. 1758)) in eastern North America migrated directly to their wintering areas without utilizing stopover locations in between (Robert et al. 2008). In contrast, Common Eider have a protracted fall migration that can last several weeks and include several stopover locations along the route (Savard et al. 2011). King Eiders in Alaska typically take 3-105 days during fall migration to reach wintering areas, with $60 \%$ of birds taking longer than three weeks to complete migration after utilizing several stopovers for up to six weeks (Oppel et al. 2008). The phenology of fall migration for female scoters originating from different molting areas showed little to no variability, suggesting that annual harvest along migration does not disproportionately target any segment of the population.

\section{Population delineation and migratory connectivity}

Population delineation and migratory connectivity for species of waterfowl have usually relied on band recovery data (Madsen et al. 2014; Guillemain et al. 2017), genetic markers (Fleskes et al. 2010; Liu et al. 2012), stable isotopes (Swoboda 2007; Caizergues et al. 2016), or some combination thereof (Pearce et al. 2008, 2014). Assessing stable isotopes or genetic markers, such as nuclear or mitochondrial DNA, can reliably identify overlap in population units and estimate gene flow between discrete breeding locations (Mehl et al. 2005; Sonsthagen et al. 2009). However, information from tracking individuals provides insights into whether such population delineation has resulted in coordinated movements across the annual cycle and thus strong connectivity (Webster et al. 2002; Moore and Krementz 2017), and can identify 
key breeding, stopover, molting, and wintering areas used (Mehl et al. 2005; Bustnes et al. 2010; Barbaree et al. 2016).

We identified two primary breeding regions for White-winged Scoters in the Northwest Territories and the lowlands southwest of Hudson Bay. These two areas corresponded with areas of high scoter density identified by the Waterfowl Breeding Population and Habitat Survey conducted by the U.S. Fish and Wildlife Service (Bowman et al. 2015), though this survey does not distinguish between the three scoter species. As population structure in sea ducks is heavily female-mediated due to strong natal and breeding area philopatry (Eadie and Savard 2015; Mallory 2015), one would expect any spatial population structure to be evident within the breeding areas, though pair formation during the non-breeding season is common (Robertson et al. 1998; Smith et al. 2000) and should ensure genetic mixing as males disperse based on their paired status (Anderson et al. 1992). We estimated weak connectivity between breeding locations and other life stages, and thus little evidence of population delineation among eastern White-winged Scoters, although we recognize that these calculations are based on tracking relatively few females $(n=27)$ captured at wintering and molting areas. Scoters captured at the molting site in the St. Lawrence River estuary subsequently occurred across the same east-west extent as those captured in southern New England. However, some scoters captured in the St. Lawrence migrated to breeding areas in areas of northern Quebec that the birds captured in southern New England did not. Our conclusions regarding population delineation and migratory connectivity were supported when only scoters captured in Quebec were included in the analyses, which provides some validation that birds 
captured on the St. Lawrence molting grounds provide an adequate representation of the eastern population of White-winged Scoters. Future capture efforts of eastern White-winged Scoters should consider this area, as winter conditions and seasonallyvariable scoter distributions make capture efforts during the winter more unpredictable.

Studies of migratory connectivity typically describe movements of individuals between breeding and non-breeding areas (Webster et al. 2002). However, studies of connectivity in waterfowl species must also consider the post-breeding flightless remigial molt period as an additional critical life stage where population structure and mixing may differ from either the breeding or wintering periods. In our study, the strength of migratory connectivity was dependent on which life stages were being compared. Though all were non-significant, connectivity was weakest between winter and breeding, and strongest between molting and wintering sites. This highlights the importance of accounting for the entire annual cycle when assessing migratory connectivity and population delineation in waterfowl.

This study has important implications for conservation and management of eastern White-winged Scoters and provides new insights into their life history. We identified probable breeding locations in Nunavut, northern Ontario, and Quebec that fall outside of published breeding range maps and could warrant further refinement of species range maps and expansion of breeding survey areas. Additionally, this study documented the importance of James Bay and the St. Lawrence River estuary as prominent molting and staging areas for this population, corroborating findings also reported by Lepage et al. (unpublished data). As in many other bird species, these 
staging and molting areas often act as geographic bottlenecks where large numbers of birds congregate for extended periods of time and thus present unique implications for conservation and management (Leu and Thompson 2002; Lok et al. 2011; Fox et al. 2014; Barbaree et al. 2016). Conservation efforts should consider the value these molting areas provide to White-winged Scoters.

\section{ACKNOWLEDGEMENTS}

We would like to thank the dedicated field crews from Biodiversity Research Institute (BRI), University of Rhode Island (URI), Rhode Island Department of Environmental Management (RIDEM), U.S. Fish and Wildlife Service (USFWS), and Canadian Wildlife Service for long hours in the field conducting this study. Drs. Gavino Puggioni (URI), Juliet Lamb (URI), and Brian Gerber (URI) provided helpful insight on statistical analyses. We thank Carlyn Caldwell (USGS Patuxent) for preparing the transmitters for implanting as well as obtaining and organizing surgical supplies. Sea Duck Joint Venture and RIDEM provided satellite transmitter funding and field support. We thank Andrew Gilbert (BRI) for compiling and archiving telemetry data. Finally, a very special thanks to Drs. Michelle Kneeland and Ginger Stout (BRI), Drs. Stéphane Lair, Rozenn Le Net, and Benjamin Lamglait (University of Montreal, Quebec), and Cara Papakyrikos (Tufts University) for their tireless work performing surgical implants. Funding for this research was provided by the Rhode Island Department of Environmental Management, Division of Fish and Wildlife (WSFR Wildlife Restoration Grant W-38-R), the University of Rhode Island, and the Canadian Wildlife Service of Environment and Climate Change Canada. 


\section{LITERATURE CITED}

Alisauskas, R.T., Traylor, J.J., Swoboda, C.J., and Kehoe, F.P. 2004. Components of population growth rate for white-winged scoters in Saskatchewan, Canada. Anim. Biodivers. Conserv. 27(1): 451-460.

Ambrosini, R., Møller, A.P., and Saino, N. 2009. A quantitative measure of migratory connectivity. J. Theor. Biol. 257(2): 203-211.

Anderson, M.G., Rhymer, J.M., and Rohwer, F.C. 1992. Philopatry, dispersal and the genetic structure of waterfowl populations. In Ecology and Management of Breeding Waterfowl. Edited by B.D.J. Batt, A.D. Afton, C.D. Ankney, D.H. Johnson, J.A. Kadlec, and G.L. Krapu. University of Minnesota Press, Minneapolis, MN. pp. 365-395.

Ankerst, M., Breunig, M.M., Kriegel, H.-P., and Sander, J. 1999. Optics: ordering points to identify the clustering structure. ACM Sigmod Rec.: 49-60.

Baldassarre, G. 2014. Ducks, Geese, and Swans of North America. John Hopkins University Press, Baltimore, MD.

Barbaree, B.A., Reiter, M.E., Hickey, C.M., and Page, G.W. 2016. Molt migration and migratory connectivity of the long-billed dowitcher. J. Wildl. Manage. 80(2): $256-265$.

Barron, D.G., Brawn, J.D., and Weatherhead, P.J. 2010. Meta-analysis of transmitter effects on avian behaviour and ecology. Methods Ecol. Evol. 1: 180-187.

Benoit, R., Lalumiere, R., and Reed, A. 1994. Etude de la sauvagine sur la cote nordest de la Baie James - 1993. Report for the Societe d'Enerie de la Baie James, Direction Ingenierie et Environnement, Service Ecologie. Groupe Environnement 
Shooner, QC.

Benoit, R., Lalumiere, R., and Reed, A. 1996. Etude de la sauvagine sur la cote nordest de la Baie James - 1995. Report for the Societe d'Enerie de la Baie James, Direction Ingenierie et Environnement, Service Ecologie. Groupe Environnement Shooner, QC.

Beuth, J.M., Mcwilliams, S.R., Paton, P.W.C., and Osenkowski, J.E. 2017. Habitat use and movements of common eiders wintering in southern New England. J. Wildl. Manage. 81(7): 1276-1286.

Bowman, T.D., Silverman, E.D., Gilliland, S.G., and Leirness, J.B. 2015. Status and trends of North American sea ducks. In Ecology and Conservation of North American Sea Ducks. Edited by J.-P.L. Savard, D.V. Derksen, D. Esler, and J.M. Eadie. Studies in Avian Biology, CRC Press, New York, NY. pp. 1-28.

Breault, A.M., and Cheng, K.M. 1990. Use of submerged mist nets to capture diving birds. J. Field Ornithol. 61(3): 328-330.

Brodeur, S., Mittelhauser, G.H., Savard, J.-P.L., Thomas, P.W., Titman, R.D., and Comeau, D. 2008. Capture methods for migrating, wintering and molting sea ducks. Waterbirds 31(2): 133-137.

Brown, P.W., and Brown, M.A. 1981. Nesting biology of the white-winged scoter. J. Wildl. Manage. 45(1): 38-45.

Brown, P.W., and Fredrickson, L.H. 1997. White-winged Scoter (Melanitta fusca). Available from https://birdsna.org/Species-Account/bna/species/whwsco.

Bustnes, J.O., Mosbech, A., Sonne, C., and Systad, G.H. 2010. Migration patterns, breeding and moulting locations of king eiders wintering in north-eastern 
Norway. Polar Biol. 33(10): 1379-1385.

Caizergues, A., Van Wilgenburg, S.L., and Hobson, K.A. 2016. Unraveling migratory connectivity of two European diving ducks: a stable isotope approach. Eur. J. Wildl. Res. 62(6): 701-711.

Carney, S.M. 1992. Species, age and sex identification of ducks using wing plumage. U.S. Department of the Interior, U.S. Fish and Wildlife Service, Washington, DC, USA.

Collecte Localisation Satellites. 2017. Argos User's Manual. Available from http://argos-system.org/wpcontent/uploads/2016/09/ArgosWeb_User_Manual.pdf.

De La Cruz, S.E.W., Eadie, J.M., Miles, A.K., Yee, J., Spragens, K.A., Palm, E.C., and Takekawa, J.Y. 2014. Resource selection and space use by sea ducks during the non-breeding season: Implications for habitat conservation planning in urbanized estuaries. Biol. Conserv. 169: 68-78.

De La Cruz, S.E.W., Takekawa, J.Y., Wilson, M.T., Nysewander, D.R., Evenson, J.R., Esler, D., Boyd, W.S., and Ward, D.H. 2009. Spring migration routes and chronology of surf scoters (Melanitta perspicillata): a synthesis of Pacific coast studies. Can. J. Zool. 87(11): 1069-1086.

Dickson, R.D., Esler, D., Hupp, J.W., Anderson, E.M., Evenson, J.R., and Barrett, J. 2012. Phenology and duration of remigial moult in surf scoters (Melanitta perspicillata) and white-winged scoters (Melanitta fusca) on the Pacific coast of North America. Can. J. Zool. Can. Zool. 90(8): 932-944.

Douglas, D.C., Weinzierl, R., C. Davidson, S., Kays, R., Wikelski, M., and Bohrer, G. 
2012. Moderating Argos location errors in animal tracking data. Methods Ecol. Evol. 3(6): 999-1007.

Dray, S., and Dufour, A.-B. 2007. The ade4 package: implementing the duality diagram for ecologists. J. Stat. Softw. 22(4).

Eadie, J.M., and Savard, J.-P.L. 2015. Breeding systems, spacing behavior, and reproductive behavior in sea ducks. In Ecology and Conservation of North American Sea Ducks. Edited by J.-P.L. Savard, D.V. Derksen, D. Esler, and J.M. Eadie. Studies in Avian Biology, CRC Press, New York, NY. pp. 365-415.

Esler, D. 2000. Applying metapopulation theory to conservation of migratory. Conserv. Biol. 14(2): 366-372.

Fleskes, J.P., Fowler, A.C., Casazza, M.L., and Eadie, J.M. 2010. Population structure and relatedness among female northern pintails in three California wintering regions. Waterbirds 33(1): 1-9.

Fox, A.D., Flint, P.L., Hohman, W.L., and Savard, J.P.L. 2014. Waterfowl habitat use and selection during the remigial moult period in the northern hemisphere. Wildfowl (4): 131-168.

Fraser, K.C., Stutchbury, B.J.M., Kramer, P., Silverio, C., Barrow, J., Newstead, D., Mickle, N., Shaheen, T., Mammenga, P., Applegate, K., Bridge, E., and Tautin, J. 2013. Consistent range-wide pattern in fall migration strategy of purple martin (Progne subis), despite different migration routes at the Gulf of Mexico. Auk 130(2): 291-296.

Guillemain, M., Calenge, C., Champagnon, J., and Hearn, R. 2017. Determining the boundaries and plasticity of migratory bird flyways: a Bayesian model for 
Eurasian teal (Anas crecca) in western Europe. J. Avian Biol. (June): 1-11.

Gurney, K.E.B., Wood, C.J., Alisauskas, R.T., Wayland, M., Devink, J.A., and Slattery, S.M. 2014. Identifying carry-over effects of wintering area on reproductive parameters in white-winged scoters : an isotopic approach. Condor 116: $251-264$.

Hahsler, M. 2016. dbscan: density based clustering of applications with noise (DBSCAN) and related algorithms. R package version 0.9-8. Available from https://cran.r-project.org/package=dbscan.

Hallworth, M.T., Sillett, T.S., Van Wilgenburg, S.L., Hobson, K.A., and Marra, P.P. 2015. Migratory connectivity of a neotropical migratory songbird revealed by archival light-level geolocators. Ecol. Appl. 25(2): 336-347.

Heath, J.P., Robertson, G.J., and Montevecchi, W.A. 2006. Population structure of breeding harlequin ducks and the influence of predation risk. Can. J. Zool. 84(6): $855-864$.

Heusmann, H.W. 1999. Special hunting seasons and resident Canada goose populations. Wildl. Soc. Bull. 27(2): 456-464.

Hull, J.M., and Girman, D.J. 2005. Effects of Holocene climate change on the historical demography of migrating sharp-shinned hawks (Accipiter striatus velox) in North America. Mol. Ecol. 14(1): 159-170.

Iverson, S.A., Boyd, W.S., Esler, D., Mulcahy, D.M., and Bowman, T.D. 2006. Comparison of the effects and performance of four types of radiotransmitters for use with scoters. Wildl. Soc. Bull. 34(3): 656-663.

Korschgen, C.E., Kenow, K.P., Gendron-Fitzpatrick, A., Green, W.L., and Dein, F.J. 
1996. Implanting intra-abdominal radiotransmitters with external whip antennas in ducks. J. Wildl. Manage. 60(1): 132-137.

Krapu, G.L., Brandt, D. a, Jones, K.L., and Johnson, D.H. 2011. Geographic distribution of the mid-continent population of sandhill cranes and related management applications. Wildl. Monogr. 175(1): 1-38.

Leu, M., and Thompson, C.W. 2002. The potential importance of migratory stopover sites as flight feather molt staging areas: a review for neotropical migrants. Biol. Conserv. 106(1): 45-56.

Liu, Y., Keller, I., and Heckel, G. 2012. Breeding site fidelity and winter admixture in a long-distance migrant, the tufted duck (Aythya fuligula). Heredity (Edinb). 109(2): 108-116.

Lok, E.K., Esler, D., Takekawa, J.Y., De La Cruz, S.W., Boyd, W.S., Nysewander, D.R., Evenson, J.R., and Ward, D.H. 2011. Stopover habitats of spring migrating surf scoters in southeast Alaska. J. Wildl. Manage. 75(1): 92-100.

Loring, P.H., Paton, P.W.C., Osenkowski, J.E., Gilliland, S.G., Savard, J.-P.L., and Mcwilliams, S.R. 2014. Habitat use and selection of black scoters in southern New England and siting of offshore wind energy facilities. J. Wildl. Manage. 78(4): 645-656.

Madsen, J., Tjørnløv, R.S., Frederiksen, M., Mitchell, C., and Sigfússon, A.T. 2014. Connectivity between flyway populations of waterbirds: Assessment of rates of exchange, their causes and consequences. J. Appl. Ecol. 51(1): 183-193.

Mallory, M. 2015. Site fidelity, breeding habitats, and the reproductive strategies of sea ducks. In Ecology and Conservation of North American Sea Ducks. Edited by 
J.-P.L. Savard, D.V. Derksen, D. Esler, and J.M. Eadie. Studies in Avian Biology, CRC Press, New York, NY. pp. 337-364.

Mallory, M.L., Akearok, J., North, N.R., Weseloh, D.V., and Lair, S. 2006. Movements of long-tailed ducks wintering on Lake Ontario to breeding areas in Nunavut, Canada. Wilson J. Ornithol. 118(4): 494-501. doi:10.1676/05-068.1.

Mather, D.D., and Esler, D. 1999. Evaluation of bursal depth as an indicator of age class of harlequin ducks. J. F. Ornithol. 70(2): 200-205.

Meattey, D., Savoy, L., Gilbert, A., Tash, J., Gray, C., Berlin, A., Lepage, C., Gilliland, S., Bowman, T., Osenkowski, J., and Spiegel, C. 2015. Wintering movements and habitat use of Surf Scoter (Melanitta perspicillata) in the midAtlantic U.S. In Wildlife densities and habitat use across temporal and spatial scales on the mid-Atlantic outer continental shelf: Final report to the Department of Energy EERE Wind \& Water Power Technologies Office. Edited by K.A. Williams, E.E. Connelly, S.M. Johnson, and I.J. Stenhouse. Award Number: DEEE0005362. Report BRI 2015-11, Biodiversity Research Institute, Portland, ME, USA.

Mehl, K.R., Alisauskas, R.T., Hobson, K.A., and Merkel, F.R. 2005. Linking breeding and wintering areas of king eiders: making use of polar isotopic gradients. J. Wildl. Manage. 69(3): 1297-1304.

Menu, S., Gauthier, G., and Reed, A. 2002. Changes in survival rates and population dynamics of greater snow geese over a 30-year period: implications for hunting regulations. J. Appl. Ecol. 39(1): 91-102.

Moore, J.D., and Krementz, D.G. 2017. Migratory connectivity of American 
woodcock using band return data. J. Wildl. Manage. 81(6): 1063-1072.

Mosbech, A., Gilchrist, G., Merkel, F., Sonne, C., Flagstad, A., Nyegaard, H., Mosbech, A., Gilchrist, G., Merkel, F., Sonne, C., Flagstad, A., and Nyegaard, H. 2006. Year-round movements of northern common eiders (Somateria mollissima) borealis breeding in arctic Canada and west Greenland followed by satellite telemetry. Ardea 94(3): 651-665.

Oosterhuis, R., and van Dijk, K. 2002. Effect of food shortage on the reproductive output of common eiders (Somateria mollissima) breeding at Griend (Wadden Sea). Atl. Seabirds 4(1): 29-38.

Oppel, S., Powell, A.N., and Dickson, D.L. 2008. Timing and distance of king eider migration and winter movements. Condor 110(2): 296-305.

Pearce, J.M., Blums, P., and Lindberg, M.S. 2008. Site fidelity is an inconsistent determinant of population structure in the hooded Merganser (Lophodytes cucullatus): evidence from genetic, mark-recapture, and comparative data. Auk 125(3): 711-722.

Pearce, J.M., Eadie, J.M., Savard, J.-P.L., Christensen, T.K., Berdeen, J., Taylor, E.J., Boyd, S., Einarsson, Á., and Talbot, S.L. 2014. Comparative population structure of cavity-nesting sea ducks. Auk 131(2): 195-207.

Petersen, M.R. 1980. Observations of wing-feather moult and summer feeding ecology of Steller's eiders at Nelson Lagoon, Alaska. Wildfowl 31: 99-106.

Petersen, M.R. 1981. Populations, feeding ecology and molt of Steller's eiders. Condor 83(3): 256-262.

Petersen, M.R. 2009. Multiple spring migration strategies in a population of Pacific 
common eiders. Condor 111(1): 59-70.

Petersen, M.R., Bustnes, J.O., and Systad, G.H. 2006. Breeding and moulting locations and migration patterns of the Atlantic population of Steller's eiders (Polysticta stelleri) as determined from satellite telemetry. J. Avian Biol. 37(1): $58-68$.

R Core Team. 2016. R: A language and environment for statistical computing. $\mathrm{R}$ Foundation for Statistical Computing, Vienna, Austria. ISBN 3-9000-07-0. Available from http://www.r-project.org/.

Robert, M., Mittelhauser, G.G.H., and Jobin, B. 2008. New insights on harlequin duck population structure in eastern North America as revealed by satellite telemetry. Waterbirds 31(2): 159-172.

Robertson, G.J., and Cooke, F. 1999. Winter philopatry in migratory waterfowl. Auk 116(1): 20-34.

Robertson, G.J., Cooke, F., Goudie, R.I., and Boyd, W.S. 1998. The timing of pair formation in harlequin ducks. Condor 100(3): 551-555.

Safine, D.E., and Lindberg, M.S. 2008. Nest habitat selection of white-winged scoters on Yukon Flats, Alaska. Wilson J. Ornithol. 120(3): 582-593.

Savard, J.-P.L., and Petersen, M.R. 2015. Remigial molt of sea ducks. In Ecology and Conservation of North American Sea Ducks. Edited by J.-P.L. Savard, D.V. Derksen, D. Esler, and J.M. Eadie. Studies in Avian Biology, CRC Press, New York, NY. pp. 337-364.

Savard, J.-P.L., Lesage, L., Gilliland, S.G., and Gilchrist, H.G. 2011. Molting, staging, and wintering locations of common eiders breeding in the Gyrfalcon 
Archipelago, Ungava Bay. Arctic 64(2): 197-206.

Savard, J.-P.L., Reed, A., and Lesage, L. 2007. Chronology of breeding and molt migration in surf scoters (Melanitta perspicillata). Waterbirds 30(2): 223-229.

Sea Duck Joint Venture. 2015. Atlantic and Great Lakes sea duck migration study: progress report June 2015. Available from http://seaduckjv.org/wpcontent/uploads/2014/12/AGLSDMS-Progress-Report-June2015_web.pdf.

Sea Duck Joint Venture Management Board. 2014. Sea Duck Joint Venture Strategic Plan 2014-2018. U.S. Fish and Wildlife Service, Anchorage, Alaska, USA; Canadian Wildlife Service, Sackville, New Brunswick, Canada.

Sedinger, J.S., and Alisauskas, R.T. 2014. Cross-seasonal effects and the dynamics of waterfowl populations. Wildfowl (4): 277-304.

Sexson, M.G., Mulcahy, D.M., Spriggs, M., and Myers, G.E. 2014. Factors influencing immediate post-release survival of spectacled eiders following surgical implantation of transmitters with percutaneous antennae. J. Wildl. Manage. 78(3): 550-560.

Sheaffer, S.E., Malecki, R.A., Swift, B.L., Dunn, J., and Scribner, K. 2007. Management implications of molt migration by the atlantic flyway resident population of Canada geese, Branta canadensis. Can. Field-Naturalist 121(3): $313-320$.

Silverman, E.D., Leirness, J.B., Saalfeld, D.T., Koneff, M.D., and Richkus, K.D. 2012. Atlantic coast wintering sea duck survey, 2008-2011. Division of Migratory Bird Management, U.S. Fish and Wildlife Service, Laurel, MD, USA. Silverman, E.D., Saalfeld, D.T., Leirness, J.B., and Koneff, M.D. 2013. Wintering sea 
duck distribution along the Atlantic coast of the United States. J. Fish Wildl. Manag. 4(1): 178-198.

Smith, C.M., Cooke, F., Robertson, G.J., Goudie, R.I., and Boyd, W.S. 2000. Longterm pair bonds in harlequin ducks. Condor 102(1): 201-205.

Sonsthagen, S.A., Rosenfield, R.N., Bielefeldt, J., Murphy, R.K., Stewart, A.C., Stout, W.E., Driscoll, T.G., Bozek, M.A., Sloss, B.L., and Talbot, S.L. 2012. Genetic and morphological divergence among Cooper's hawk (Accipiter cooperii) populations breeding in north-central and western North America. Auk 129(3): $427-437$.

Sonsthagen, S.A., Talbot, S.L., Lanctot, R.B., Scribner, K.T., and McCracken, K.G. 2009. Hierarchical spatial genetic structure of common eiders (Somateria mollissima) breeding along a migratory corridor. Auk 126(4): 744-754.

Stanley, C.Q., Mckinnon, E.A., Fraser, K.C., Macpherson, M.P., Casbourn, G., Friesen, L., Marra, P.P., Studds, C., Ryder, T.B., Diggs, N.E., and Stutchbury, B.J.M. 2015. Connectivity of wood thrush breeding, wintering, and migration sites based on range-wide tracking. Conserv. Biol. 29(1): 164-174.

Swoboda, C.J. 2007. Population delineation and wintering ground influence on vital rates of white-winged scoters. M.Sc. thesis, Department of Biology, University of Saskatchewan Saskatoon.

Takekawa, J.Y., De La Cruz, S.W., Wilson, M.T., Palm, E.C., Yee, J., Nysewander, D.R., Evenson, J.R., Eadie, J.M., Esler, D., Boyd, W.S., and Ward, D.H. 2011. Breeding distribution and ecology of Pacific coast Surf Scoters. In Boreal birds of North America: a hemispheric view of their conservation links and significance. 
Stud. Avian Biol. 41: 41-64.

Talbot, S.L., Sonsthagen, S.A., Pearce, J.M., and Scribner, K.T. 2015. Phylogenetics, phylogeography, and population genetics of North American sea ducks (tribe: Mergini). In Ecology and Conservation of North American Sea Ducks. Edited by J.-P.L. Savard, D.V. Derksen, D. Esler, and J.M. Eadie. Studies in Avian Biology, CRC Press, New York, NY. pp. 29-61.

Traylor, J.J., Alisauskas, R.T., and Kehoe, F.P. 2004. Nesting ecology of whitewinged scoters (Melanitta fusca deglandi) at Redberry Lake, Saskatchewan. Auk 121(3): 950-962.

Trierweiler, C., Klaassen, R.H.G., Drent, R.H., Exo, K.-M., Komdeur, J., Bairlein, F., and Koks, B.J. 2014. Migratory connectivity and population-specific migration routes in a long-distance migratory bird. Proc. R. Soc. B Biol. Sci. 281(1778): $20132897-20132897$.

Uher-Koch, B.D., Esler, D., Dickson, R.D., Hupp, J.W., Evenson, J.R., Anderson, E.M., Barrett, J., and Schmutz, J.A. 2014. Survival of surf scoters and whitewinged scoters during remigial molt. J. Wildl. Manage. 78(7): 1189-1196.

Veit, R.R., White, T.P., Perkins, S.A., and Curley, S. 2016. Abundance and distribution of seabirds off southeastern Massachusetts, 2011-2015. U.S. Department of the Interior, OCS Study BOEM 2016-067, Sterling, VA, USA.

Webster, M.S., Marra, P.P., Haig, S.M., Bensch, S., and Holmes, R.T. 2002. Links between worlds: unraveling migratory connectivity. Trends Ecol. Evol. 17(2): 76-83.

White, C.R., Cassey, P., Schimpf, N.G., Halsey, L.G., Green, J.A., and Portugal, S.J. 
2013. Implantation reduces the negative effects of bio-logging devices on birds.

J. Exp. Biol. 216(4): 537-542.

Yarris, G.S., Mclandress, M.R., and Perkins, A.E.H. 1994. Molt migration of postbreeding female mallards from Suisun Marsh, California. Condor 96(1): 3645.

Žydelis, R., Esler, D., Boyd, W.S., Lacroix, D.L., and Kirk, M. 2006. Habitat use by wintering surf and white-winged scoters: effects of environmental attributes and shellfish aquaculture. J. Wildl. Manage. 70(6): 1754-1762. 
Table 2-1. Criteria used for assigning individual White-winged Scoter (Melanitta fusca) locations to four stages of their annual cycle.

\begin{tabular}{lcccc}
\hline & Breeding & Molting & Wintering & Staging \\
\cline { 2 - 5 } Minimum length of stay & $\geq 25$ days $^{\mathrm{a}}$ & $\geq 48$ days $^{\mathrm{b}}$ & None & $\geq 7$ days $^{\mathrm{c}}$ \\
Arrival date & May to June & July to September & October to January & N/A \\
Departure date & July to August & August to October & April to May & N/A \\
\hline
\end{tabular}

${ }^{a}$ Takekawa et al. 2011

${ }^{b}$ Dickson et al. 2012

${ }^{c}$ De La Cruz et al. 2009 
Figure 2-1. Three locations where female White-winged Scoters (Melanitta fusca; $n=$ 52) were captured in 2015 and 2016 in eastern North America.

Figure 2-2. Migration chronology for female White-winged Scoters (Melanitta fusca; $n=52$ ) wintering in eastern North America. All 52 scoters captured are depicted, including those who did not provide data long enough to be included in summary or statistical analyses. Life stage blocks are based on median arrival and departure dates to and from each life stage.

Figure 2-3. Estimated spring migration routes $(n=27)$ between wintering and breeding areas for female White-winged Scoters (Melanitta fusca) captured in eastern North America. Lines represent connections of consecutive locations along migration, but do not necessarily represent actual migration paths. Colors symbolize identified migration routes: Blue $=$ direct overland, Orange $=$ coastal route, Green $=$ Great Lakes route, Red $=$ James Bay route.

Figure 2-4. Estimated molt migration routes $(n=21)$ between breeding and molting areas and fall migration routes $(n=17)$ between molting/staging and wintering areas of female White-winged Scoters (Melanitta fusca) captured in eastern North America. Lines represent connections of consecutive locations along migration, but do not necessarily represent actual migration paths.

Figure 2-5. Annual cycle migratory connectivity of female White-winged Scoters (Melanitta fusca; $n=27$ ) that migrated between breeding, molting, and wintering areas. Colored areas represent life stage area clusters identified by cluster analysis. Connectivity correlations account for migration between locations not assigned to 
clusters. Line width symbolizes comparative strength of connectivity. Lines indicate direction of migration, but do not represent actual migration routes. 
Figure 2-1.

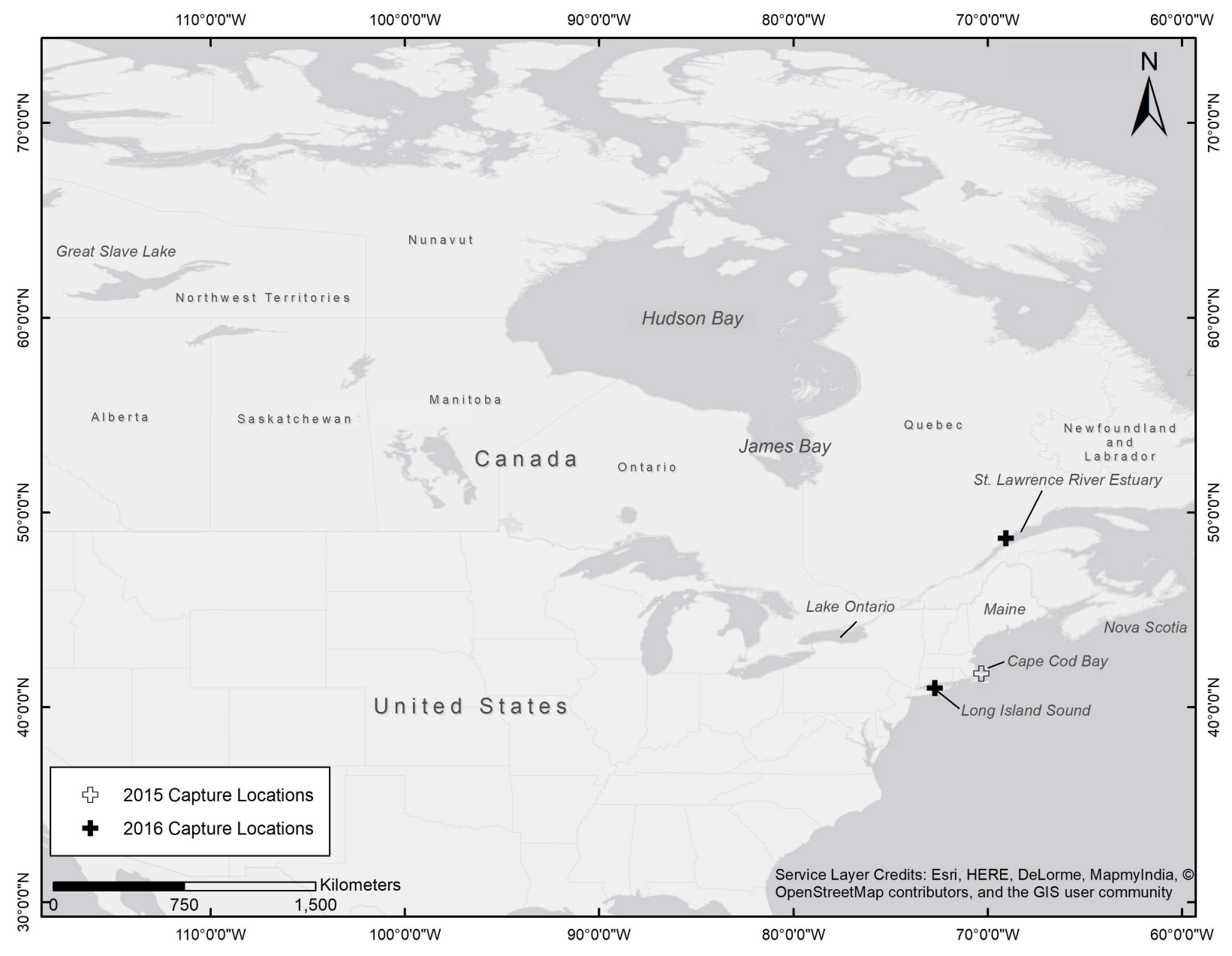


Figure 2-2.

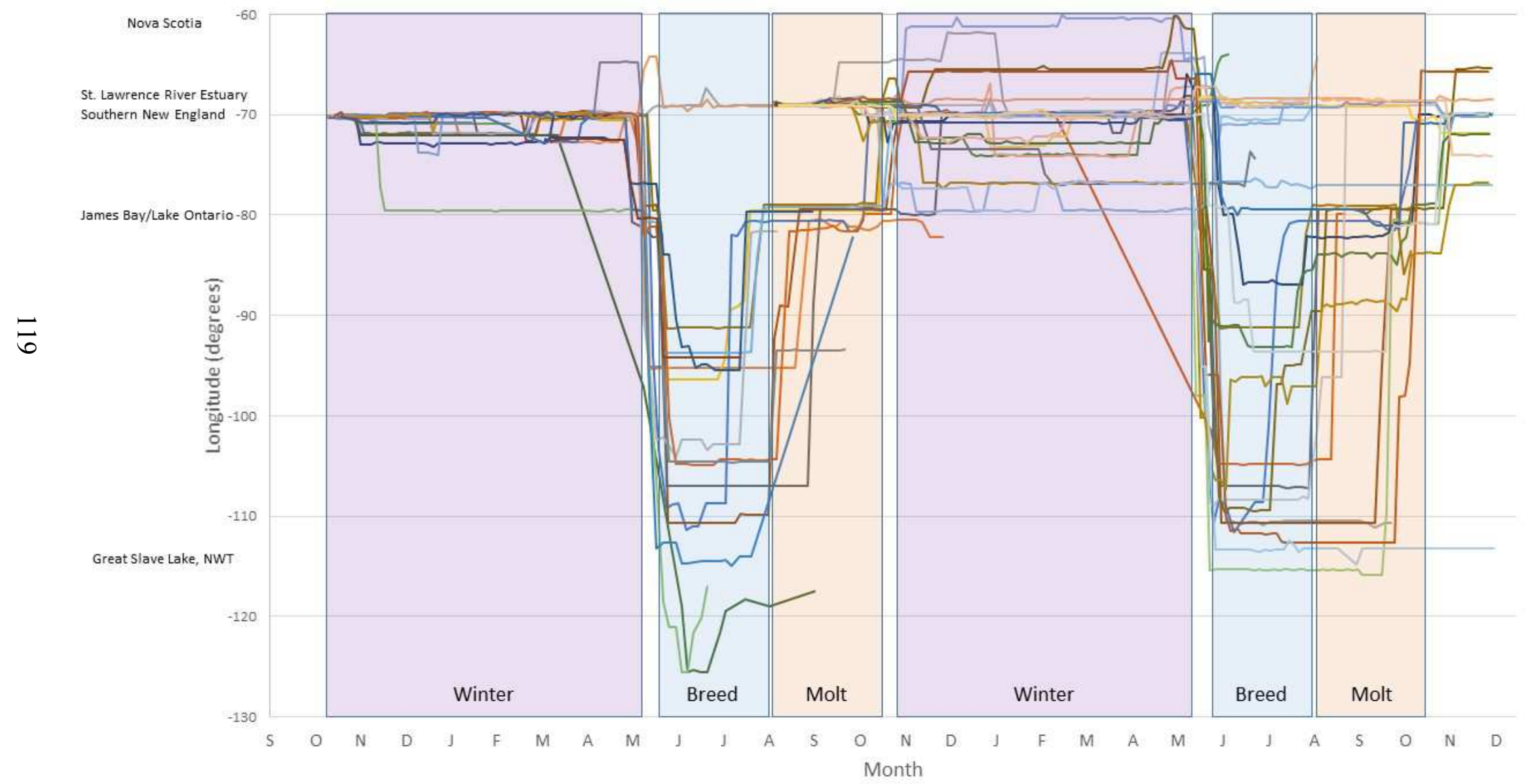




\section{Figure 2-3.}

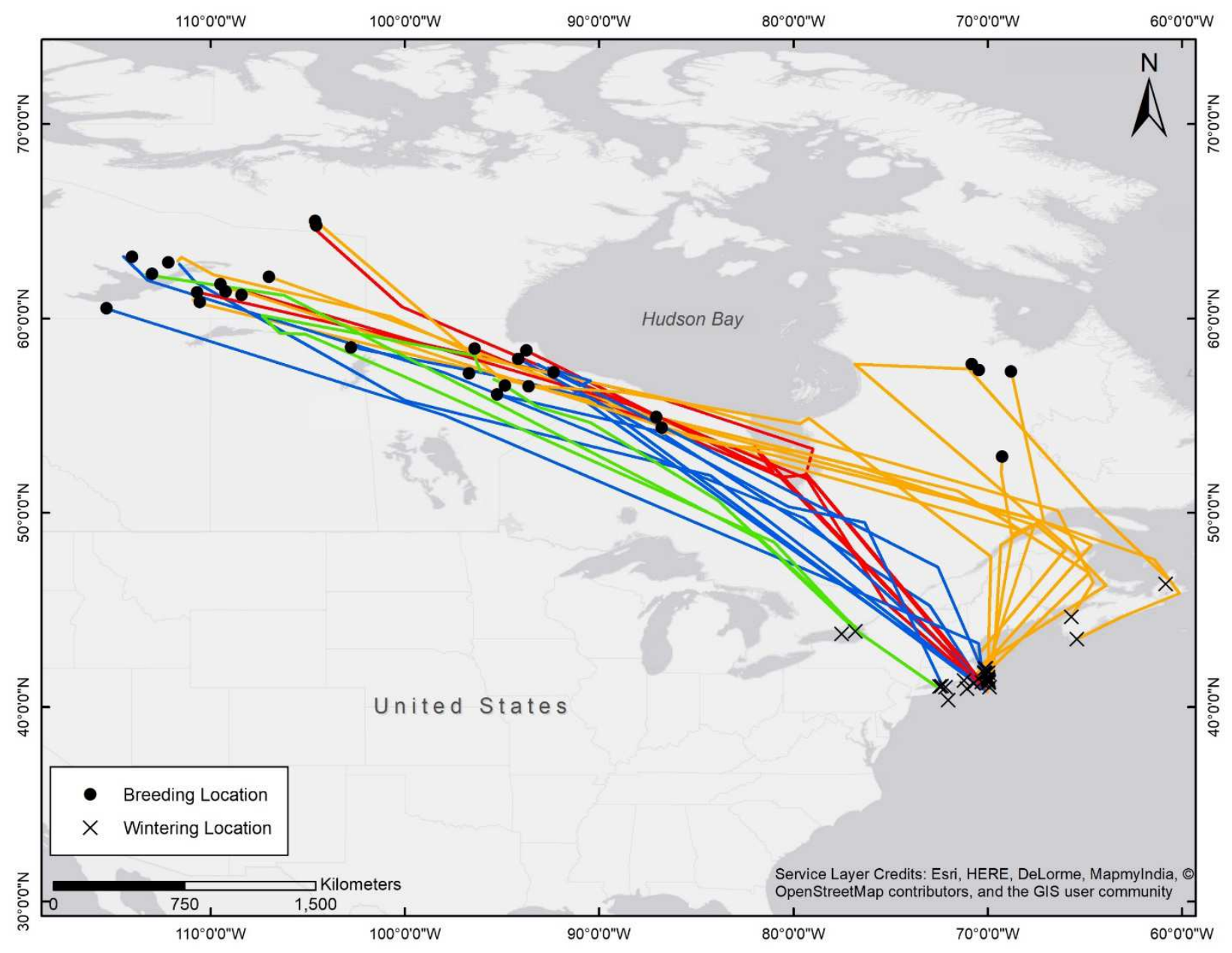


Figure 2-4.

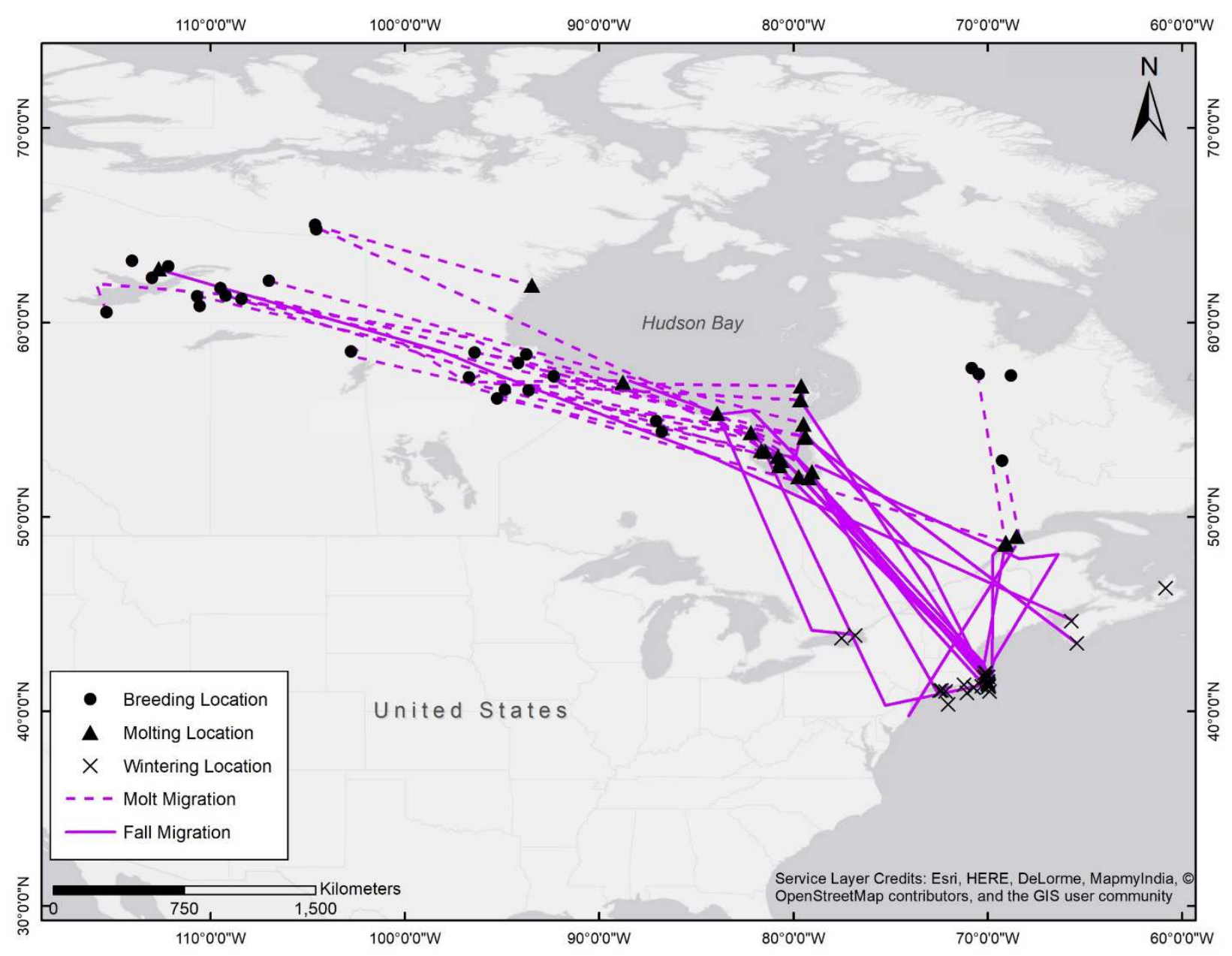


Figure 2-5.

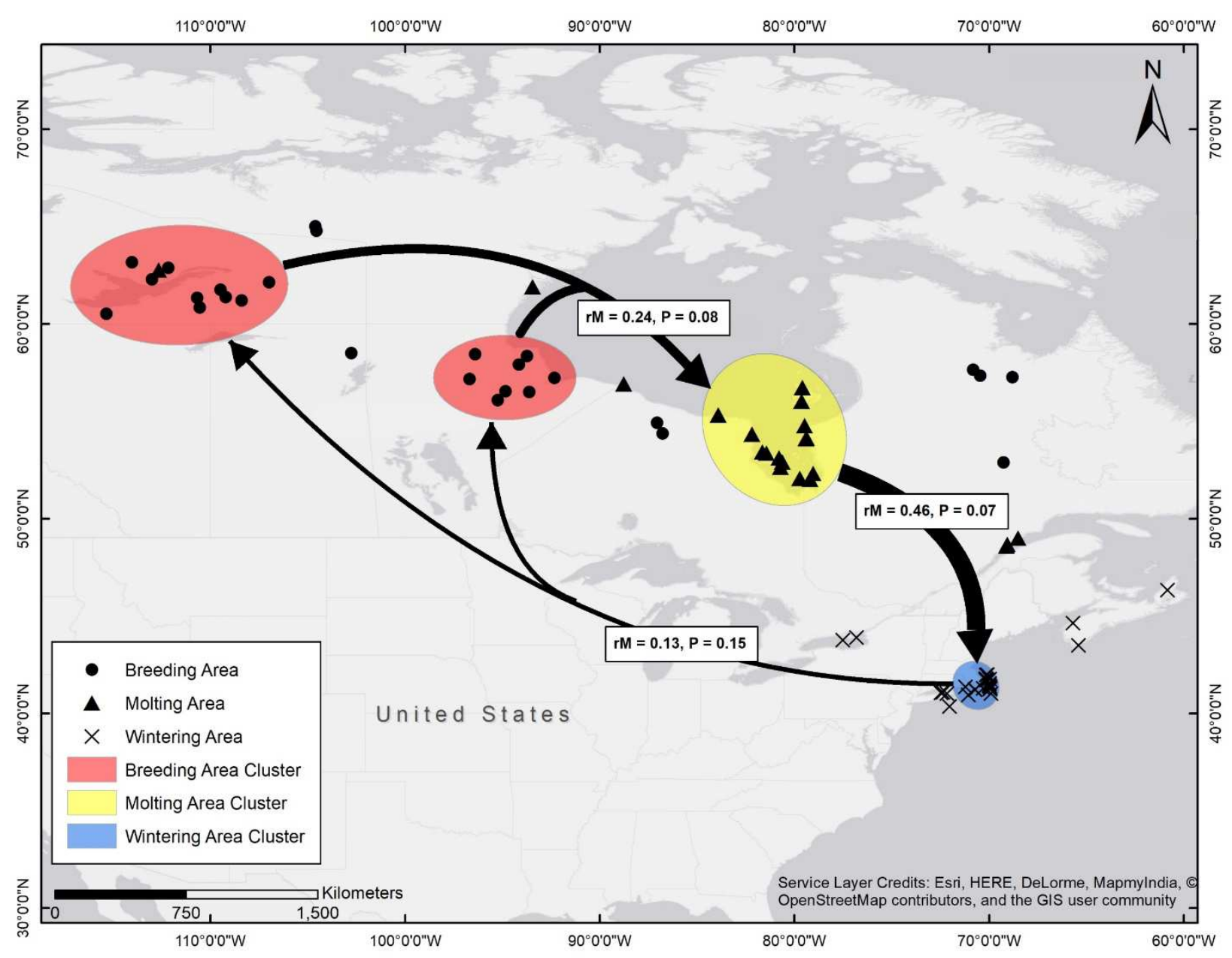




\section{APPENDIX II}

Figure A-2-1. Best per duty cycle locations for 52 adult female White-winged Scoters (Melanitta fusca) captured on wintering areas in southern New England and a molting area in the St. Lawrence River estuary, QC. Location dates range from 27 October 2015 to 6 December 2017. 
Figure A-2-1.

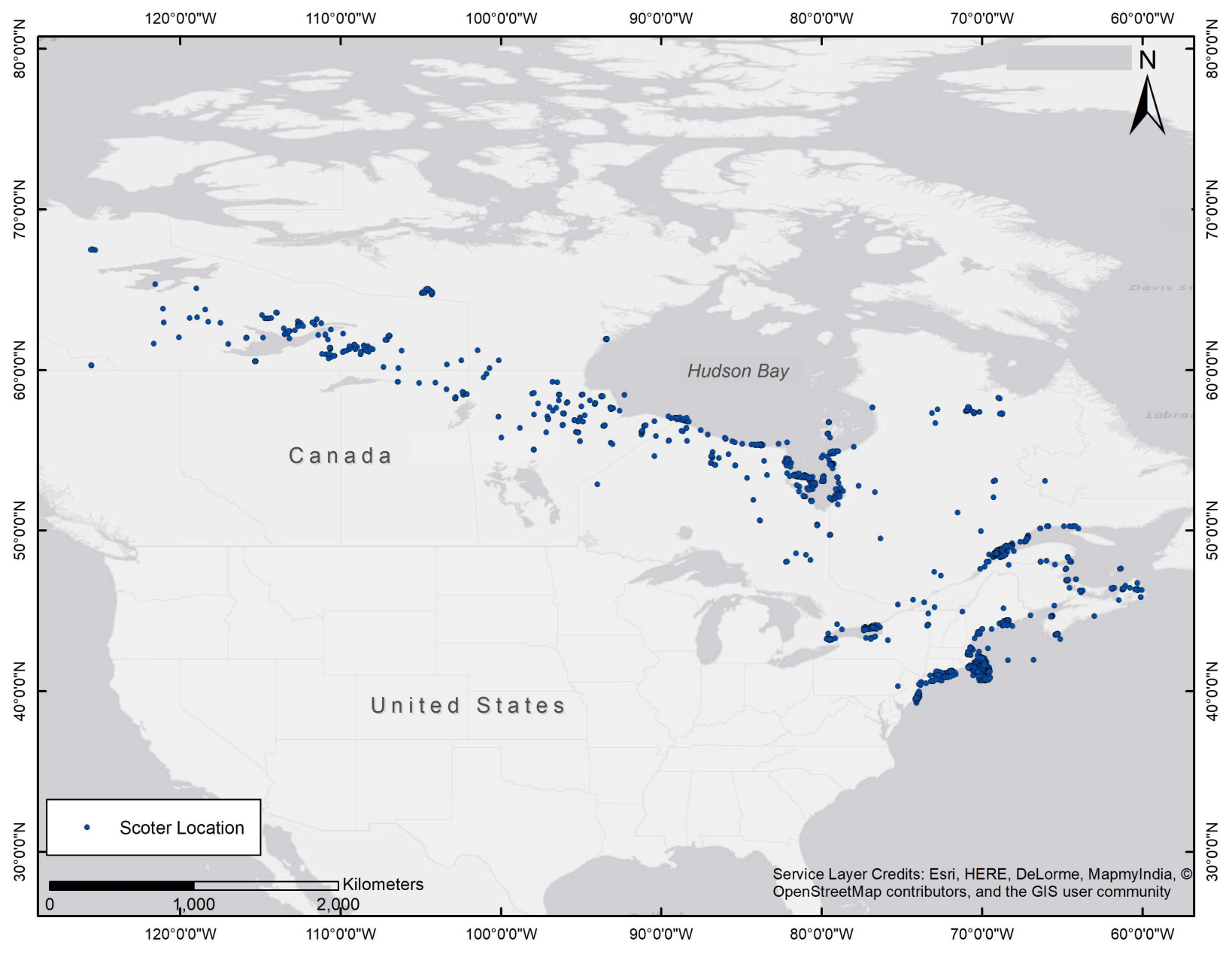

